CARLOS EDUARDO GURGEL PAIOLA

TÉCNICAS INTRUSIVAS DE DETECÇÃO DE ATRITO EM VÁLVULAS DE CONTROLE 
CARLOS EDUARDO GURGEL PAIOLA

\section{TÉCNICAS INTRUSIVAS DE DETECÇÃO DE ATRITO EM VÁLVULAS DE CONTROLE}

Dissertação apresentada à Escola

Politécnica da Universidade de São

Paulo para obtenção do título de Mestre em Engenharia 


\section{CARLOS EDUARDO GURGEL PAIOLA}

\section{TÉCNICAS INTRUSIVAS DE DETECÇÃO DE ATRITO EM VÁLVULAS DE CONTROLE}

Dissertação apresentada à Escola Politécnica da Universidade de São

Paulo para obtenção do título de Mestre em Engenharia

Área de Concentração:

Engenharia de Sistemas

Orientador: Prof. Dr. Claudio Garcia 
Este exemplar foi revisado e alterado em relação à versão original, sob responsabilidade única do autor e com a anuência de seu orientador.

São Paulo, 31 de julho de 2008

Assinatura do autor

Assinatura do orientador

FICHA CATALOGRÁFICA

Paiola, Carlos Eduardo Gurgel

Técnicas intrusivas de detecção de atrito em válvulas de controle/ C.E.G. Paiola. -- São Paulo, 2008.

$80 \mathrm{p}$.

Dissertação (Mestrado) - Escola Politécnica da Universidade de São Paulo. Departamento de Engenharia de Telecomunicações e Controle.

1. Controle de processos (Variabilidade) 2. Válvulas de controle pneumático 3. Atrito 4. Sistemas de controle I. Universidade de São Paulo. Escola Politécnica. Departamento de Engenharia de Telecomunicações e Controle II. t. 


\section{AGRADECIMENTOS}

Ao querido Professor Claudio Garcia, um exemplo dentro e fora da vida profissional, por toda orientação e paciência que fizeram deste trabalho uma realidade.

Aos professores da banca examinadora e aos mestres de cada disciplina cursada durante o mestrado, cujas contribuições foram de grande valia.

À minha querida esposa Carol, meu ponto de referência e porto seguro, que abriu tantas concessões quanto possíveis para que este trabalho fosse concretizado.

Aos meus queridos pais, Antonio e Ana Maria e irmãs, Renata e Simone, que assim como o resto de minha família, estiveram sempre presentes, me apoiando e suportando durante toda minha vida.

Aos meus colegas de pesquisa Gury e Uehara, amigos fiéis e solidários, que muito contribuíram para a conclusão deste estudo.

Às empresas em que trabalhei durante o decorrer do meu Mestrado, que me possibilitaram cursar as disciplinas e me ausentar em momentos cruciais.

$E$ a todos os amigos não citados mas que, sem sombra de dúvidas, foram muito importantes, direta ou indiretamente, em mais esta conquista de minha vida. 


\section{RESUMO}

A variabilidade é um problema presente na maioria das malhas de controle de processos industriais, trazendo prejuízo ao causar perda de produtividade e utilização excessiva de matéria prima e energia. Muitas vezes ela é causada pela presença do atrito em válvulas de controle, os atuadores mais usados em processos industriais. Há uma série de métodos propostos para diagnosticar as perturbações causadas pelo atrito nas válvulas, classificados em intrusivos e não-intrusivos. Neste trabalho, foram estudados dois métodos intrusivos. Eles foram aplicados de maneira automática em simulações computacionais, que foram realizadas em um sistema híbrido de teste (HIL) de uma planta de vazão, com dois níveis de atrito da válvula, e também em um ambiente inteiramente simulado, visando analisar o desempenho dos dois métodos. Os resultados obtidos com ambos os métodos foram satisfatórios, muito embora um dos métodos tenha confundido os efeitos gerados pelo atrito com os produzidos por má sintonia do controlador da malha.

Palavras-chave: Diagnóstico. Atrito. Atrito estático. Válvula de controle. Variabilidade. 


\begin{abstract}
The variability is a problem present on the most of control loops in industrial processes. It causes losses in plant productivity and in material and energy usage. Many times it is caused by the presence of friction in control valves, the most used actuator in industrial processes. There are many methods proposed to diagnose the disturbances caused by control valve friction, which are classified in intrusive and non-intrusive. In this work, two intrusive methods are studied. They were applied automatically by computer simulations that were performed in a hybrid test system (HIL) of a flow plant, with two valve friction levels. Additionally they were applied in a completely simulated environment, aiming at analyzing the performance of both methods. The results with the two methods were satisfactory, although one of the methods has not separated the effects generated by the friction from the ones produced by a bad tuning of the loop controller.
\end{abstract}

Keywords: Diagnose. Friction. Stiction. Control valve. Variability. 


\section{ÍNDICE DE FIGURAS}

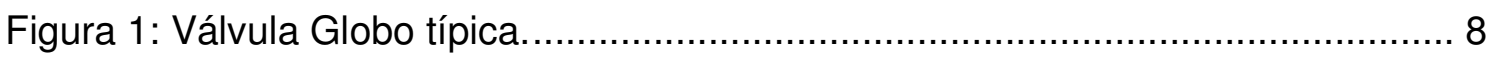

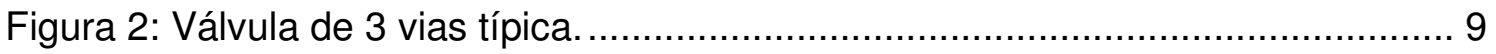

Figura 3: Válvula Borboleta típica. ................................................................. 9

Figura 4: Elementos de uma válvula de controle - adaptado de (FISHER

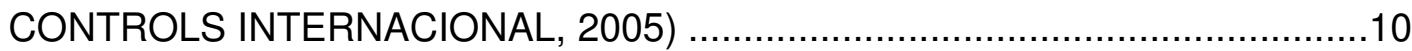

Figura 5: Diagrama de blocos de uma malha de controle típica..............................12

Figura 6: llustração do Backlash. ..................................................................15

Figura 7: Ilustração da Banda Morta.............................................................15

Figura 8: Ilustração da Saturação..................................................................16

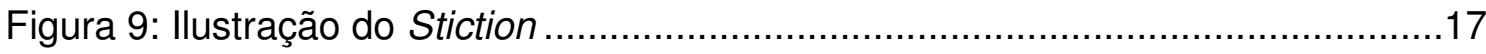

Figura 10: Árvore de métodos para o diagnóstico das causas da variabilidade ........22

Figura 11: Modelo Simplificado de uma Válvula de Controle. .................................28

Figura 12: Diagrama simplificado da malha de controle de vazão estudada..............31

Figura 13: Diagrama do ambiente HIL...............................................................34

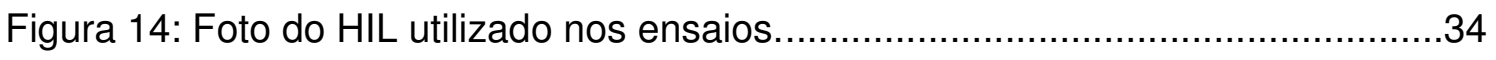

Figura 15: Detalhes da válvula de controle Fisher...............................................35

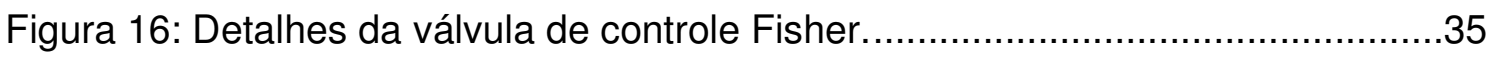

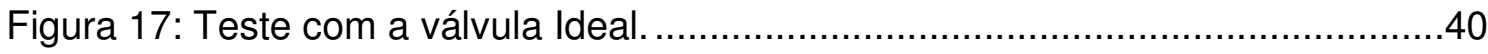

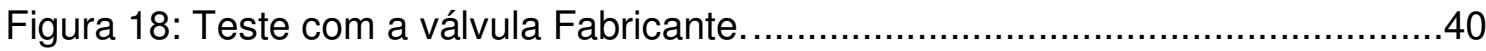

Figura 19: Teste com a válvula Nominal................................................................ 41

Figura 20: Vazão $Q(\%)$ com a válvula Ideal. .......................................................

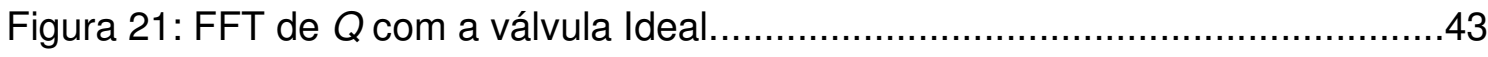

Figura 22: Vazão $Q(\%)$ com a válvula Fabricante. ...............................................4

Figura 23: FFT de $Q$ com a válvula Fabricante. ..................................................4

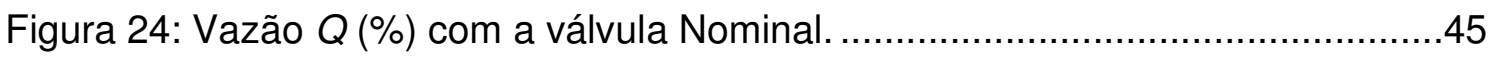

Figura 25: FFT de $Q$ com a válvula Nominal. ..........................................................

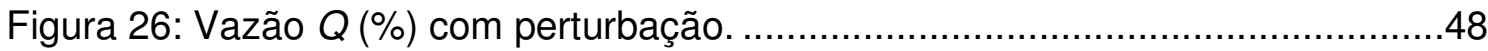

Figura 27: Detalhe do sinal de vazão $Q(\%)$ com perturbação. ..................................48

Figura 28: Vazão $Q(\%)$ com perturbação para a válvula Ideal. ................................49

Figura 29: FFT de $Q$ com perturbação para a válvula Ideal. .....................................49

Figura 30: Vazão $Q(\%)$ com perturbação para válvula Fabricante. ..........................50 
Figura 31: FFT de $Q$ com perturbação para válvula Fabricante. ...............................51

Figura 32: Vazão $Q(\%)$ com perturbação para válvula Nominal.............................52

Figura 33: FFT de $Q$ com perturbação para válvula Nominal. ..................................52

Figura 34: Vazão $Q(\%)$ com controlador mal sintonizado......................................54

Figura 35: Vazão $Q(\%)$ com má sintonia para válvula Ideal...................................55

Figura 36: FFT de $Q$ com má sintonia para válvula Ideal. ...................................55

Figura 37: Vazão $Q(\%)$ com má sintonia para válvula Fabricante............................56

Figura 38: FFT de $Q$ com má sintonia para válvula Fabricante..............................56

Figura 39: Vazão $Q$ (\%) com má sintonia para válvula Nominal................................57

Figura 40: FFT de $Q$ com má sintonia para válvula Nominal.................................58

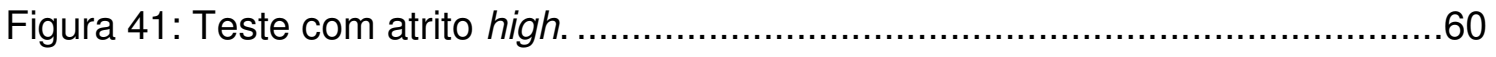

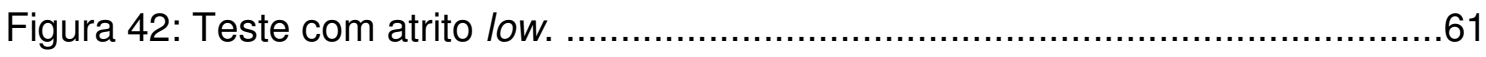

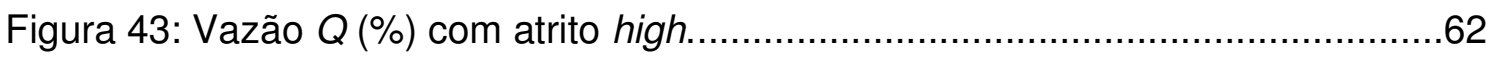

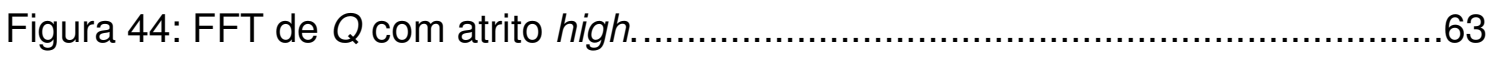

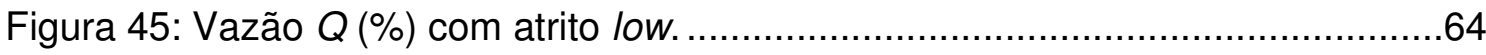

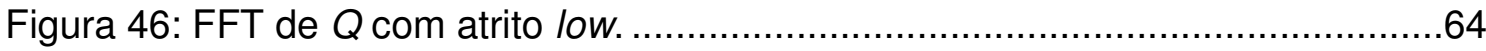

Figura 47: Vazão $Q(\%)$ com perturbação. ..........................................................66

Figura 48: Vazão $Q(\%)$ com perturbação e atrito high.............................................67

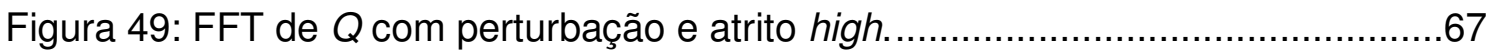

Figura 50: Vazão $Q(\%)$ com perturbação e atrito low...............................................68

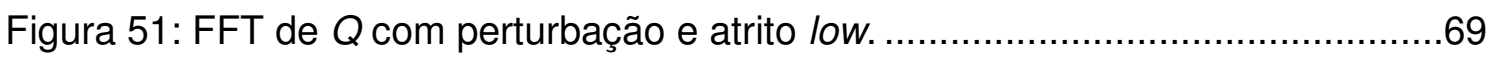

Figura 52: Vazão $Q(\%)$ com controlador mal sintonizado.......................................70

Figura 53: Vazão $Q(\%)$ com má sintonia e atrito high. ..........................................71

Figura 54: FFT de $Q$ com má sintonia e atrito high. ………...................................

Figura 55: Vazão $Q(\%)$ com má sintonia e atrito low................................................73

Figura 56: FFT de $Q$ com má sintonia e atrito low................................................73 


\section{ÍNDICE DE TABELAS}

Tabela 1: Tipos de atrito das válvulas ensaiadas no ambiente totalmente simulado.36 Tabela 2: Parâmetros das válvulas ensaiadas no ambiente totalmente simulado.....38

Tabela 3: Parâmetros das válvulas ensaiadas no ambiente HIL. .............................59

Tabela 4: Comparação entre os métodos estudados. ...........................................76 


\section{LISTA DE ABREVIATURAS E SIGLAS}

$\begin{array}{ll}\text { ACF } & \text { Auto Covariance Function } \\ \text { CLPM } & \text { Control Loop Performance Monitoring } \\ \text { DCS } & \text { Digital Control System } \\ \text { FFT } & \text { Fast Fourier Transform } \\ \text { HIL } & \text { Hardware In the Loop } \\ \text { ICA } & \text { Independent Component Analysis } \\ \text { ISA } & \text { The Instrumentation, Systems and Automation Society } \\ \text { MV } & \text { Manipulated Variable } \\ \text { NMF } & \text { Non-negative Matrix Factorization } \\ \text { OP } & \text { Output Variable } \\ \text { PCA } & \text { Principal Component Analysis } \\ \text { PI } & \text { Proportional Integral } \\ \text { PID } & \text { Proportional Integral Derivative } \\ \text { PV } & \text { Process Variable } \\ \text { SCADA } & \text { Supervisory Control and Data Acquisition } \\ \text { SISO } & \text { Single Input Single Output } \\ \text { SP } & \text { Set Point }\end{array}$




\section{LISTA DE SÍMBOLOS}

\begin{tabular}{|c|c|}
\hline$m$ & Massa das partes móveis da válvula \\
\hline$x_{1}$ & Posição da haste da válvula \\
\hline$x_{2}$ & Velocidade da haste da válvula \\
\hline $\boldsymbol{F}_{\mathrm{a}}$ & Força aplicada pelo atuador da válvula \\
\hline $\boldsymbol{F}_{r}$ & Força da mola \\
\hline$F_{f}$ & Força de atrito \\
\hline$F_{\text {fluido }}$ & Força relacionada à perda de carga do fluido \\
\hline$F_{\text {sede }}$ & $\begin{array}{l}\text { Força adicional necessária para acomodar o obturador na sede } \\
\text { da válvula }\end{array}$ \\
\hline $\boldsymbol{A}$ & Área do diafragma do atuador pneumático \\
\hline $\boldsymbol{U}$ & Pressão de ar \\
\hline$K$ & Constante elástica da mola \\
\hline$\alpha$ & Área desbalanceada do obturador \\
\hline$\Delta P$ & Perda de carga \\
\hline$F_{C}$ & Coeficiente de atrito de Coulomb \\
\hline$F_{S}$ & Coeficiente de atrito estático \\
\hline$F_{V}$ & Coeficiente de atrito viscoso \\
\hline$v_{s}$ & Velocidade de Stribeck \\
\hline$D V$ & Intervalo de velocidade nula no modelo de Karnopp \\
\hline Kc & Ganho do controlador PI da malha de vazão \\
\hline Ti & Tempo integral do controlador PI \\
\hline
\end{tabular}




\section{SUMÁRIO}

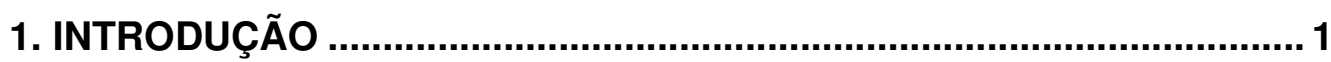

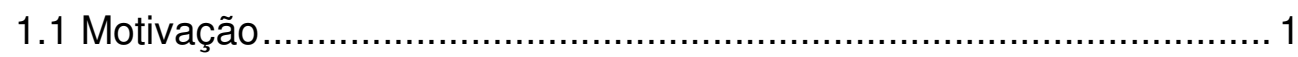

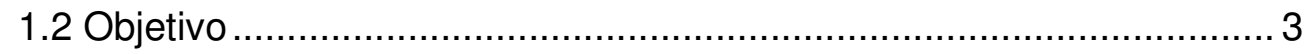

1.3 Revisão Bibliográfica Resumida................................................... 3

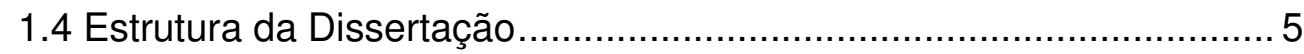

2. DESCRIÇÃO DO PROBLEMA …......................................................

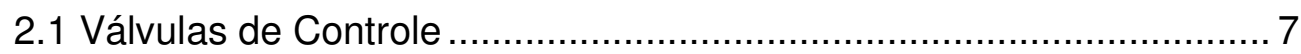

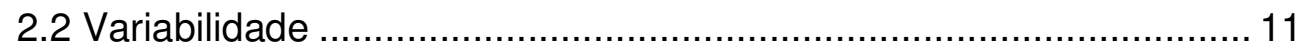

2.3 Fontes de Variabilidade .............................................................. 11

2.3.1 Sintonia do Controlador ........................................................ 12

2.3.2 Superdimensionamento de Válvulas ........................................ 13

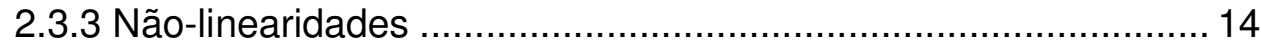

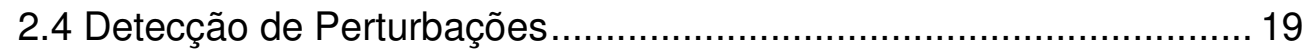

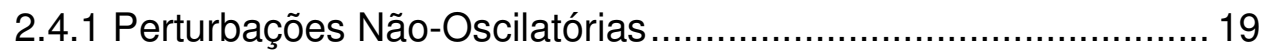

2.4.2 Métodos de Deteç̧ão de Perturbações Não-Oscilatórias ........... 19

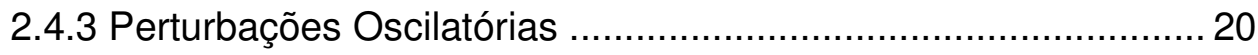

2.4.4 Métodos de Deteç̧ão de Perturbações Oscilatórias.................... 20

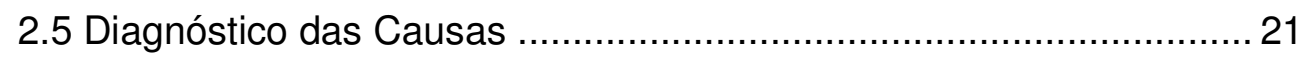

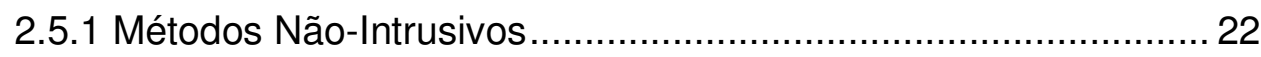

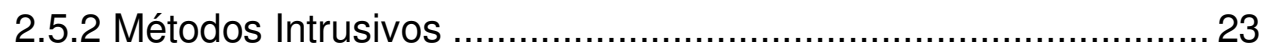

2.6 Implementação dos Métodos Intrusivos ........................................... 24

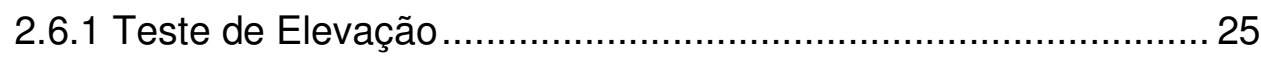

2.6.2 Teste de Mudanças no Ganho do Controlador .......................... 26

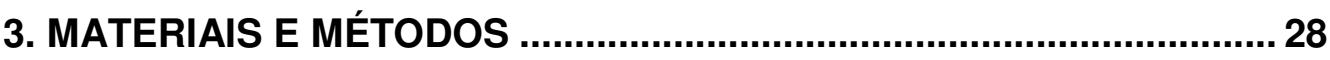

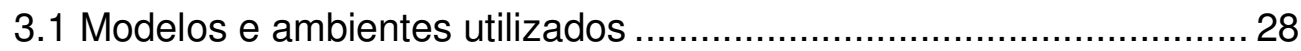

3.1.1 O modelo de atrito de Karnopp e a válvula de controle .............. 28 


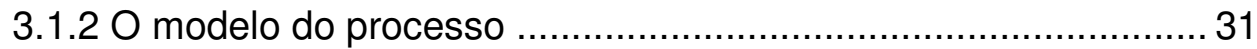

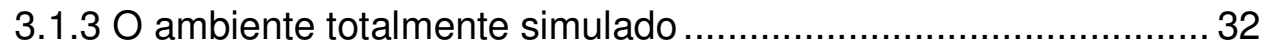

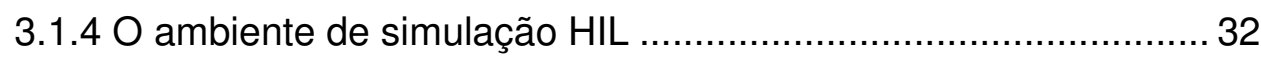

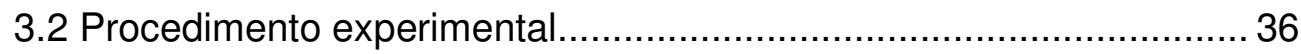

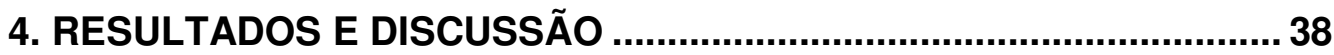

4.1 Ensaios no ambiente totalmente simulado...................................... 38

4.1.1 Ensaios com o Teste de Elevação ……………............................ 39

4.1.2 Ensaios com as Mudanças no Ganho do Controlador ................ 41

4.1.3 Ensaios com as Mudanças no Ganho do Controlador com a presença de perturbação externa..................................................... 46

4.1.4 Ensaios com as Mudanças no Ganho do Controlador para um

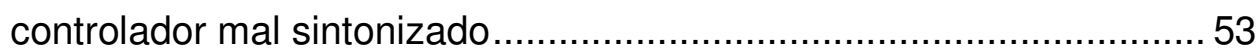

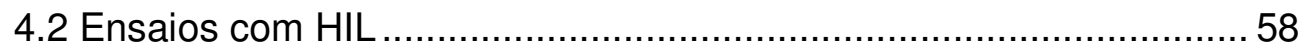

4.2.1 Ensaios com o Teste de Elevação ………………...................... 59

4.2.2 Ensaios com as Mudanças no Ganho do Controlador ................. 61

4.2.3 Ensaios com as Mudanças no Ganho do Controlador com a

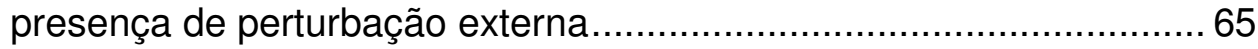

4.2.4 Ensaios com as Mudanças no Ganho do Controlador para um

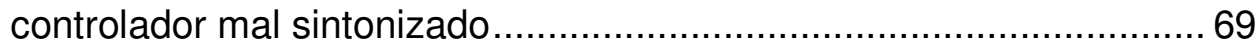

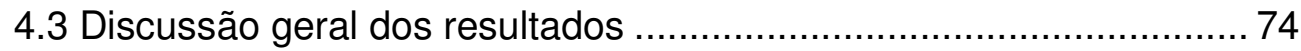

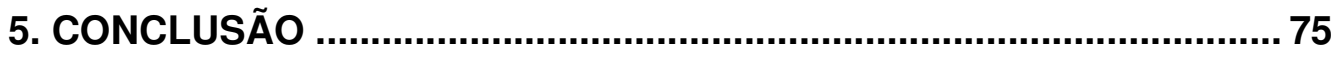

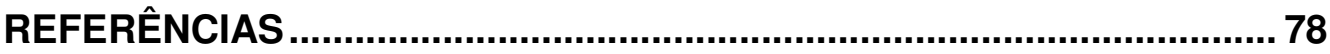




\section{INTRODUÇÃO}

\subsection{Motivação}

A avaliação do desempenho das malhas de controle tem sido uma preocupação crescente dentro do meio industrial. Ela é justificada pela competição acirrada do mercado, que força os processos de produção a serem cada vez mais precisos e eficientes.

Uma planta industrial possui, geralmente, centenas de malhas de controle. Para que a planta trabalhe próxima de seu limite de qualidade, é natural operar utilizando-se de recursos como ciclos de reuso e aquecimento integrado, que acabam promovendo integração e influência entre as diversas malhas de controle. Estas práticas, largamente utilizadas, dificultam o controle da planta de maneira global, propagando a variabilidade entre as malhas. Em geral, uma única fonte de oscilações pode propagá-las a dezenas de outras variáveis de processo, de maneira complexa e de difícil identificação.

No estudo de Controle Moderno, variabilidade pode ser definida como uma medida estatística que determina a proximidade do valor de referência com relação à variável de processo que está sendo controlada. Ela é geralmente indicada como um valor percentual que demonstra a relação entre o erro e a medida absoluta do valor desejado para a variável controlada.

Há diversas fontes de variabilidade, pode-se citar: mau ajuste do controlador de uma malha de controle, mau dimensionamento e má instalação de válvulas e sensores e, notavelmente, agarramento dos elementos atuadores do sistema. Este último, causado geralmente pelo atrito nas válvulas de controle (grandes fontes de não-linearidade do processo), será o foco deste trabalho. Choudhury et al. (2005) estimam que este problema seja responsável por cerca de $30 \%$ dos casos de variabilidade em malhas de controle.

É extremamente importante detectar e diagnosticar as causas da variabilidade de uma planta, para que se possa combater diretamente a fonte do problema. Diversas técnicas têm sido apresentadas, tanto para a detecção quanto para o 
diagnóstico da causa. Para a detecção das perturbações de uma planta, existem métodos tanto no domínio do tempo, quanto no domínio da freqüência (THORNHILL; $\mathrm{HORCH}, 2006)$.

Uma vez detectada a perturbação, deve-se diagnosticar ainda seu tipo e causa. Existem, basicamente, perturbações geradas por causas lineares e nãolineares. Para os dois tipos, existem algumas técnicas descritas na literatura. Thornhill e Horch (2006) apresentam o resumo destes possíveis métodos, divididos para os dois tipos de causas. Para as lineares, há o diagnóstico de ajuste do controlador e o estrutural. Para as não-lineares, há a análise não-linear das tendências temporais, os métodos de ciclo-limite e finalmente, os métodos de diagnóstico de válvula. Estes últimos estão divididos em intrusivos e não-intrusivos.

Neste trabalho estão focadas as técnicas intrusivas de detecção de atrito nas válvulas de controle, ou seja, os métodos de interação com o processo para a obtenção de dados que possam comprovar a origem e tipo da não-linearidade causadora da variabilidade da planta.

Atualmente, como visto em (CHOUDHURY et al., 2005), tem-se duas técnicas intrusivas propostas: o teste de elevação (bump test ou valve travel) e o de mudanças no ganho do controlador (changes in controller gain). Geralmente, 0 primeiro método afeta o processo estudado, enquanto que o segundo é apresentado por Choudhury et al. (2005) como uma técnica que pode ser aplicada sem afetar o processo de maneira significativa.

A importância da aplicação destes métodos está na confirmação do problema que afeta a planta e de sua origem.

Caso a existência e tipo do atrito sejam passíveis de confirmação, a manutenção dos elementos causadores da variabilidade, em geral válvulas, pode ser feita de maneira muito precisa e rápida, sem riscos de desperdício de tempo e esforço. Muitas vezes, esta simples manutenção da válvula de controle defeituosa reduz o atrito e, conseqüentemente, elimina ou reduz a variabilidade do processo como um todo.

Quando o atrito em válvulas é detectado e confirmado, pode-se ainda fazer o uso de compensadores de atrito, com o intuito de anular o efeito desta nãolinearidade, mesmo sem eliminá-la do processo (KAYIHAN; DOYLE III, 2000; GURY et al., 2008). 


\subsection{Objetivo}

Neste trabalho são implementados os métodos intrusivos citados anteriormente, de tal forma que sejam executáveis de maneira automática, sem a necessidade de nenhuma intervenção humana durante sua aplicação. De maneira adicional, são estudados e analisados os resultados obtidos através destas aplicações, realizadas para diferentes níveis e tipos de atrito, através de simulações realizadas no ambiente Simulink do aplicativo Matlab®.

Os métodos não-intrusivos são geralmente utilizados para um diagnóstico inicial das causas da variabilidade de um processo, mas sabidamente trazem uma certa incerteza no diagnóstico resultante de sua aplicação. Através da implementação dos algoritmos intrusivos, proposta por este trabalho, deseja-se analisar a eficiência dos mesmos para uma eventual confirmação da presença de atrito como causa das perturbações de determinado processo.

\subsection{Revisão Bibliográfica Resumida}

Thornhill e Horch (2006) apresentam um panorama geral sobre todos os assuntos que permeiam a variabilidade no controle de processos e uma visão crítica dos artigos já publicados nesta área de estudo. Os autores resumem os avanços na detecção e no diagnóstico de distúrbios globais de uma planta em sistemas de controle de processos químicos, discutindo as tendências e novos horizontes desta área. As causas de distúrbios globais de uma planta incluem ciclos-limite devido às não-linearidades em malhas de controle, interações do controlador e problemas de ajustes. O diagnóstico de não-linearidades, especialmente com relação ao stiction (atrito estático) da válvula tem sido uma área de estudo muito ativa. A detecção de interações do controlador e os distúrbios devidos à estrutura da planta permanecem abertos ao estudo. A análise baseada em dados do processo com um modelo qualitativo para o mesmo, parece bem promissora.

Thornhill; Cox e Paulonis (2003) também trazem uma idéia geral do estudo

dos distúrbios existentes no controle de processos de uma planta. É realizada uma análise detalhada deste assunto, baseada em informações reais e práticas. Os distúrbios que se propagam por toda uma planta devidos ao fluxo de reciclo, 
integração de calor ou outros meios, podem ter um grande impacto na qualidade de produto e em custos de operação. Há assim uma grande motivação para a detecção automatizada de um distúrbio global da planta e para a determinação de sua causa, de modo que o distúrbio possa ser removido. As técnicas baseadas em dados foram usadas para diagnosticar uma oscilação global em uma planta da companhia Eastman Chemical. Um índice numérico de não-linearidade obtido através de medições rotineiras, pode indicar as causas do problema. O sucesso do estudo sugere que há uma perspectiva promissora para futuras pesquisas no relacionamento automático da análise baseada em dados do processo com informação sobre a estrutura e a conectividade do processo.

Choudhury et al. (2005) e (GERRY; RUEL, 2001) trazem ainda importantes contribuições para o tema, pois tratam dos métodos intrusivos de detecção de atrito aplicados no diagnóstico das causas da variabilidade de processos industriais, abordando de maneira direta os dois métodos analisados nesta dissertação.

Stiction é um problema comum na maioria das válvulas de controle utilizadas na indústria. Vários métodos estão disponíveis para a detecção do stiction nestas válvulas. Após a detecção, porém, um teste é necessário para a confirmação de que a válvula em questão esteja realmente sofrendo deste problema. Choudhury et al. (2005) apresentam um teste simples em malha fechada, baseado na mudança do ganho do controlador. Ele não requer que a malha seja colocada em manual, o que poderia perturbar o processo. A utilidade deste teste é demonstrada através de estudos de simulações e de uma aplicação industrial. Outro método utilizado para a confirmação do stiction, durante a operação do processo, é apresentado em (GERRY; RUEL, 2001).

Estes dois artigos ilustram o efeito do stiction no desempenho de atuadores operando em malha fechada e a importância de técnicas a serem incorporadas no sistema de monitoração, para a detecção automática deste fenômeno. É demonstrado como as variáveis de malha são afetadas por parâmetros do stiction e por características do processo.

Trabalhos mais antigos (WALLÉN, 1997), (TAHA; DUMONT; DAVIES, 1996) servem de base para os outros citados anteriormente. Em (WALLÉN, 1997), é apresentado um sistema integrado de ajuste automático do controlador e diagnóstico da válvula de controle. A finalidade é a detecção de não-linearidades, tais como o atrito e a histerese, que podem diminuir drasticamente o desempenho do controle. 
Um procedimento automático para o diagnóstico de oscilações em malhas de controle é apresentado em (TAHA; DUMONT; DAVIES, 1996). Este procedimento é uma das características de um sistema de Monitoração de Desempenho de Malha de Controle - Control Loop Performance Monitoring (CLPM), e funciona on-line, sem perturbar a operação normal da planta. Quando uma malha de controle oscilatória é detectada, a ferramenta de diagnóstico permite determinar a causa do comportamento oscilatório. Isto pode ser causado pelo atrito excessivo na válvula de controle, um controlador mal ajustado ou a presença de perturbações externas ao processo.

\subsection{Estrutura da Dissertação}

Nesta seção são apresentadas a estrutura da dissertação e uma breve descrição de cada um dos capítulos. O trabalho está dividido em 5 capítulos:

Capítulo 1 - Introdução: Neste capítulo são descritos o objetivo do trabalho, as motivações e justificativas que levaram ao desenvolvimento do mesmo. A seguir, é apresentada uma revisão bibliográfica acerca das principais publicações encontradas relacionadas ao tema da dissertação e, por fim, uma explicação da estrutura geral desta.

Capítulo 2 - Descrição do Problema: Faz-se uma rápida introdução sobre a variabilidade no controle de processos industriais. São descritas as válvulas de controle, os tipos de não-linearidades encontradas nestes elementos, bem como a detecção de oscilações no processo.

Capítulo 3 - Materiais e Métodos: Este capítulo consiste na apresentação dos métodos utilizados para o diagnóstico da causa da variabilidade nas malhas de controle. É dada uma maior atenção aos métodos intrusivos de diagnóstico, o foco deste trabalho. São descritas as formas propostas para a implementação destes métodos e para a obtenção dos resultados desejados. 
Capítulo 4 - Resultados e Discussão: Aqui são descritos os procedimentos e parâmetros adotados na aplicação dos métodos intrusivos para a detecção do stiction, bem como os problemas encontrados durante os testes. Os resultados obtidos com os ensaios são apresentados e analisados neste capítulo.

Capítulo 5 - Conclusão: Neste capítulo são consideradas as contribuições a respeito dos resultados do trabalho, as conclusões obtidas e sugestões de trabalhos futuros. 


\section{DESCRIÇÃO DO PROBLEMA}

\subsection{Válvulas de Controle}

As plantas possuem centenas ou mesmo milhares de malhas de controle, todas interconectadas para gerar um produto final. Cada uma destas malhas é projetada para manter alguma variável de processo dentro de uma certa faixa de valores, de forma a manter a segurança, qualidade e precisão do processo, garantindo assim, a qualidade do produto final. Estas variáveis podem ser temperatura, pressão, vazão, nível, pH etc.

As malhas de controle são desenhadas para uma operação ideal, mas em geral, cada uma delas pode gerar internamente ou receber de outras, uma série de perturbações que acabam por afetar as variáveis de processo e, conseqüentemente, o processo como um todo. Desta forma, acabam por originar a variabilidade do processo.

Sensores e transmissores coletam informações sobre as variáveis de processo. O controlador processa essas informações e as compara com seus respectivos pontos de ajuste, tomando assim as devidas decisões de quais devem ser as ações corretivas para trazer a variável de processo de volta ao seu valor de referência. Uma vez que as decisões estejam tomadas pelo controlador, deve-se ter um elemento final que atue no processo.

O elemento atuador mais comum nas indústrias de controle de processo é a válvula de controle. Ela atua manipulando a vazão de algum fluido, como gás, água, produtos químicos ou vapor, com o objetivo de compensar alguma perturbação e manter as variáveis de processo o mais próximo possível do valor desejado.

Não se pode afirmar que a válvula seja o elemento mais importante de uma malha de controle, mas é tão importante quanto todos os outros elementos, do sensor ao controlador e, portanto, não pode conter defeitos ou qualquer tipo de problema que prejudique seu desempenho.

A válvula tem a função de regular a taxa de vazão do fluido que trafega por seu corpo, conforme a posição de sua haste ou disco é variada, de acordo com a 
força aplicada por seu atuador. Para tanto, a válvula não deve possuir nenhuma espécie de vazamento, deve ter as dimensões necessárias e suficientes para a demanda de fluido imposta a ela, tem que ser capaz de lidar com as possíveis características erosivas, corrosivas e térmicas do processo.

Uma válvula de controle é composta por uma série de partes e acessórios. Tipicamente, há o corpo da válvula, o atuador responsável em prover a força necessária para a operação da válvula, os posicionadores, os transdutores, os reguladores de pressão, os internos, o castelo, a haste, entre outros acessórios mais.

Cada tipo de válvula traz elementos e acessórios comuns e também exclusivos. Existe uma série de tipos de válvula, algumas são aplicadas largamente no meio industrial e outras porém, são utilizadas em aplicações muito específicas, sendo menos utilizadas. Seus tipos estão associados a seus formatos, alguns dos mais comuns são: globo, borboleta, de 3 vias, esfera, entre outros.

Alguns desses tipos estão ilustrados nas Figuras 1 à 3, obtidas em (FISHER CONTROLS INTERNACIONAL, 2005).

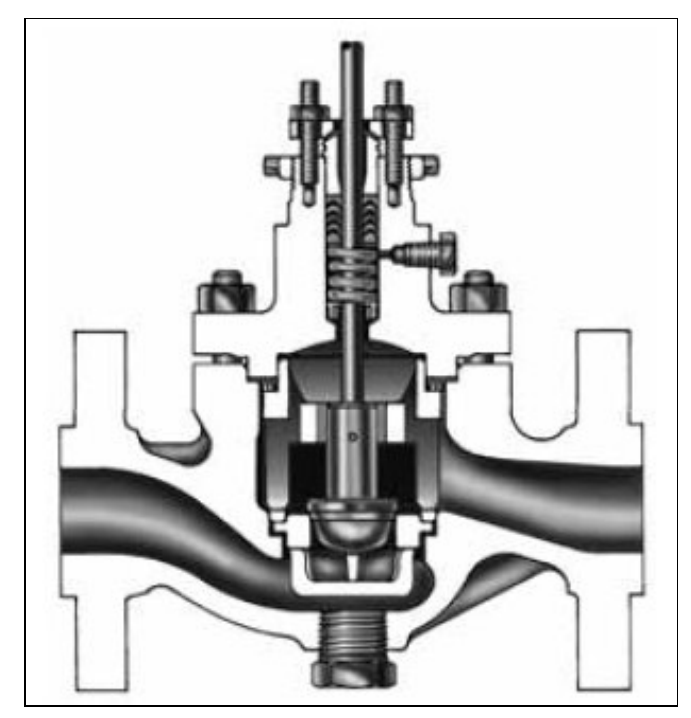

Figura 1: Válvula Globo típica. 


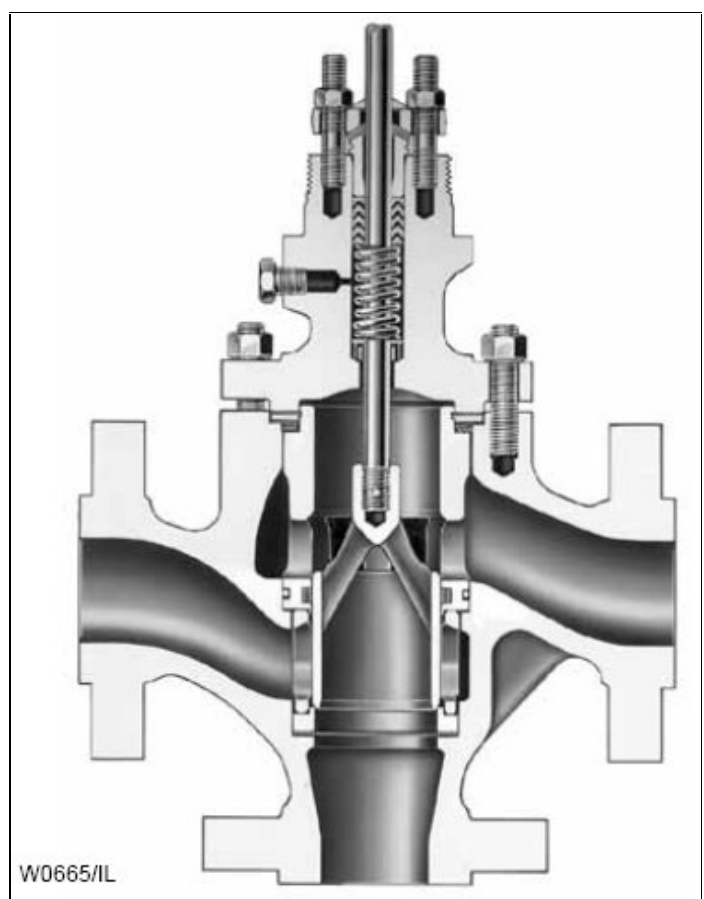

Figura 2: Válvula de 3 vias típica.

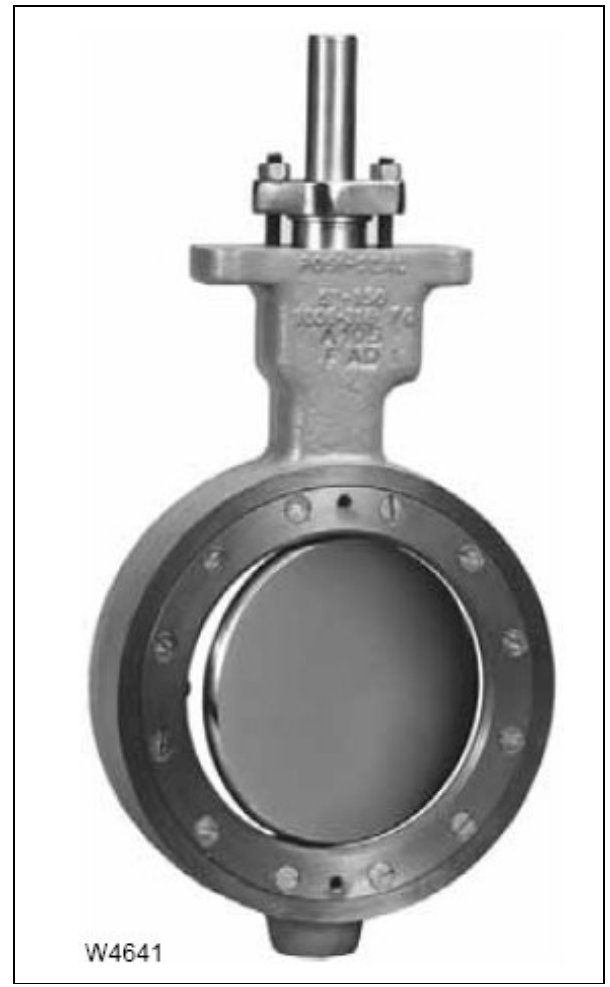

Figura 3: Válvula Borboleta típica. 
Alguns dos elementos principais de uma válvula de controle, ilustrados na Figura 4, são:

- O atuador, responsável pelo acionamento da parte móvel de uma válvula;

- A haste, é quem transmite o acionamento ao obturador;

- O castelo, é a estrutura que sustenta o atuador;

- O corpo, é o elemento pelo qual o fluido irá transitar;

- Os internos, consistem no obturador e na sede.

Os atuadores podem ser pneumáticos (diafragmas, pistões), elétricos (motores, solenóides) ou hidráulicos (pistões). Há ainda válvulas que podem possuir um volante manual. O castelo, que é o local por onde a haste penetra no corpo, pode ter vários materiais de engaxetamento de vedação, pode ter conexão para lubrificador, pode ser alongado ou estendido (para criogenia), aletado para fluidos quentes, ou mesmo possuir um fole de vedação para fluidos perigosos.

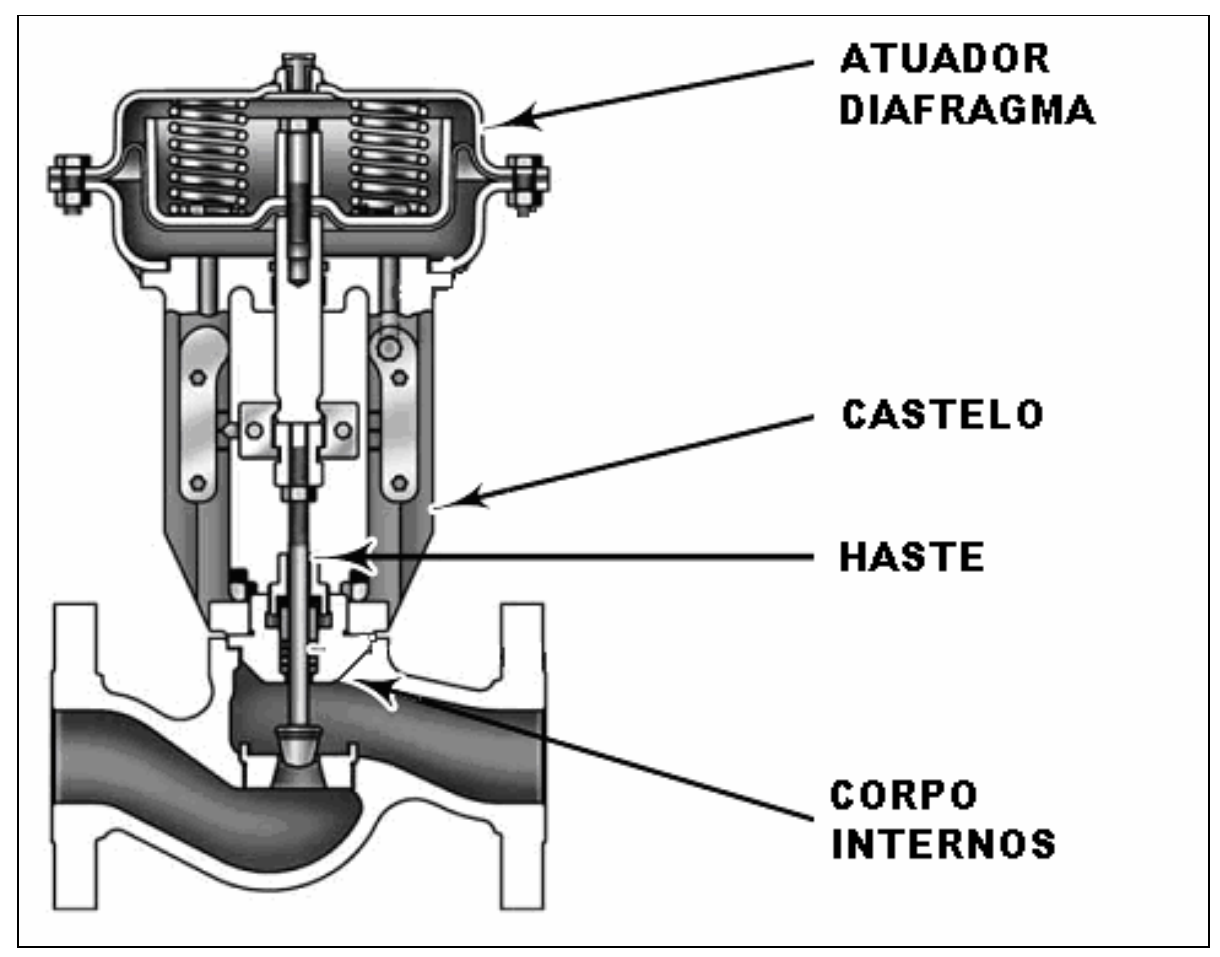

Figura 4: Elementos de uma válvula de controle - adaptado de (FISHER CONTROLS INTERNACIONAL, 2005) 


\subsection{Variabilidade}

Para que seja possível atingir um retorno aceitável para os investidores, os gerentes industriais de todo o mundo estão certos de que devem otimizar o uso de matéria-prima, reduzindo a quantidade de refugo e perdas durante a produção, aumentando assim a sua produtividade. Este fato confere aos gerentes industriais a necessidade de que a variabilidade de um processo, ou seja, a diferença entre o valor real das variáveis controladas de uma planta e seus respectivos valores de ajuste desejados, seja cada vez mais reduzida e, se possível for, eliminada da realidade de uma planta.

Reduzir a variabilidade de uma planta através da aplicação de tecnologias de controle de processo é hoje em dia, uma obrigação das empresas que desejem competir em seu meio. Um produto de qualidade, objetivo maior de toda empresa que deseja maior lucro, deve seguir uma série de especificações. Qualquer desvio das especificações estabelecidas significa decréscimo no lucro, devido a uso excessivo de matéria-prima, custos de reprocessamento ou refugo de produto final. Um dos principais objetivos do investimento em melhores tecnologias de controle e da redução da variabilidade é portanto, a idéia de produzir certo da primeira vez.

A não-uniformidade inerente à matéria-prima e do processo de produção como um todo, são causas comuns dos desvios nas variáveis de processo com relação aos seus pontos de ajuste.

\subsection{Fontes de Variabilidade}

São vários os fatores que podem dar origem à variabilidade de um processo. As fontes causadoras mais comuns são: mau ajuste do controlador de uma malha de controle, superdimensionamento dos elementos atuadores (válvulas de controle) ou agarramento nos mesmos.

Pode-se citar entre as causas de perturbação:

- Restrições de processo;

- Problemas de sintonia do controlador;

- Ruído excessivo do processo e das medições;

- Superdimensionamento dos atuadores do sistema; 
- Agarramento e outras não-linearidades nos atuadores do processo.

\subsubsection{Sintonia do Controlador}

Suspeita-se que, depois das não-linearidades presentes nos processos e em seus elementos, o maior responsável pela variabilidade nas malhas de controle é o próprio controlador, uma vez que esteja mal ajustado. É costumeiro no meio industrial o uso de ferramentas de software comerciais para a deteç̧ão de controladores mal ajustados em malhas de controle SISO (Single Input Single Output). Porém, mesmo com o uso destas ferramentas, resta quase sempre uma dúvida sobre a origem das oscilações, quando detectadas. Na Figura 5 é apresentado um diagrama de blocos correspondente a uma malha de controle fechada, para um sistema SISO com cada elemento e variável pertencentes ao processo: SP (set point), OP (output variable), MV (manipulated variable) e PV (process variable). SP é o ponto de ajuste, valor de referência no qual deseja-se que a PV seja mantida; para tanto, o controlador deve agir através de sua variável de saída OP na válvula, de tal forma que a MV aplicada ao processo garanta esta condição com seu valor.

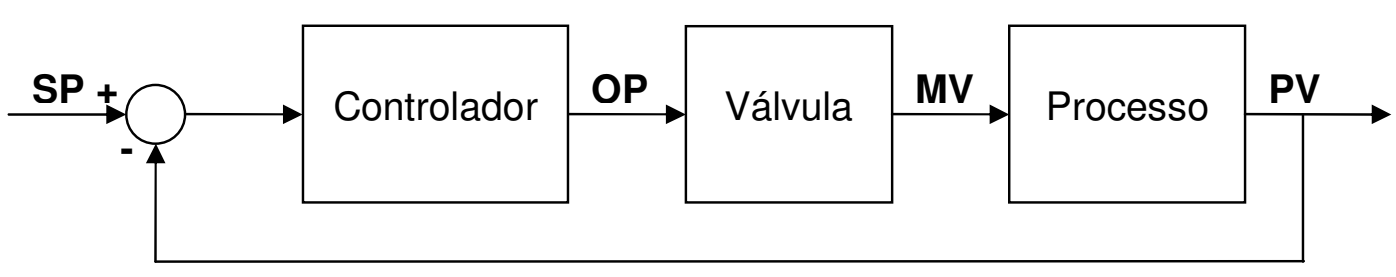

Figura 5: Diagrama de blocos de uma malha de controle típica.

Poucos trabalhos abordam o estudo do diagnóstico de problemas na malha de controle utilizando dados de operação do processo. Thornhill e Horch (2006) afirmam que há trabalhos que levam em conta o estudo de causa e efeito no processamento de sinais, utilizando técnicas que permitam encontrar a origem da perturbação, porém com grande sensibilidade a atrasos, atenuações e à presença de ruídos que afetem a propagação dos sinais. O resultado desse estudo é um 
modelo qualitativo do processo, que demonstre as relações causais entre as variáveis.

\subsubsection{Superdimensionamento de Válvulas}

É comum ocorrer o superdimensionamento de válvulas quando deseja-se otimizar um processo, tentando reduzir a sua variabilidade. Esse é o resultado do uso de válvulas com tamanhos desproporcionais à necessidade do processo, geralmente associado a ações conservadoras provindas de múltiplos fatores de segurança impostos no projeto do sistema. Este superdimensionamento afeta o sistema de duas formas, como apresentado na seqüência.

Primeiro, a válvula superdimensionada adiciona um ganho excessivo ao sistema, ocasionando perda de flexibilidade no ajuste do controlador. Quanto mais o sistema depender do ganho do controlador, melhor será o desempenho da malha de controle.

O aumento do ganho do processo, provindo do superdimensionamento de uma válvula, força um decréscimo do ganho do controlador para garantir a estabilidade da malha de controle. Naturalmente, isto acarreta um aumento da variabilidade do processo.

A segunda maneira da válvula superdimensionada colaborar com a variabilidade do processo, é acrescentando tempo morto ao sistema. Como a válvula superdimensionada produz uma mudança desproporcionalmente grande na vazão controlada para cada incremento imposto ao atuador da mesma, este fenômeno pode aumentar a variabilidade do sistema devido à banda morta originada do atrito excessivo.

Algumas observações podem ser feitas com relação à detecção do superdimensionamento de válvulas. Taha; Dumont e Davies (1996) afirmam que:

"Se a válvula de controle está superdimensionada, o ganho do processo será maior, amplificando assim as oscilações. A escolha de uma válvula menor, permite que o ganho do controlador PID seja aumentado, de tal forma que o conjunto atuadorposicionador da válvula seja menos sensível ao atrito. Um método simples para analisar o problema de superdimensionamento é comparar a abertura completa da válvula com a máxima vazão necessária para o controle do processo. Para a máxima 
vazão, a abertura da válvula deve ser maior que $75 \%$ de sua capacidade, caso contrário estará constatado o superdimensionamento." ((TAHA; DUMONT; DAVIES, 1996), p.2435).

Muitas vezes, as válvulas são superdimensionadas pela escolha de válvulas de menor custo, sem a preocupação com o sacrifício de desempenho da malha de controle, através do aumento da variabilidade do processo, quando da operação do sistema. Infelizmente, esta situação é muito comum no projeto de sistemas de controle. Estudos apontam que para algumas indústrias, a maioria das válvulas é superdimensionada para a demanda de sua aplicação. Ao se especificar uma válvula de controle, é imprescindível considerar o seu tipo, desenho e tamanho, que afetará diretamente a controlabilidade do sistema.

\subsubsection{Não-linearidades}

Entre os diversos tipos de não-linearidades encontrados nas válvulas de controle, pode-se citar: backlash (folga), banda morta, stiction (atrito estático), saturação, etc.

Backlash (folga) é o nome dado para uma espécie de banda morta resultante de uma descontinuidade temporária entre a entrada e a saída de um dispositivo quando a entrada muda de direção (Figura 6). Uma outra definição possível seria a interrupção de movimento em um instrumento devido à frouxidão entre duas ou mais partes mecânicas que possuam contato entre si. É a perda de movimento após a reversão da direção de movimento entre as partes móveis de uma válvula rotativa. 


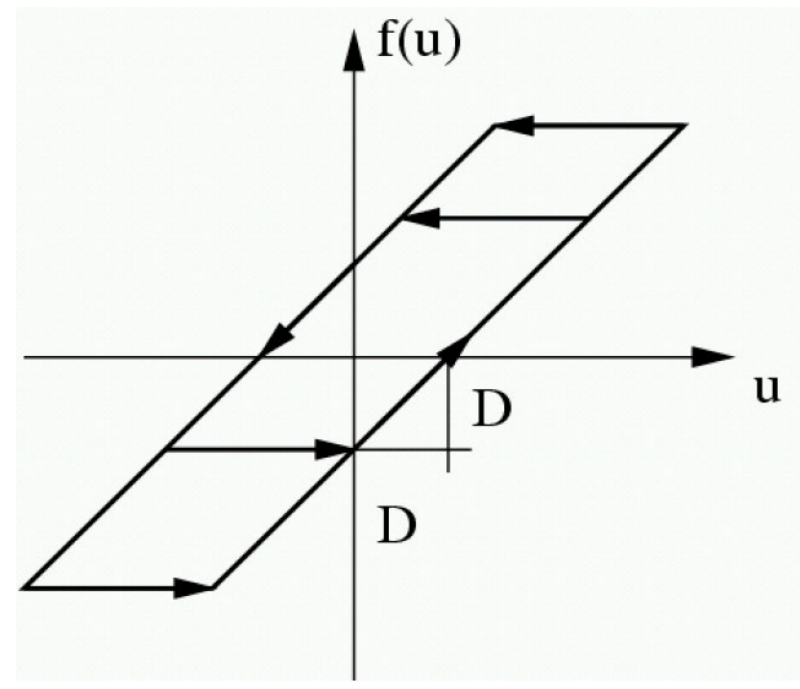

Figura 6: Ilustração do Backlash.

A Banda Morta pode ser definida como a faixa de valores através da qual um sinal de entrada pode ser variado, na direção reversa à original, sem iniciar uma mudança observável na saída do sinal (Figura 7). Banda morta (Dead Band) é o nome dado ao fenômeno geral que pode ser aplicado a qualquer dispositivo, inclusive às válvulas de controle. Dentro do escopo das válvulas, a saída do controlador é a entrada e a variável manipulada do processo, a saída. Quando o termo banda morta é utilizado, é essencial que ambas as variáveis, a de entrada e a de saída, sejam identificadas. A banda morta é tipicamente expressa como uma porcentagem da faixa do valor da variável de entrada.

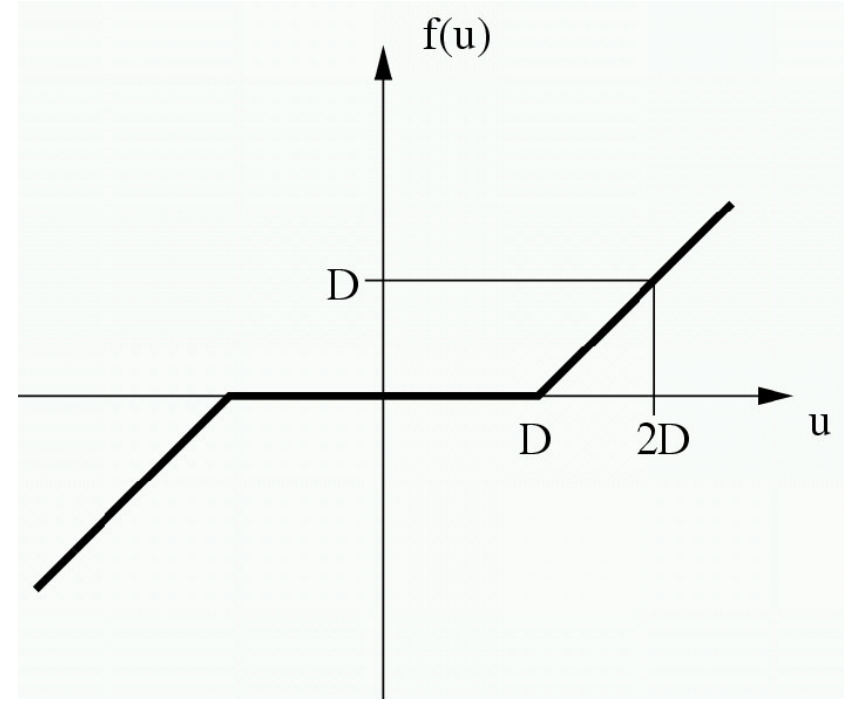

Figura 7: llustração da Banda Morta. 
A banda morta de qualquer dispositivo que compõe um sistema de controle é um dos responsáveis pelo "tempo morto" deste sistema. De maneira complementar, pode-se definir como tempo morto, o intervalo de tempo no qual não ocorre nenhuma resposta da variável de saída, após a aplicação de uma variação no sinal de entrada. Este conceito pode ser aplicável a um único dispositivo (p.e. válvula) ou a um processo inteiro.

A Saturação ocorre quando o controlador requer mais ação do que o atuador é capaz de disponibilizar. Este tipo de característica pode levar o processo a atingir restrições (Figura 8).

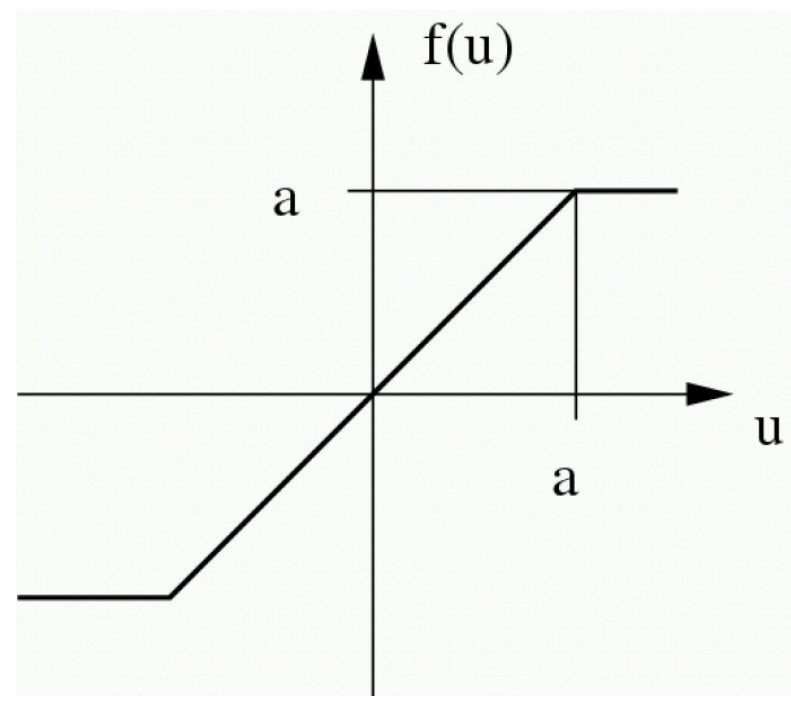

Figura 8: Ilustração da Saturação.

O Atrito consiste em uma força com tendência a se opor ao movimento relativo entre duas superfícies quaisquer que possuam contato físico entre si. A força de atrito é uma função da força normal que leva duas superfícies a se agarrarem, dificultando o movimento relativo.

O atrito pode ser estático ou dinâmico. O atrito estático é a força que deverá ser superada para que seja iniciado um movimento relativo entre duas superfícies. Uma vez que a barreira do atrito estático seja vencida e que o movimento seja iniciado, o atrito dinâmico passa a atuar. 
Stick (emperrar) e slip (escorregar) são termos utilizados para descrever o atrito estático. O termo stiction (static + friction) é amplamente utilizado para descrever o atrito estático, que constitui uma das maiores causas de banda morta dentro do universo das válvulas de controle. Há uma série de definições para o stiction. Uma revisão destas possíveis definições é realizada por Choudhury; Thornhill e Shah (2004). Entre as definições citadas, está por exemplo, a da ISA (The Instrumentation, Systems and Automation Society): "stiction é a resistência para o início do movimento, geralmente medida como a diferença entre os valores de excursão exigidos para superar o atrito estático nas duas direções". Choudhury et al. (2005) descrevem que "stiction é a propriedade de um elemento cujo movimento suave em resposta a variação da entrada, é precedido por um comportamento estático (sem movimento) seguido por um salto repentino e abrupto".

Segundo Choudhury; Thornhill e Shah (2004), o estudo das definições demonstra que todas as tentativas formais, concordam que stiction é o atrito estático que impede um objeto de movimentar-se e que quando a força externa o supera, o objeto começa a movimentar-se. As principais divergências verificadas dizem respeito ao modo como o stiction é medido e como pode ser modelado.

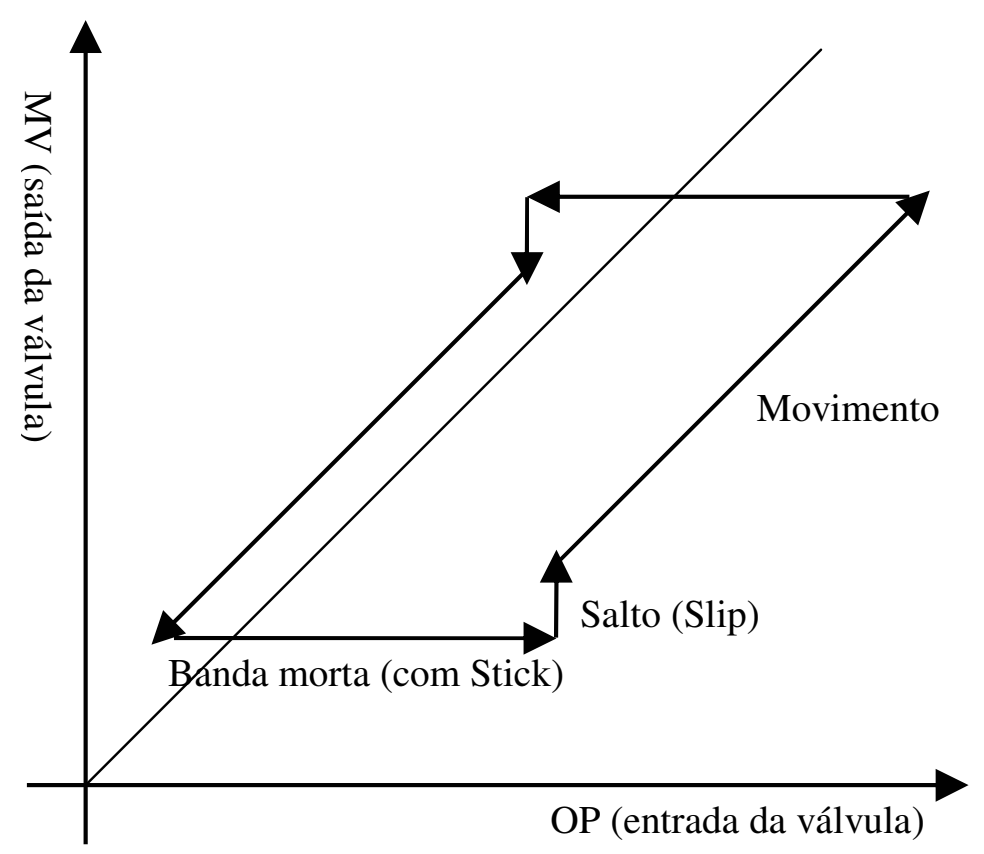

Figura 9: llustração do Stiction 
A Figura 9, ilustra a relação entre o sinal de saída e de entrada de uma válvula com stiction, ou seja, da variável manipulada pela variável de saída do controlador. Pela figura, pode-se notar três fases distintas, uma de valor constante, outra que representa um salto e outra ainda que representa o movimento da variável de saída, de maneira proporcional à entrada. Em suma:

- Banda morta ou valor constante: a variável de saída da válvula é constante com o tempo, pela presença da força do atrito estático, contrária ao movimento desejado, emperrando assim o movimento da haste da válvula.;

- Salto (Slip jump): a variável de saída da válvula muda abruptamente, quando a força de atrito estático é vencida, liberando o movimento da haste da válvula, levando-a a deslizar de maneira desproporcional à variação de sua entrada;

- Movimento: a variável de saída da válvula varia gradualmente e de maneira proporcional à variação da de entrada; neste momento há apenas a ação da força de atrito dinâmico.

No caso de ocorrência de stiction, a variável manipulada apresenta um comportamento temporal oscilatório. Esta tendência do comportamento da variável manipulada é também propagada à variável de processo, apesar de que "filtrada" pela dinâmica do processo. É desta forma que o stiction contribui com a variabilidade do processo, causando esta oscilação na variável de processo e, conseqüentemente, uma perda de desempenho da malha de controle.

O stiction, assim como as outras forças de atrito atuantes na válvula de controle, é causado principalmente pelo engaxetamento empregado pela mesma. O engaxetamento é formado por anéis tipicamente de grafite ou teflon, que são responsáveis por selar a fronteira entre o atuador e o material que flui através da válvula. O tipo de engaxetamento depende dos níveis de temperatura e de pressão aos quais a válvula será submetida durante sua operação. A aperto excessivo do engaxetamento de uma válvula, bem como seu desgaste, também podem aumentar os níveis de atrito de maneira considerável, originando stiction. 


\subsection{Detecção de Perturbações}

O sempre desejado controle de desempenho de uma planta, é melhor efetuado com a deteç̧ão e o mapeamento das perturbações existentes em seus processos de maneira precisa e pontual. Esta deteç̧ão possibilita a aplicação de métodos úteis no descobrimento da origem das causas das perturbações, permitindo combatê-las de modo efetivo.

As perturbações podem ser de natureza oscilatória ou não-oscilatória, cada qual com seus próprios métodos de deteç̧ão.

\subsubsection{Perturbações Não-Oscilatórias}

Perturbações não-oscilatórias são caracterizadas pela presença irregular de alterações no comportamento temporal normal de determinada variável, que pode se parecer com picos ou vales, mas às vezes pode parecer com perturbações oscilatórias. Causas comuns para perturbações não-oscilatórias podem estar relacionadas a restrições ou problemas do processo. Não é incomum a ocorrência simultânea de ambos os tipos de efeito, oscilatórios e não-oscilatórios. Todavia, perturbações não-oscilatórias persistentes são geralmente caracterizadas por seus espectros, e isso faz do domínio da freqüência um potencial candidato para a detecção das perturbações não-oscilatórias.

\subsubsection{Métodos de Detecção de Perturbações Não-Oscilatórias}

Perturbações não-oscilatórias persistentes são geralmente caracterizadas por seu espectro, que pode apresentar como característica a ocorrência de múltiplos picos. O problema de detecção de perturbações não-oscilatórias em uma planta requer um tempo de medida conveniente, através do qual possa se analisar a similaridade de espectro entre grupos de medições.

Thornhill e Horch (2006) resumem os métodos existentes para a detecção de perturbações não-oscilatórias, a saber: PCA (Principal Component Analysis), ICA (Independent Component Analysis), NMF (Non-negative Matrix Factorization) e 
Análise de Correlação. Todos estes métodos são baseados na análise espectral dos sinais do processo.

\subsubsection{Perturbações Oscilatórias}

As oscilações são os principais indicadores da deterioração do controlador ou do desempenho do processo como um todo. Estudos como (CHOUDHURY et al., 2005) relatam que cerca de $30 \%$ das malhas de controle costumam apresentar oscilações, seja qual for o seu segmento industrial.

O fato de que algumas malhas oscilem é freqüentemente conhecido pelos operadores de um sistema. Todavia, o que não é conhecida é a causa, nem quais devem ser as medidas corretas a serem aplicadas no trabalho de identificação.

Como resultado, malhas oscilatórias tendem a serem aceitas como um problema inevitável e, portanto, é comum ser ignorado ou ser passado o controle para manual. A origem das oscilações em uma malha de controle pode ser endógena ou exógena. Qualquer estudo de redução de variabilidade de uma malha deve sempre levar em conta a possibilidade de causas tanto internas, quanto externas à malha de controle.

\subsubsection{Métodos de Detecção de Perturbações Oscilatórias}

Os métodos de detecção de perturbações oscilatórias seguem três classes principais, conforme resumido por Thornhill e Horch (2006): análise no domínio do tempo, análise da função de auto-covariância e detecção de picos espectrais.

Uma descrição mais detalhada destes métodos e suas principais características é feita por Thornhill e Horch (2006):

"Filtragem ou algum outro meio de tratamento de ruídos é normalmente necessário nas aplicações no domínio do tempo. [...] A maioria dos métodos são off-line e exploram as vantagens de se estar off-line, como o uso de todo um conjunto consolidado de dados para determinar um espectro ou a função de auto-covariância. [...] Os métodos citados permitem a detecção da oscilação de uma medida por vez. Porém, é necessário muito mais para a detecção de oscilações de uma planta como um todo [...]" ((THORNHILL; HORCH, 2006), p.30). 
Na prática, não basta detectar a oscilação de uma única malha de controle, separadamente. É necessário uma análise que permita correlacionar as oscilações de diferentes malhas entre si, respondendo se são iguais ou não. Esta análise é muito difícil pois, mesmo que as oscilações de duas malhas sejam iguais, os sinais destas duas malhas podem ser muito diferentes, devido à presença de interferências e perturbações secundárias.

\subsection{Diagnóstico das Causas}

Uma vez que as perturbações atuantes em uma malha de controle ou em toda a planta sejam identificadas, o próximo passo é diagnosticar suas causas. $O$ problema de diagnóstico das causas pode ser decomposto em duas partes (THORNHILL; HORCH, 2006). Primeiramente, a causa de cada fonte de perturbação deve ser distinguida entre as perturbações secundárias que possam ser propagadas por esta fonte. A segunda parte consiste, geralmente, em testar os possíveis candidatos a fontes de perturbações para a confirmação do diagnóstico.

Thornhill e Horch (2006) apresentam uma árvore que resume os métodos existentes para o diagnóstico de diferentes causas de perturbações em uma planta, divididas em lineares e não-lineares. Essa árvore foi simplificada e resumida, gerando-se o diagrama apresentado na Figura 10. 


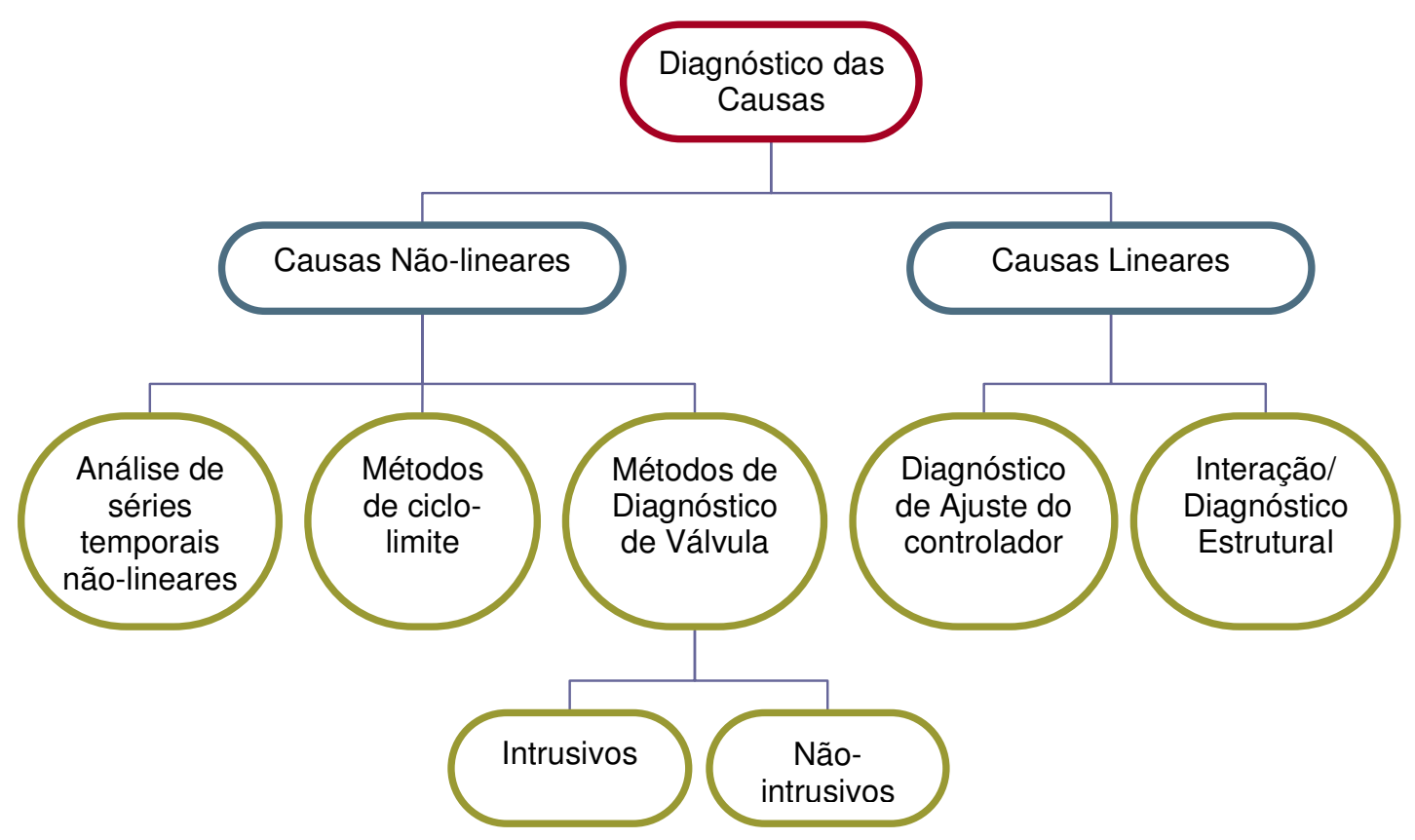

Figura 10: Árvore de métodos para o diagnóstico das causas da variabilidade

Neste trabalho, foram estudadas as causas não-lineares das perturbações atuantes em uma malha de controle, com ênfase nos métodos de diagnóstico de válvula.

\subsubsection{Métodos Não-Intrusivos}

Os métodos não-intrusivos de diagnóstico das causas são aqueles baseados em uma análise off-line de dados operacionais de uma planta, sem nenhum tipo de interação humana durante a coleta das informações. Estes são, sem dúvida, os métodos mais estudados e testados na literatura. Diferentes métodos foram recentemente propostos, sendo alguns dos mais relevantes no meio industrial e acadêmico os métodos Waveform Shape (RENGASWAMI et al., 2001), Signal pdf (HORCH, 2002) e o Cross Correlation. Este último, sugerido por Horch (1999), é o mais utilizado no meio industrial, devido à sua facilidade de aplicação e análise.

Além destes, outros métodos não-intrusivos são descritos e analisados (HORCH, 1999; STENMAN; FORSMAN; GUSTAFSSON, 2002; ROSSI; SCALI, 2005; SINGHAL; SALSBURY, 2005; CHOUDHURY et al., 2006; YAMASHITA, 2006; 
JIANG; CHOUDHURY; SHAH, 2007;), mas nenhum dos métodos não-intrusivos é infalível em seu diagnóstico.

Simulações realizadas em (ROSSI; SCALI, 2005) demonstram que não se pode considerar que os métodos anteriormente citados sejam válidos para qualquer situação, já que estes métodos são influenciados de forma significativa pela dinâmica do processo e pelos parâmetros de stiction (Slip Jump e Stick Band), os quais contemplam informações que mudam de maneira significativa os sinais considerados em uma malha de controle.

\subsubsection{Métodos Intrusivos}

Nenhum dos métodos não-intrusivos citados anteriormente é capaz de identificar de forma inequívoca a presença do atrito na válvula de controle. Sendo assim, para a confirmação da presença do atrito nas válvulas de uma malha de controle, são empregados métodos intrusivos, ou seja, que necessitam de intervenção em tempo real durante a operação do processo. São dois os métodos intrusivos já propostos na literatura: o "Teste de Elevação" (Bump Test ou Valve Travel) (GERRY; RUEL, 2001) e o de "Mudanças no Ganho do Controlador" (Changes in Controller Gain) (CHOUDHURY et al., 2005).

O Teste de Elevação considera que se pode confirmar o stiction nas válvulas de controle colocando-se o controle da válvula em manual e incrementando-se o sinal de controle em pequenos degraus, até que se possa observar uma mudança considerável na saída do processo. Este teste é conhecido como teste de elevação e está descrito em (TAHA; DUMONT; DAVIES, 1996; WALLÉN, 1997; GERRY; RUEL, 2001). De fato, a idéia principal deste método é variar o sinal de entrada da válvula até descobrir o limiar em que a força de atrito estático atuante seja vencida, confirmando ou não assim a sua presença.

Há, no entanto, um ponto desfavorável na utilização deste método. Como ele requer que o controlador seja colocado em manual, há um risco de perturbação na dinâmica do processo durante a execução do teste, o que pode levar à obtenção de produtos fora da especificação desejada. Desta forma, para a aplicação deste 
método, deve-se sempre avaliar os riscos de perda de produção e, principalmente, os custos que podem surgir de sua aplicação.

O Teste de Mudanças no Ganho do Controlador tem como objetivo ser uma alternativa mais viável ao método intrusivo mais utilizado até então, o teste de elevação. Este método, proposto por Choudhury et al. (2005), também pode ser aplicado em tempo real durante a operação do processo, mas sem afeta-lo de maneira significativa.

A presença de stiction em uma malha de controle produz oscilações na variável de saída do processo e, segundo Choudhury et al. (2005), também na variável de saída do controlador. Sendo assim, variações na amplitude do ganho do controlador causam mudanças na amplitude e, principalmente, na freqüência destas oscilações. Desta forma, uma vez que o stiction tenha sido detectado, este método pode confirmar a sua presença através da constatação da variação da freqüência das oscilações de saída, com a variação do ganho do controlador.

\subsection{Implementação dos Métodos Intrusivos}

Para a aplicação dos dois métodos intrusivos abordados, foi utilizado o ambiente Simulink do aplicativo Matlab®. A intenção foi implementar os métodos considerados neste trabalho de tal forma, que não fosse necessária nenhuma intervenção humana durante sua execução e análise. Assim sendo, uma vez ajustados os parâmetros iniciais para o teste, ele deve possuir autonomia de execução e de análise dos dados obtidos, apresentando a conclusão sobre a presença da não-linearidade na malha de controle estudada.

Os ensaios foram realizados em dois ambientes: um totalmente simulado, onde tanto o processo quanto a válvula de controle a serem utilizados são modelos implementados por Garcia (2006, 2008), com o auxílio do aplicativo Matlab®; o outro ambiente, híbrido, associa o modelo do processo a uma válvula real através de uma técnica denominada HIL (Hardware In The Loop). Esses ensaios foram realizados para diferentes níveis de atrito na válvula de controle simulada e real.

O modelo de atrito utilizado para a válvula de controle simulada foi o modelo de Karnopp (GARCIA, 2006, 2008). Este modelo é baseado nas forças atuantes na 
dinâmica de uma válvula, sua utilização está exemplificada em (TAHA; DUMONT; DAVIES, 1996).

Para cada ensaio realizado, são inseridos os parâmetros iniciais pelo usuário e inicia-se então o algoritmo responsável pela execução dos testes e simulações, utilizando o modelo selecionado. Após o final dos testes, os dados obtidos pela simulação são analisados e é gerada uma informação resumida e objetiva, que indica a presença ou ausência da não-linearidade no processo, ou seja, do atrito na válvula de controle.

\subsubsection{Teste de Elevação}

A seguir é apresentado o esboço do algoritmo para a implementação do Teste de Elevação, baseado em (GERRY; RUEL, 2001).

Passo 1: Colocar o controlador em manual com o valor da saída próximo à faixa normal de operação;

Passo 2: Começar a armazenar os dados de teste, gravando tanto a variável de saída do controlador, quanto a variável de saída do processo;

Passo 3: Aumentar a saída do controlador em 5 ou 10\% para vencer a banda morta da malha. Se a variável de processo não se mover com esta mudança, repetir este passo até que a variável se mova;

Passo 4: Aguardar que a variável de processo se estabilize;

Passo 5: Fazer pequenos incrementos na saída do controlador, algo em torno de $2 \%$, sempre no mesmo sentido do último degrau, de maneira crescente. Aguardar o mesmo intervalo de tempo (dependente da dinâmica do processo em estudo) pela variação da variável de processo, após o incremento da saída do controlador;

Passo 6: Repetir o último passo até que a variável de processo se mova.

Uma vez executado o teste, deve ser possível identificar a existência do atrito e até mesmo quantificá-lo. O total de atrito estático existente na válvula pode ser obtido a partir da variação total necessária no sinal de saída do controlador para que a variável de processo seja movimentada. 
Uma dificuldade encontrada na implementação deste método foi a determinação do tempo de espera para a verificação da variação da PV após cada novo incremento na MV. Para tanto, foram implementadas algumas modificações no algoritmo proposto em (GERRY; RUEL, 2001). A solução encontrada foi determinar o tempo de acomodação do sistema adotado como referência para o tempo de espera, baseado na obtenção automática da constante de tempo do sistema. Ogata (2000) define tempo de acomodação como:

\footnotetext{
"Tempo necessário para que a curva de resposta do sistema alcance valores dentro de uma faixa em torno do valor final e aí permaneça. O intervalo de valores no interior da faixa é especificado por uma porcentagem absoluta do valor final (normalmente $2 \%$ ou $5 \%$ ). O tempo de acomodação está relacionado com a maior constante de tempo do sistema de controle. A escolha de que porcentagem usar no critério de erro pode ser determinada a partir dos objetivos do projeto do sistema em questão." (OGATA, 2000, p.126)
}

Ogata (2000) demonstra ainda que, no intervalo de tempo correspondente a uma constante de tempo, a resposta de um sistema varia de 0 a $63,2 \%$ do valor final. Em duas constantes de tempo, a resposta alcança $86,5 \%$ do valor final. Nos tempos iguais a três vezes a constante de tempo $(T)$, quatro vezes $T$ e cinco vezes $T$, a resposta alcança 95\%, 98,2\% e 99,3\%, respectivamente, do valor final. Portanto, para o tempo maior que cinco vezes $T$, a resposta apresenta uma tolerância de $1 \%$ do valor final.

Sendo assim, pelo primeiro degrau aplicado durante o método, é estimada automaticamente a constante de tempo do sistema. A partir daí, espera-se o tempo de acomodação de cinco vezes $T$ em cada novo incremento da MV para a análise de variação da PV. Uma vez que a PV varia, para-se a simulação ou então, caso não seja apresentada variação da $\mathrm{PV}$, continua-se até o término do tempo de simulação programado $\left(T_{\text {sim }}\right)$.

\subsubsection{Teste de Mudanças no Ganho do Controlador}

A seguir é apresentado o esboço do algoritmo para a implementação do teste de mudanças no ganho do controlador, baseado em (CHOUDHURY et al., 2005). 
Passo 1: Começar a armazenar os dados de teste, gravando tanto a variável de saída do controlador, quanto a variável de saída do processo. Determinar $T_{\text {sim }}$ como o tempo total de simulação;

Passo 2: Duplicar o ganho proporcional do controlador após um terço de $T_{\text {sim; }}$;

Passo 3: Dividir pela metade o ganho proporcional original do controlador após outro terço de $T_{\text {sim; }}$;

Passo 4: Voltar o ganho proporcional do controlador ao seu valor inicial após a totalização do tempo de simulação $T_{\text {sim }}$.

Após a execução destes passos, é analisado o comportamento do sinal da variável de processo. Uma vez que seja confirmada uma variação significativa na freqüência do sinal da variável de processo para cada acréscimo do ganho do controlador, é possível confirmar a presença do atrito na válvula de controle desta malha.

Vale ressaltar que nos procedimentos descritos por Choudhury et al. (2005), o ganho do controlador é sempre duplicado a cada nova mudança em seu valor. Neste trabalho, foi proposto que, ao invés de sempre aumentar o ganho, também fosse diminuído o ganho original, na tentativa de minimizar o impacto da aplicação do método, visando não levar o processo à instabilidade.

Sobre os resultados obtidos pela implementação deste método (CHOUDHURY et al., 2005) concluíram que:

- Se uma oscilação é gerada internamente a uma malha de controle devido à presença de stiction em uma válvula, um acréscimo no ganho do controlador irá incrementar a freqüência da oscilação;

- Se uma oscilação entra em uma malha de controle através de uma perturbação externa, a mudança no ganho do controlador não irá alterar a freqüência da oscilação;

- Não há relação consistente entre a mudança na amplitude da oscilação e o ganho do controlador. 


\section{MATERIAIS E MÉTODOS}

\subsection{Modelos e ambientes utilizados}

Nesta seção são descritos os dois ambientes de simulação que são utilizados para a realização dos ensaios e os modelos inseridos e utilizados em cada ambiente. Primeiramente é descrito o modelo de atrito de Karnopp, que é utilizado para a simulação da válvula de controle, no ambiente totalmente simulado, que também é descrito na seqüência. Descreve-se então o modelo do processo e, por fim, é feita a apresentação do conceito HIL e a descrição de seu ambiente de simulação.

\subsubsection{O modelo de atrito de Karnopp e a válvula de controle}

Conforme Taha; Dumont e Davies (1996), na maioria dos casos práticos é comum se lidar com uma válvula de controle pneumática, que é composta por um posicionador, pelo atuador e pelo corpo da válvula. Uma válvula, por melhor que seja, sempre apresentará algum tipo de não-linearidade. Em geral, estas não-linearidades não são fáceis de serem eliminadas, uma vez que são parte intrínseca da natureza dos mecanismos físicos da válvula. Um esquema simplificado de uma válvula de controle é apresentado na Figura 11.

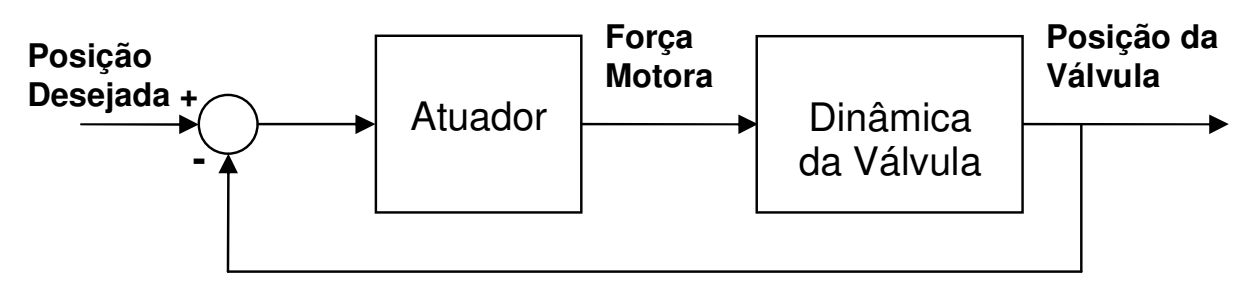

Figura 11: Modelo Simplificado de uma Válvula de Controle. 
A força motora é produzida pelo atuador através da manipulação da pressão de ar dentro da câmara. A posição atual da válvula é comparada ao valor desejado e então, a vazão de ar comprimido da entrada é calculada de acordo com o desvio existente entre ambos. Forças de atrito são aplicadas a todos elementos: atuadores, posicionadores e válvula. Para simplificar este estudo, pode-se assumir que as forças estejam concentradas na haste, dado que este é o elemento com maior superfície em contato e com maior excursão.

As forças motoras produzidas pelo atuador e pela força de atrito atuam paralelamente, na direção do deslocamento. As partes móveis, cujo principal componente é a haste com o obturador, são modeladas como uma massa à qual as forças são aplicadas.

O modelamento da válvula de controle de processos pneumática foi proposto por vários dos autores utilizados como referência para este trabalho. Em seus trabalhos, os autores (KAYIHAN; DOYLE III, 2000; CHOUDHURY et al., 2004; GARCIA, 2006, 2008) partem da expressão do somatório de forças para modelar a válvula de controle e suas respectivas forças de atrito, como descrito na Equação (1).

$$
m \frac{d^{2} x_{1}}{d t^{2}}=\sum \text { Forças }=F_{a}-F_{r}-F_{f}-F_{\text {fluido }}-F_{\text {sede }}
$$

Na Equação (1), $m$ é a massa das partes móveis da válvula (tipicamente a haste e o obturador), $x_{1}$ é a posição da haste da válvula, $F_{a}=A u$ é a força aplicada pelo atuador da válvula, sendo $A$ a área do diafragma e $u$ a pressão de $\operatorname{ar}, F_{r}=-k x_{1}$ é a força da mola, onde $k$ é a constante da mola, $F_{\text {fluido }}=-\alpha \Delta P$ é a força relacionada à perda de carga do fluido, onde $\alpha$ é a área desbalanceada do obturador e $\Delta P$ a perda de carga, $F_{\text {sede }}$ é a força adicional necessária para acomodar o obturador na sede da válvula e $F_{f}$ é a força de atrito.

Assim como foi feito em (KAYIHAN; DOYLE III, 2000), assumiu-se que $F_{\text {fluido }} \mathrm{e}$ $F_{\text {sede }}$ são nulos, uma vez que ambas as forças apresentam contribuição desprezível no modelo da válvula, se comparadas com as demais componentes no balanço de 
forças. Sendo assim, a Equação (1) pode ser reescrita, desprezando-se $F_{\text {fluido }}$ e $F_{\text {sede }}$. Desta forma, chega-se na Equação (2):

$$
m \frac{d^{2} x_{1}}{d t^{2}}=\sum \text { Forças }=F_{a}-F_{r}-F_{f}
$$

Um vez definido o modelo físico, a próxima etapa consiste na análise do modelo de atrito que foi adotado para este trabalho. Garcia $(2006,2008)$ estudou diversos modelos de atrito propostos anteriormente para uma válvula de controle. Os modelos de atrito podem ser divididos em três grupos: modelos estáticos, modelos dinâmicos e modelos de atrito orientados a dados de processo. Nos modelos estáticos de atrito, os parâmetros do modelo não dependem do tempo, ao contrário do que acontece nos modelos dinâmicos, nos quais alguns dos parâmetros variam com o transcorrer do tempo. Os modelos estáticos de atrito levam em conta três componentes principais: o atrito estático, o atrito viscoso e o atrito de Coulomb. Desta forma, a força de atrito pode ser descrita pela Equação (3), na qual $F_{C}$ é o coeficiente de atrito de Coulomb, $F_{S}$ é o coeficiente de atrito estático, $F_{V}$ é o coeficiente de atrito viscoso, $v_{S}$ é a velocidade de Stribeck e $x_{2}$ a velocidade da haste.

$$
F_{f}\left(x_{2}\right)=\left[F_{C}+\left(F_{S}-F_{C}\right) \mathrm{e}^{-\left(x_{2} / v_{s}\right)^{2}}\right] \operatorname{sgn}\left(x_{2}\right)+F_{V} x_{2}
$$

Desta forma, resta descrever o modelo de atrito estático que foi utilizado nas simulações realizadas neste trabalho, o modelo de Karnopp. Em (GARCIA, 2006, 2008) são estudados dois modelos estáticos de atrito: Clássico e Karnopp. A escolha do modelo de Karnopp para este trabalho é justificada pelo fato de o modelo estático clássico de atrito apresentar um comportamento indesejado em torno da velocidade nula de movimentação da haste da válvula de controle. Nas simulações realizadas com o modelo clássico, a velocidade de movimentação da haste da válvula de controle nunca alcança a velocidade nula, fazendo com que a mesma oscile em torno deste valor.

Sendo assim, para lidar com o comportamento oscilatório próximo da velocidade nula, Garcia $(2006,2008)$ sugere o modelo estático de atrito de Karnopp. 
Este modelo propõe o estabelecimento de um intervalo em torno de $x_{2}=0$, criando desta forma uma zona morta para $\left|x_{2}\right|<D V$. Se $\left|x_{2}\right|<D V$, a força de atrito é uma versão saturada da força externa $F_{e}=F_{a}-F_{r}$ ou, caso contrário, uma função estática da velocidade, conforme a Equação (2). Por este motivo, o valor no qual a velocidade da haste da válvula de controle seja forçada para zero (DV), deve ser um valor suficientemente baixo para evitar um salto considerável na força de atrito estático.

\subsubsection{O modelo do processo}

O processo escolhido para ser utilizado neste trabalho foi o de controle de vazão, por apresentar uma constante de tempo pequena (da ordem de 1s), permitindo assim que os ensaios fossem efetuados em um tempo reduzido. Como o passo de integração adotado para as simulações $\left(10^{-5} \mathrm{~s}\right)$ foi muito pequeno, processos com dinâmicas mais lentas exigiriam simulações muito longas para permitir a visualização dos fenômenos de atrito gerados e da aplicação dos métodos intrusivos para sua detecção. A Figura 12 ilustra, de maneira simplificada, o diagrama de blocos do sistema a ser estudado.

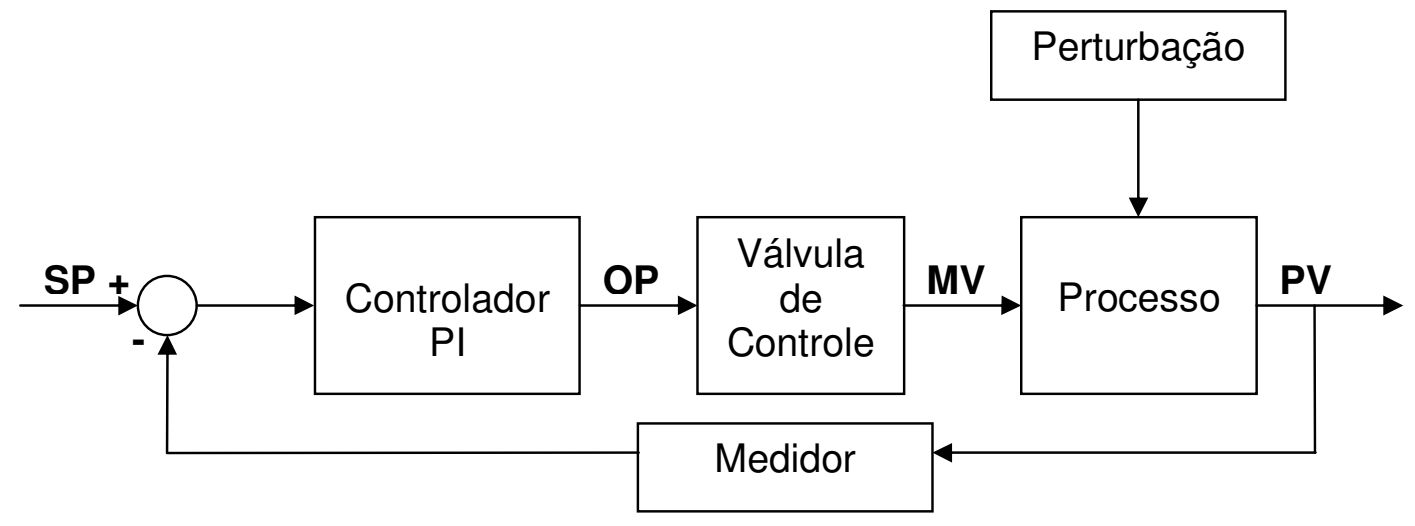

Figura 12: Diagrama simplificado da malha de controle de vazão estudada

O sistema simulado neste trabalho utiliza um circuito de vazão com tubulação de 2" de diâmetro nominal, pela qual circula água através do acionamento de uma 
bomba. A vazão é controlada através de um controlador PI, conectado a uma válvula de controle que, no ambiente totalmente simulado, tem seu atrito modelado através do modelo de Karnopp. No ambiente híbrido HIL esta válvula é real.

\subsubsection{O ambiente totalmente simulado}

Devido à praticidade experimental, alguns dos ensaios realizados neste trabalho foram realizados em um ambiente totalmente simulado, através do uso do aplicativo Matlab®. Isso significa que todo o processo, desde a válvula de controle até as perturbações, são simulados computacionalmente para este ambiente.

Esse tipo de simulação confere a flexibilidade necessária para que se possa ajustar diferentes tipos e níveis de atrito de maneira muito simples e rápida, através da simples mudança de parâmetros de ajuste nos modelos utilizados. Esta abordagem é interessante, pois proporciona a realização de testes que seriam difíceis de reproduzir em uma instalação industrial real, ou mesmo em laboratório. Em contrapartida, por melhor que seja a modelagem do sistema (processo, válvula de controle etc), este tipo de ambiente nem sempre representa com fidelidade os fenômenos de uma planta industrial real. Para tentar minimizar os efeitos das eventuais fontes de incerteza no modelo de atrito da válvula, optou-se por empregar um outro ambiente de simulação, no qual fosse utilizada uma válvula de controle real, denominado HIL (Hardware in the Loop).

\subsubsection{O ambiente de simulação HIL}

Com o objetivo de atingir resultados mais próximos da realidade industrial, foi utilizado um ambiente de simulação chamado HIL. Pode-se chamar este ambiente de híbrido devido ao fato de associar componentes simulados com elementos reais.

Nesta técnica, a válvula de controle utilizada é real e, através de interfaces de aquisição e envio de dados, é feita a troca de informações entre os modelos matemáticos do processo e do controlador implementados no ambiente de 
simulação e a válvula real. A principal vantagem da utilização desta técnica é possibilitar, através da simulação em tempo real do sistema, o estudo do comportamento de uma válvula de controle real em um ambiente laboratorial.

Para compor a parte real deste ambiente de simulação, foi utilizada a válvula pneumática de controle modelo ET 2" do tipo globo, do fabricante Fisher (Emerson). Para possibilitar a aquisição dos sinais de posição e pressão, algumas modificações foram feitas. A primeira modificação foi a instalação de um sensor de pressão no atuador da válvula. Também foi feita uma alteração no circuito elétrico do posicionador da válvula, possibilitando desta forma coletar os sinais de posição da haste da válvula. A última modificação foi a instalação de um conversor V/P (tensão/ pressão), que é responsável pela conversão do sinal elétrico enviado pela placa de aquisição de dados em um sinal de pressão, capaz de acionar o atuador da válvula.

Para a interface de envio e aquisição de informações entre o computador e os dispositivos de controle, foi utilizada a placa de aquisição de dados modelo NI6229 (16 bits de resolução e $250 \mathrm{kHz}$ de amostragem) da empresa National Instruments. Esta interface de aquisição recebe os sinais da posição da haste e da pressão no atuador, e envia os sinais para o conversor V/P. Desta forma, esta interface de aquisição possibilita a interação entre o ambiente simulado, composto pelo controlador PI, o processo, o medidor e o ambiente real, representado pela válvula e o atuador.

Este tipo de ambiente de simulação híbrido tem sido cada vez mais utilizado em estudos acadêmicos e também industriais, pois permite avaliar o comportamento de um equipamento real através de uma ferramenta de simulação, sem a necessidade de perturbar-se um processo real. No caso deste trabalho, a idéia foi avaliar o desempenho de métodos intrusivos de detecção de atrito em válvulas de controle.

A Figura 13 ilustra os elementos que compõem o ambiente de simulação HIL. As figuras 14, 15 e 16 são fotografias que registram o ambiente utilizado, com detalhes do conjunto de equipamentos e dispositivos empregados nos ensaios. 


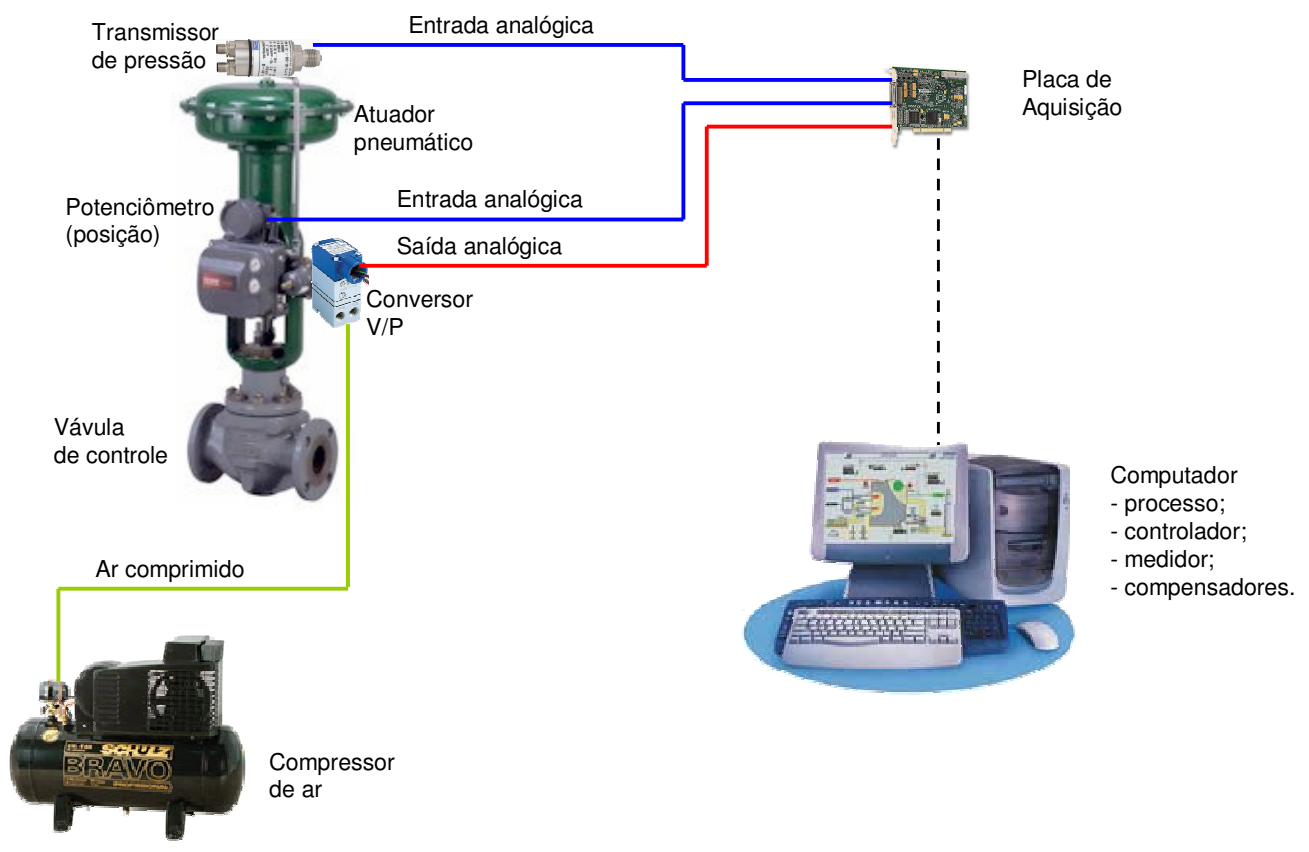

Figura 13: Diagrama do ambiente HIL.

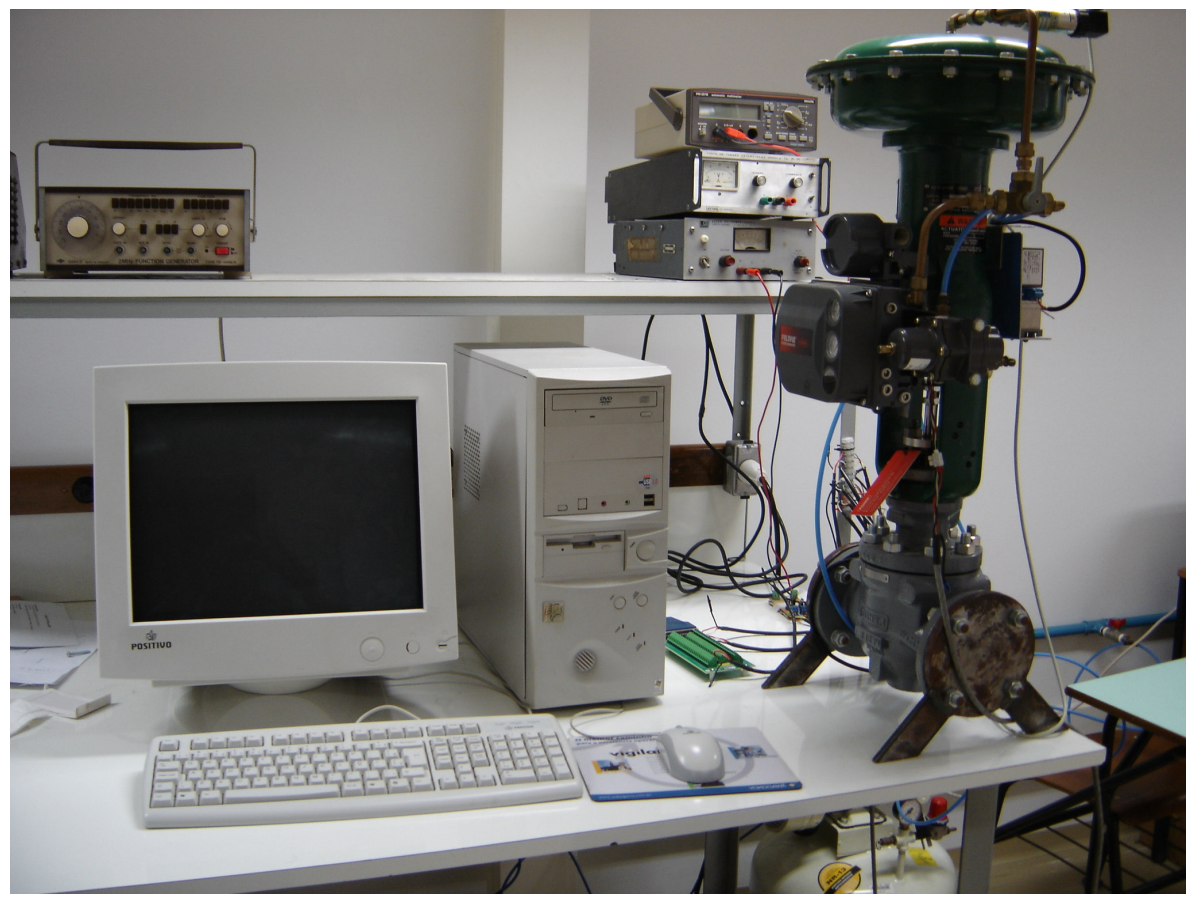

Figura 14: Foto do HIL utilizado nos ensaios. 


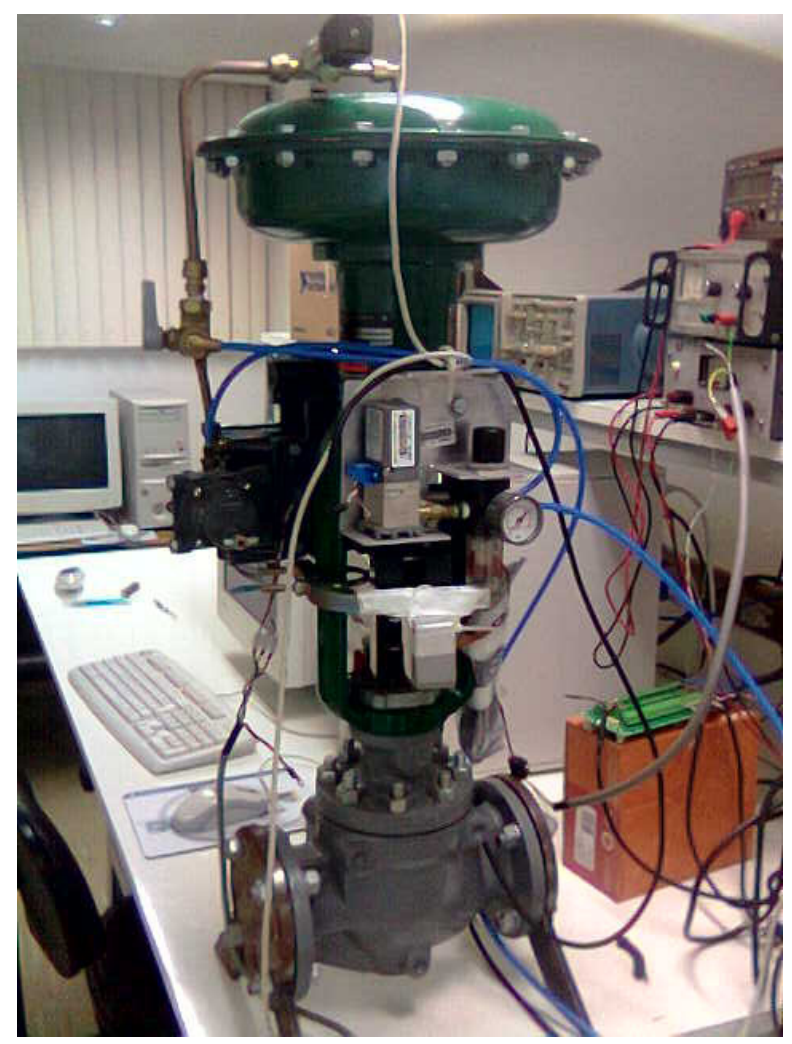

Figura 15: Detalhes da válvula de controle Fisher.

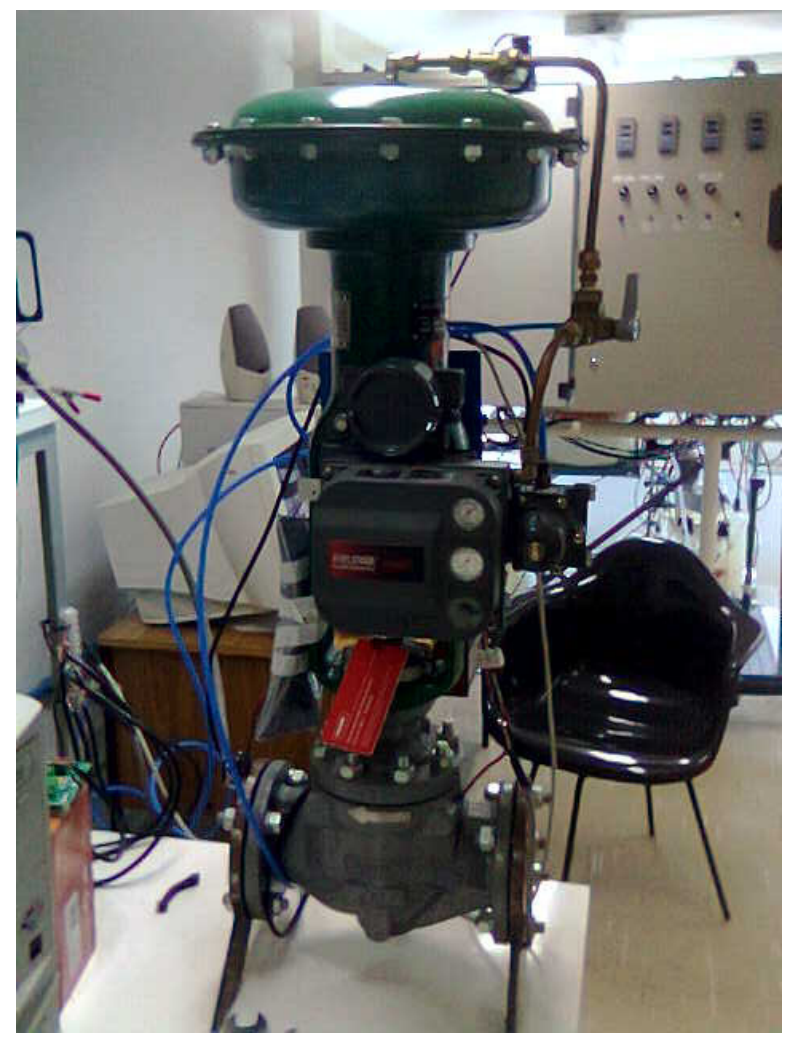

Figura 16: Detalhes da válvula de controle Fisher. 


\subsection{Procedimento experimental}

Os ensaios realizados partem do pressuposto de que as oscilações do processo já foram detectadas. Além disso, parte da premissa de que a presença de stiction e/ou outras não-linearidades na válvula de controle do processo sejam conhecidas.

As simulações tiveram como objetivo confirmar ou não a presença de atrito na malha e verificar se os métodos têm bom desempenho para níveis altos e baixos de atrito. Adicionalmente, pretendia-se verificar se estes métodos funcionam apenas na identificação do atrito estático (stiction), como proposto por Gerry e Ruel (2001) e por Choudhury et al. (2005), ou também no diagnóstico de outros tipos de atrito. Em resumo, teve-se como objetivo a verificação da eficácia do método de Mudanças do Ganho do Controlador na presença de uma perturbação externa ou de má sintonia do controlador.

Ambos os métodos intrusivos foram implementados de forma que não fosse necessária nenhuma intervenção humana durante a fase de execução dos ensaios. Sendo assim, uma vez ajustados os parâmetros iniciais para o teste, a execução e a análise dos dados obtidos é automática, devolvendo a informação já trabalhada, ou seja, o resultado sobre a presença de atrito na válvula de controle estudada.

Ao todo, foram testados dois níveis de atrito para os testes com HIL, chamados de High e Low e, para o ambiente totalmente simulado, foram feitos ensaios para quatro tipos de válvulas, chamadas de Ideal, Fabricante, Nominal e Áspera, com diferentes níveis de atrito (GARCIA, 2006, 2008), como apresentado na Tabela 1.

Tabela 1: Tipos de atrito das válvulas ensaiadas no ambiente totalmente simulado.

\begin{tabular}{|l|l|}
\hline Atrito & Válvula \\
\hline Alto com Stiction & Áspera \\
\hline Médio com Stiction & Nominal \\
\hline Médio sem Stiction & Fabricante \\
\hline Baixo sem Stiction & Ideal \\
\hline
\end{tabular}


Foram feitas simulações com a presença de stiction, utilizando-se as válvulas do tipo Áspera e Nominal e, sem stiction, considerando-se os tipos Ideal e Fabricante. Essas simulações foram realizadas para que fosse verificada a eficiência dos métodos em detectar também o Atrito de Coulomb e o Viscoso, que completam o modelo de Karnopp.

Além disso, foram efetuados testes com a presença de oscilações externas à malha de controle e também com um controlador mal sintonizado. Desta forma, foram efetuadas vinte e quatro simulações ao todo. 


\section{RESULTADOS E DISCUSSÃO}

\subsection{Ensaios no ambiente totalmente simulado}

São apresentados nesta seção os resultados dos testes efetuados com cada método intrusivo em uma válvula de controle simulada a partir do modelo de atrito de Karnopp com diferentes coeficientes de atrito, os quais são gerados variando-se os parâmetros do modelo. Foram utilizadas quatro configurações diferentes, chamadas de: Fabricante, Áspera, Nominal e Ideal. Os parâmetros de atrito estão listados na Tabela 2 que foram obtidos em (GARCIA, 2006, 2008). A área do diafragma do atuador é de 0,06452 $\mathrm{m}^{2}$, a massa das partes móveis é de 1,361 kg e a constante elástica da mola é de $5,2538 * 10^{4} \mathrm{~N} / \mathrm{m}$.

Tabela 2: Parâmetros das válvulas ensaiadas no ambiente totalmente simulado.

\begin{tabular}{|l|c|c|c|c|}
\hline Parâmetro & Ideal & Fabricante & Nominal & Áspera \\
\hline$F_{C}:$ coef. atrito Coulomb $(\mathrm{N})$ & 0 & 44,48 & 1423 & 2224 \\
\hline$F_{S}:$ coef. de stiction $(\mathrm{N})$ & 0 & 0 & 284,7 & 444,8 \\
\hline$F_{\mathrm{V}: \text { coef. atrito viscoso }(\mathrm{N} \cdot \mathrm{s} / \mathrm{m})}$ & 350,2 & 612,9 & 612,9 & 1226 \\
\hline
\end{tabular}

Foram efetuados, ao todo, dezesseis ensaios diferentes, quatro para cada nível de atrito, a saber: Teste de Elevação, Mudanças no Ganho do Controlador, Mudanças no Ganho do Controlador na presença de perturbação externa e Mudanças no Ganho do Controlador com o controlador mal sintonizado. Estas simulações foram realizadas com durações adequadas para a execução de cada método. No caso do Teste de Elevação, o tempo de simulação depende do movimento da válvula e da constante de tempo do processo. No caso das Mudanças no Ganho do Controlador, o tempo de simulação foi escolhido de forma que as oscilações do sistema sejam facilmente observáveis em um terço do seu tempo. 
Os testes realizados com a válvula Áspera não são apresentados neste trabalho, pois a mesma não respondeu a nenhum estímulo, independente do valor do degrau aplicado em sua entrada.

\subsubsection{Ensaios com o Teste de Elevação}

Os ensaios realizados no ambiente totalmente simulado para o Teste de Elevação tiveram as seguintes características:

- Duração da simulação $\left(T_{\text {sim }}\right)=70$ segundos;

- Passo de integração $=10^{-5}$ segundos;

- Decimação dos pontos $=10^{4}$;

- Instante do degrau inicial = 0,7 segundos;

- Amplitude do degrau inicial $=4 \%$ do valor de referência para as válvulas Ideal e Fabricante e 51\% para a Nominal.

- Amplitude dos degraus adicionais $=0,75 \%$ do valor de referência para as válvulas Ideal e Fabricante e $2 \%$ para a Nominal.

Com relação ao controlador PI da malha de vazão, a sintonia utilizada durante as simulações e considerada a sintonia que estabiliza a malha é a seguinte:

- Ganho do controlador $\left(K_{c}\right)=1,115$;

- Tempo integral do controlador $\left(T_{i}\right)=1,93$.

Como já especificado, para a válvula Nominal o degrau inicial teve de ser consideravelmente aumentado para que fosse vencida a histerese da mesma.

Para os ensaios com o Teste de Elevação, foram observadas a variável medida de processo, correspondente à vazão $Q$ em \% e a variável manipulada, também em \%.

Nas Figuras 17 e 18 são apresentados os resultados deste método para as válvulas Ideal e Fabricante, respectivamente, aplicando-se inicialmente na MV um degrau de $4 \%$ e depois degraus de $0,75 \%$ no mesmo sentido. 


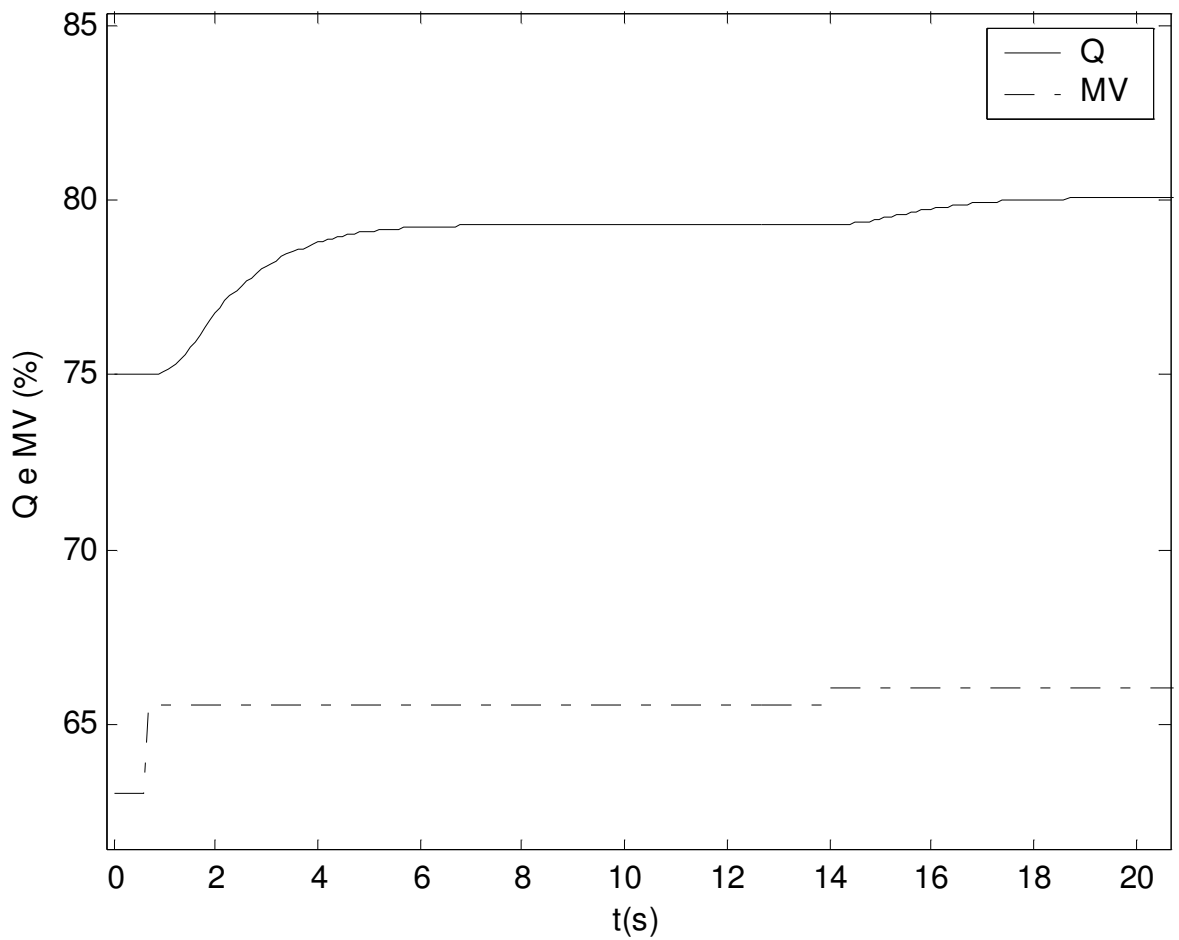

Figura 17: Teste com a válvula Ideal.

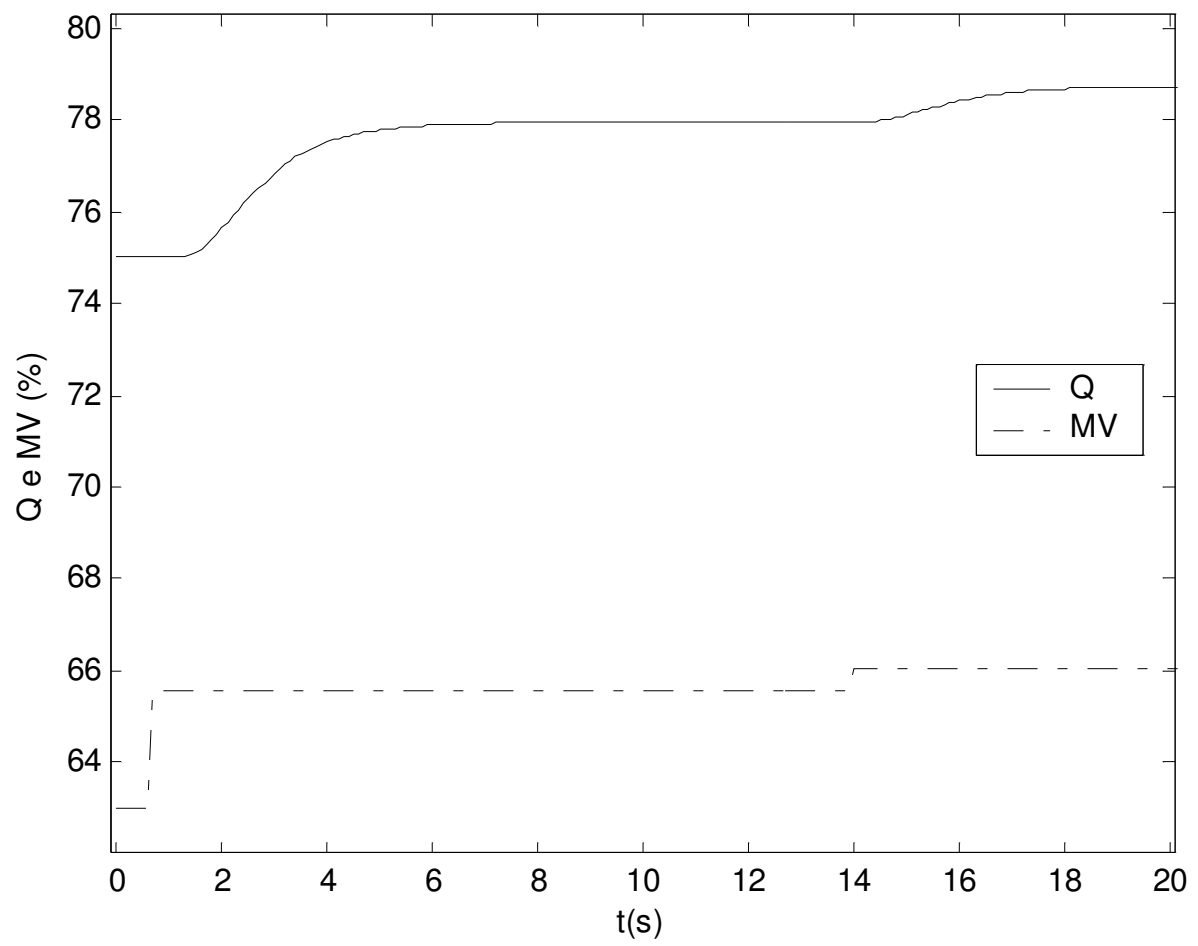

Figura 18: Teste com a válvula Fabricante. 
Pelas Figuras 17 e 18, pode-se notar que não foi detectada a presença de stiction, pois a PV acompanha qualquer variação mínima de MV, aplicada à válvula de controle.

Na Figura 19 são apresentados os resultados deste método para a válvula Nominal, aplicando-se inicialmente na MV um degrau de $51 \%$ e depois degraus de $2 \%$ no mesmo sentido.

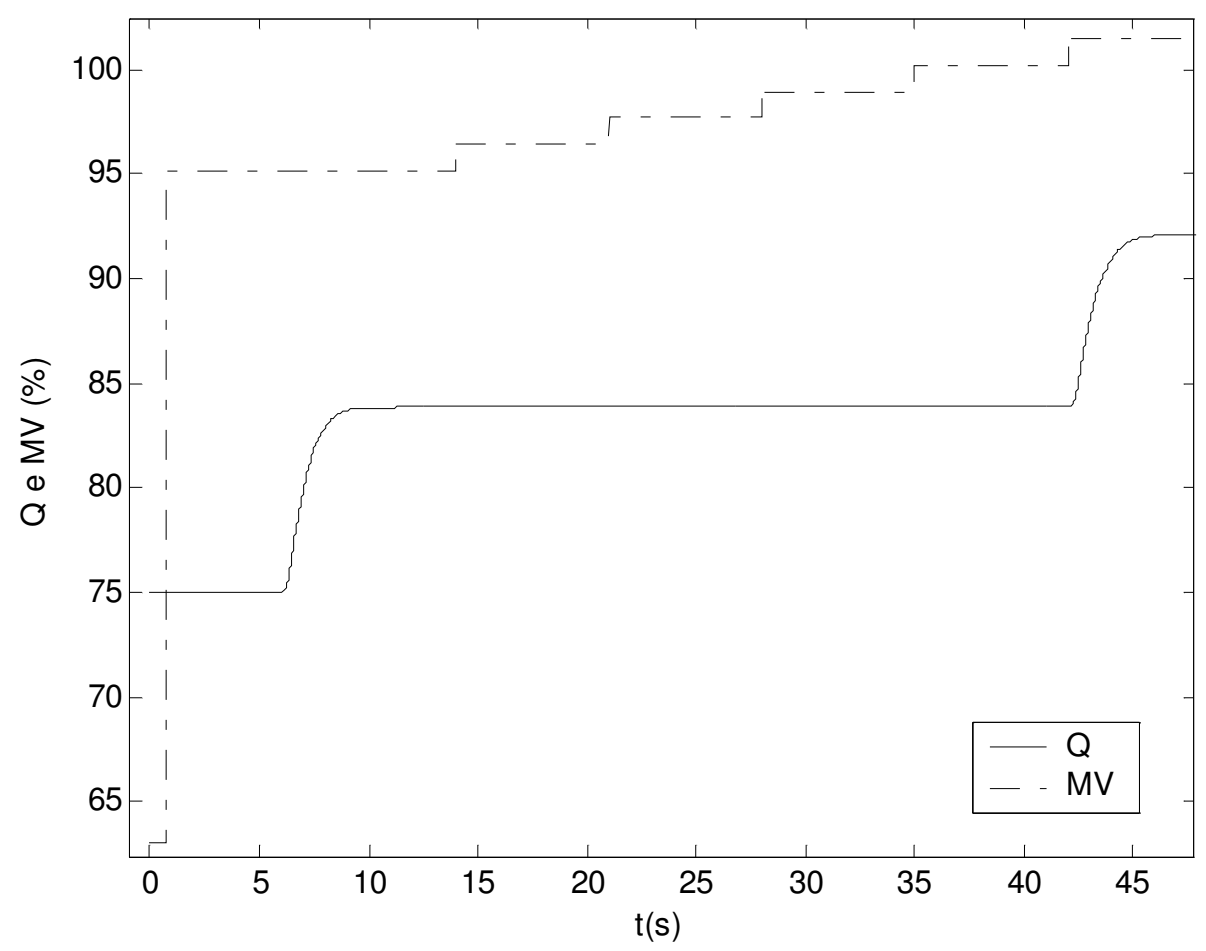

Figura 19: Teste com a válvula Nominal.

Os resultados demonstram que foram necessários cinco degraus na entrada da válvula para que a variável de processo se movimentasse, portanto houve a detecção do atrito estático.

\subsubsection{Ensaios com as Mudanças no Ganho do Controlador}

Para os ensaios com as Mudanças no Ganho do Controlador, foi observada somente a variável medida do processo (PV) e sua FFT (Fast Fourier Transform) para a análise de variação de sua freqüência durante a aplicação do método. Para a análise da FFT, o sinal da PV foi dividido em três faixas de tempos iguais, que acompanham os momentos de variação do ganho do controlador. Para cada uma 
das faixas foi aplicada a FFT e, então, efetuado o cálculo da magnitude do sinal resultante (potência do sinal). Os gráficos apresentados são resultado da potência versus a freqüência dos sinais de cada faixa.

O tempo de simulação $T_{\text {sim }}$ foi escolhido de tal forma que fosse possível verificar a variação da PV de maneira clara em cada faixa de ganho do controlador e também foi escolhido para facilitar a divisão por três. $O T_{\text {sim }}$ escolhido para a válvula Nominal foi o dobro do utilizado nos ensaios com as válvulas Ideal e Fabricante, devido ao maior agarramento da válvula e sua conseqüente maior lentidão de resposta ao sinal do controlador.

Os ensaios realizados no ambiente totalmente simulado para o Teste de Mudanças no Ganho do Controlador tiveram as seguintes características:

- Duração da simulação $\left(T_{\text {sim }}\right)=900$ segundos para as válvulas Ideal e Fabricante e 1800 para a Nominal;

- Passo de integração = $10^{-5}$ segundos;

- Decimação dos pontos $=10^{4}$;

- $\quad$ Instante do degrau inicial = 1 segundo;

- Amplitude do degrau inicial $=10 \%$ do valor de referência.

Com relação ao controlador PI da malha de vazão, a sintonia utilizada durante as simulações e considerada a sintonia que estabiliza a malha é a seguinte:

- Ganho do controlador $\left(K_{c}\right)=1,115$;

- Tempo integral do controlador $\left(T_{i}\right)=1,93$.

Nas Figuras 20 e 21 são apresentados os resultados com a válvula Ideal e nas Figuras 22 e 23, com a válvula Fabricante. As Figuras 20 e 22 representam a simples tendência temporal da vazão $Q$ de saída expressa em \%. Já as Figuras 21 e 23 são obtidas através da aplicação da transformada de Fourier aos respectivos sinais de $Q$, dividindo-os em três faixa iguais, correspondentes a cada iteração do método e suas conseqüentes mudanças no valor de $K_{c}$. 


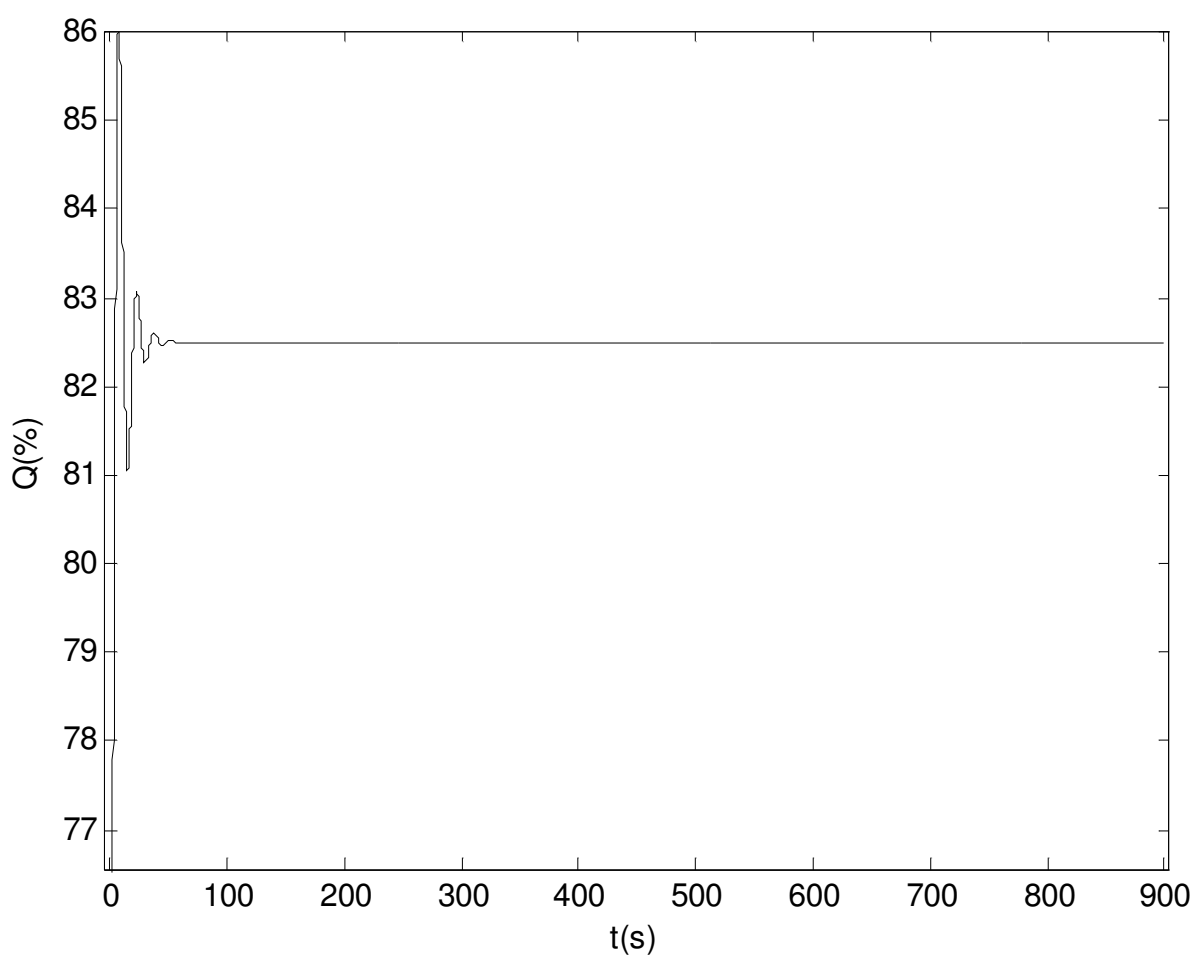

Figura 20: Vazão $Q(\%)$ com a válvula Ideal.

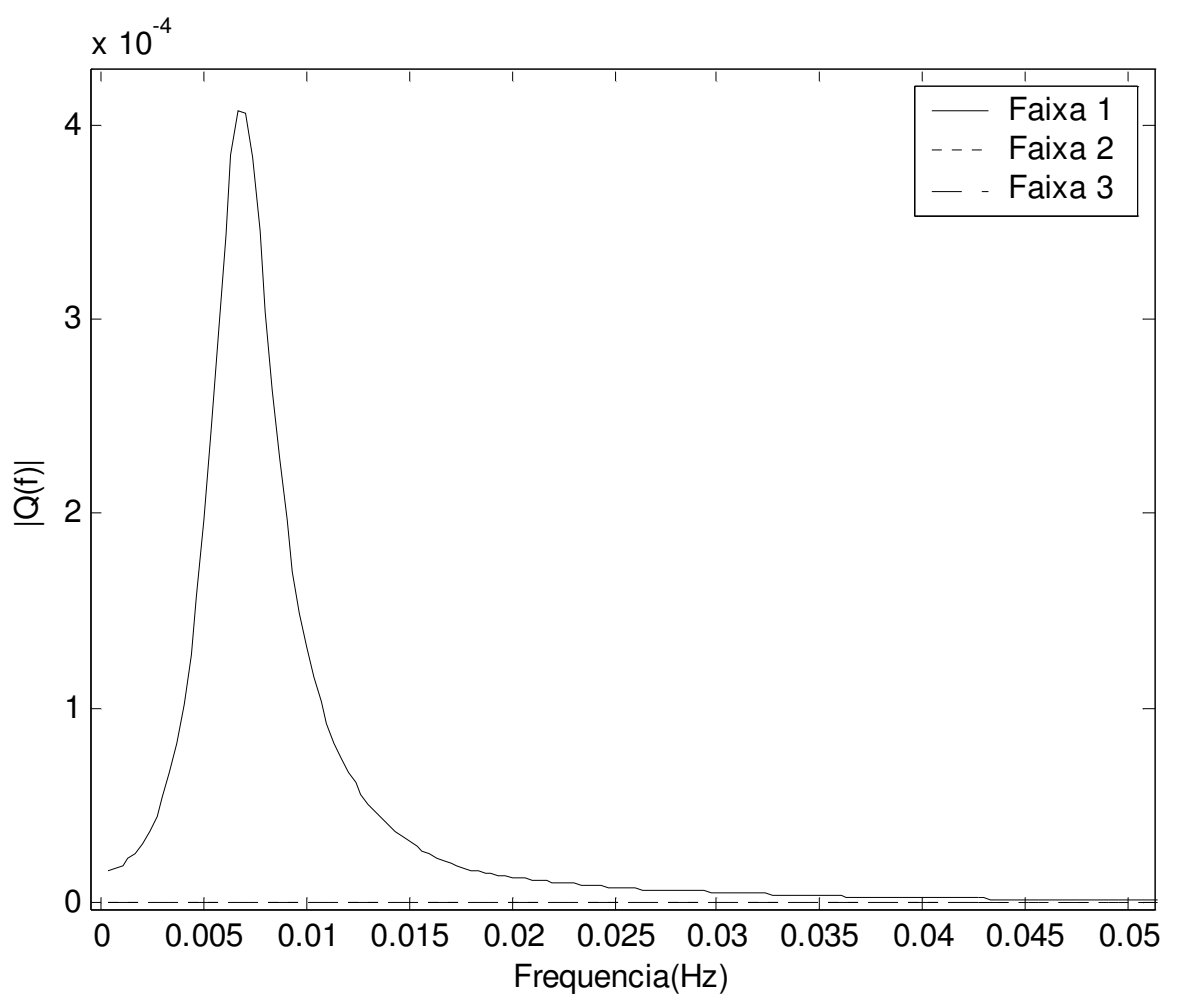

Figura 21: FFT de $Q$ com a válvula Ideal. 


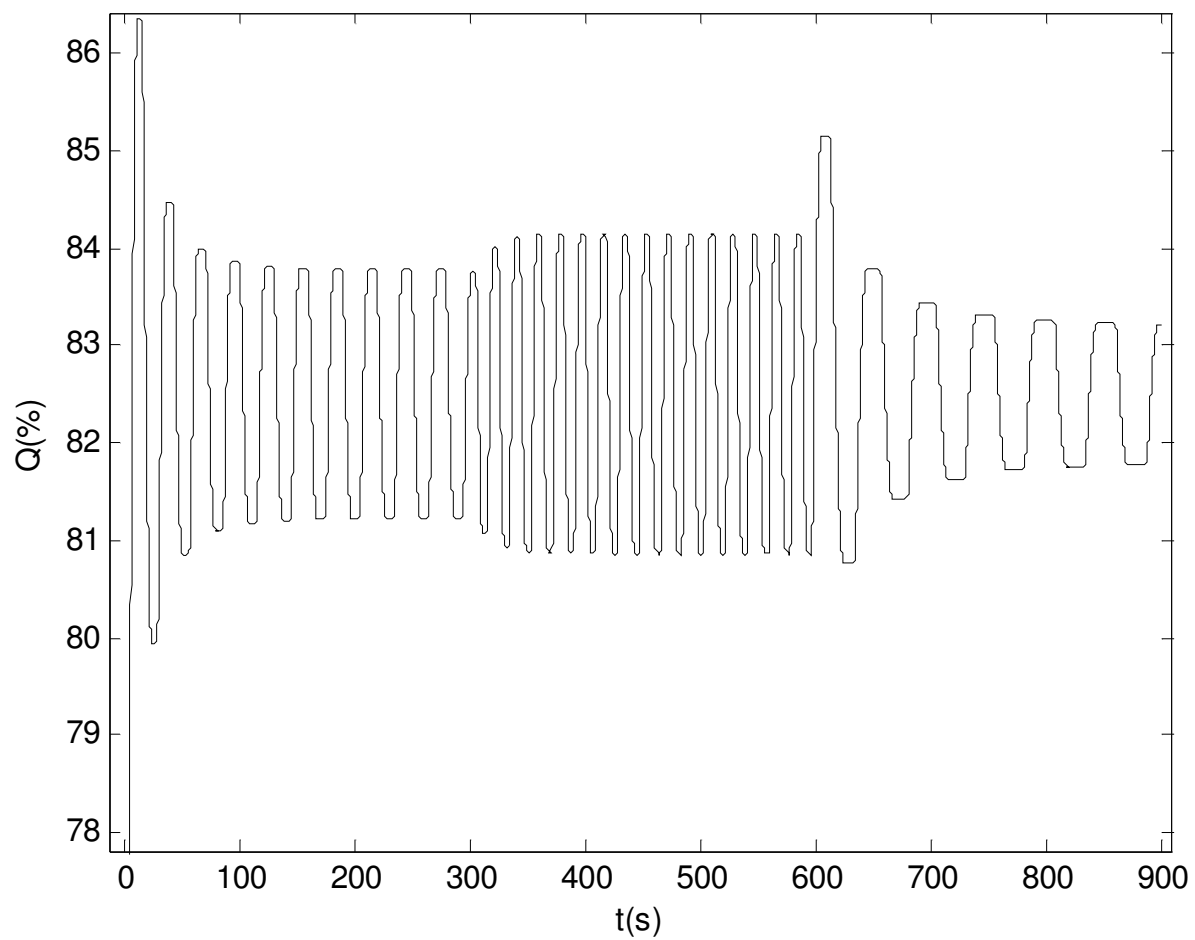

Figura 22: Vazão $Q(\%)$ com a válvula Fabricante.

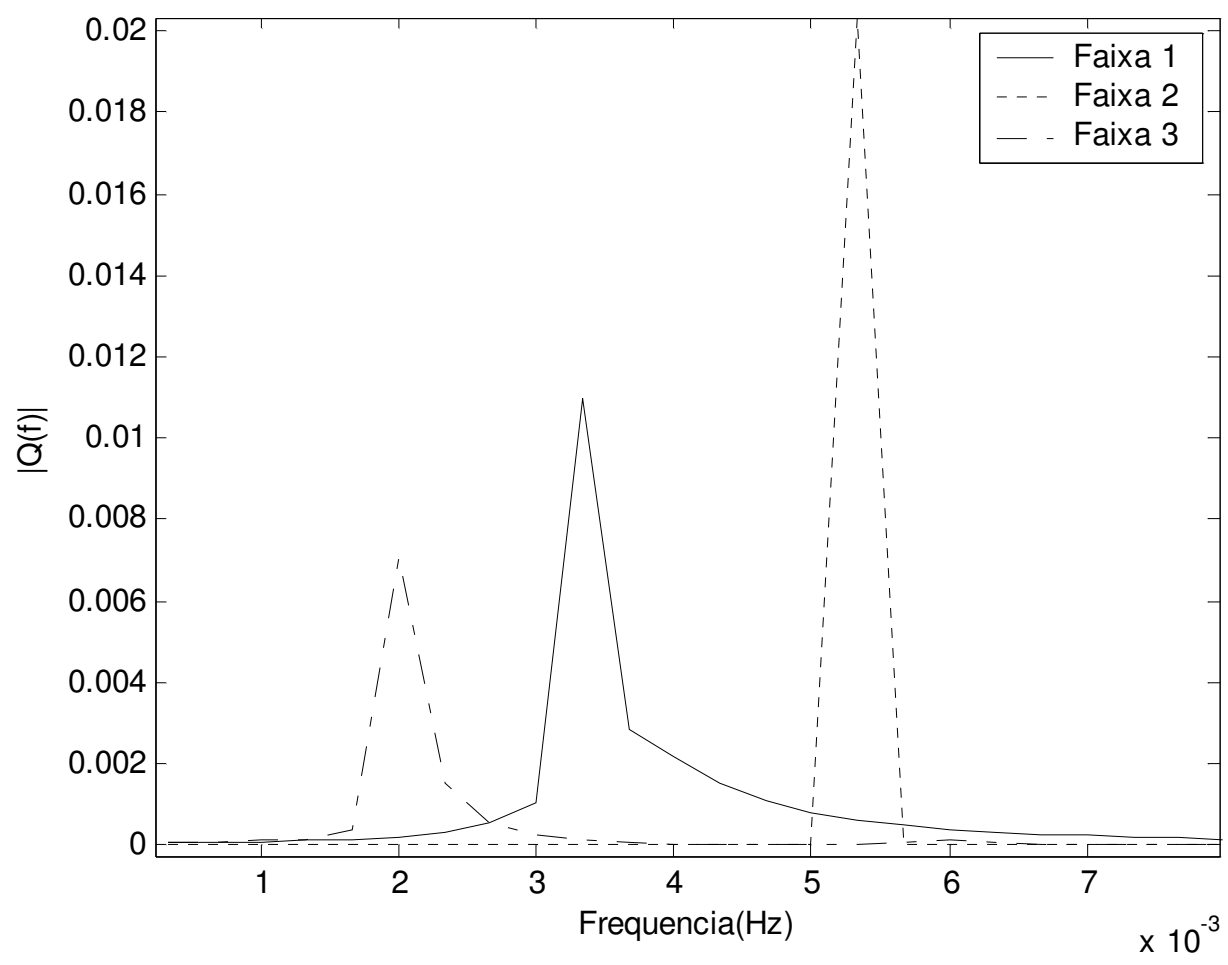

Figura 23: FFT de $Q$ com a válvula Fabricante. 
As figuras 22 e 23 demonstram a variação significativa da freqüência da PV para o caso da válvula Fabricante. Aumentando-se $K_{c}$, obteve-se o aumento da freqüência do sinal e, ao diminuir o $K_{c}$, obteve-se a diminuição da mesma. Este resultado confirmou a detecção de stiction na malha, apesar de sabidamente não existir stiction na válvula Fabricante. Aparentemente, para este caso, o método está identificando a existência de outro atrito que não o estático (atrito de Coulomb).

No caso da válvula Ideal, como se pode observar pelas Figuras 20 e 21, 0 método apontou a ausência do stiction, como era esperado devido à inexistência desta não-linearidade (Tabela 2).

A seguir são apresentados os resultados para a válvula Nominal (Figuras 24 e 25).

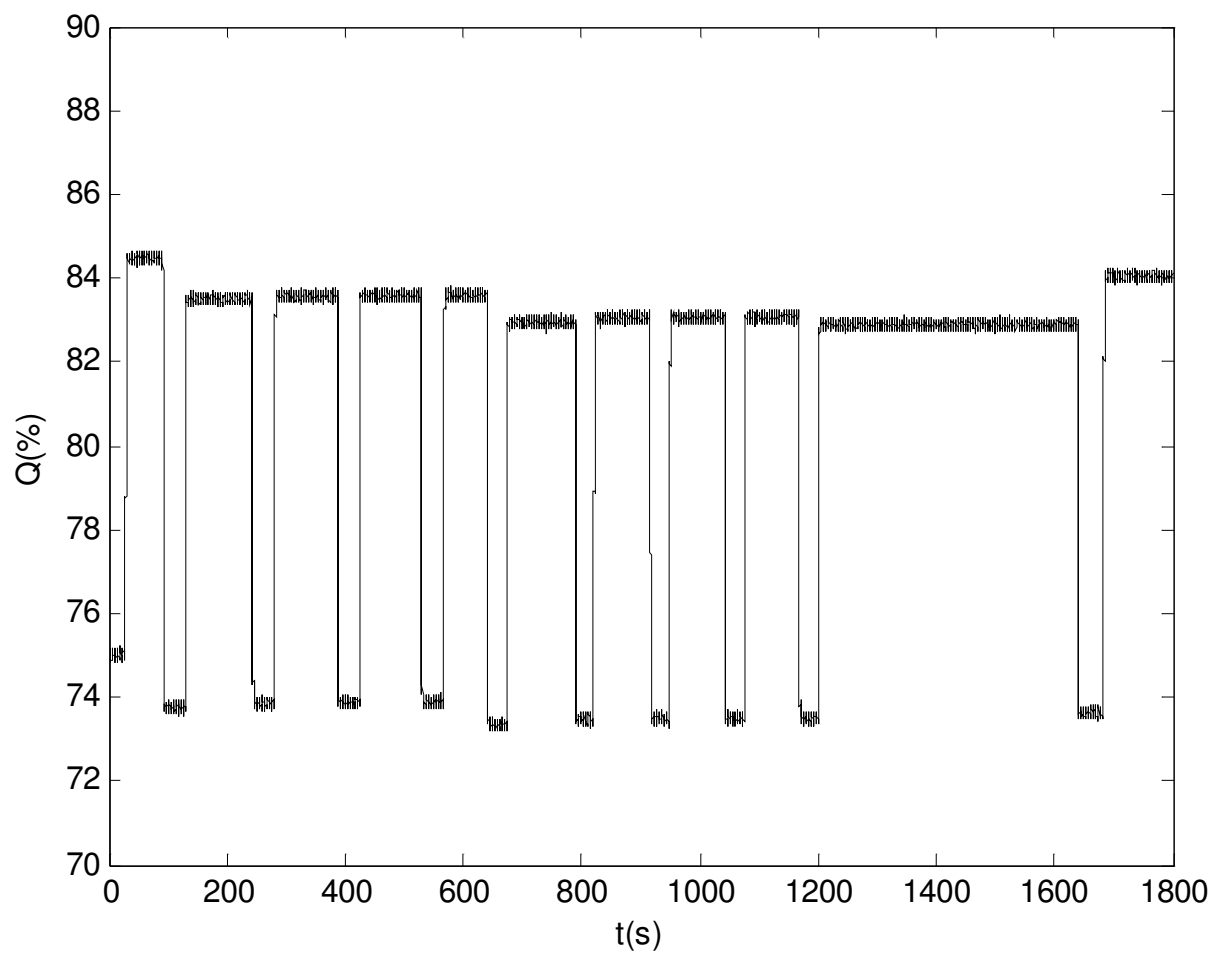

Figura 24: Vazão Q (\%) com a válvula Nominal. 


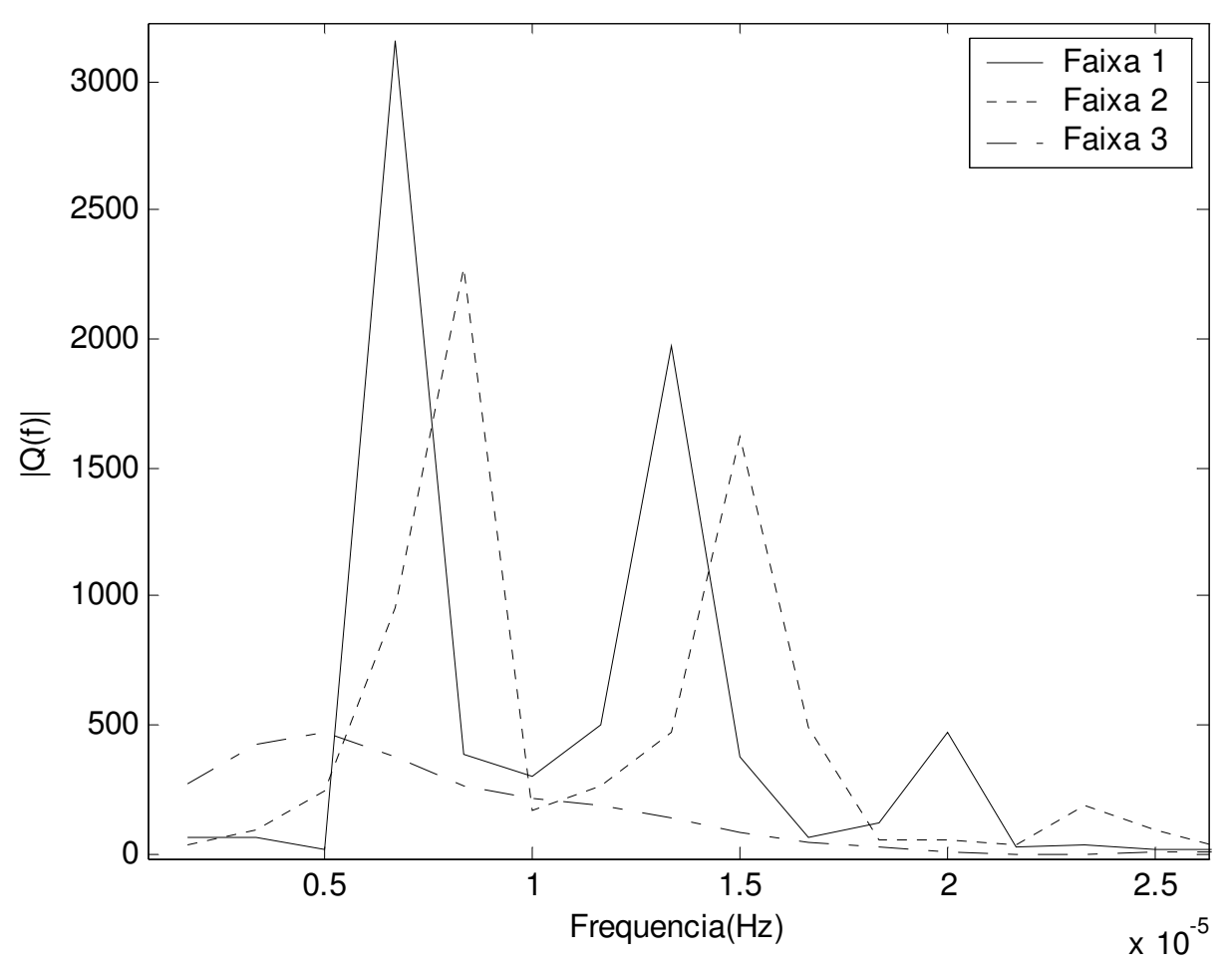

Figura 25: FFT de $Q$ com a válvula Nominal.

Nas Figuras 24 e 25 são apresentados os resultados com a válvula Nominal; eles demonstram a variação da freqüência da PV para o caso desta configuração, mesmo tendo seus resultados gráficos um pouco prejudicados pelo alto agarramento da válvula. Aumentando-se $K_{c}$, obteve-se o aumento da freqüência do sinal e, ao diminuir o $K_{c}$, obtivemos a diminuição da mesma. Este resultado confirmou a detecção de stiction na malha.

\subsubsection{Ensaios com as Mudanças no Ganho do Controlador com a presença de perturbação externa}

Com o objetivo de aproximar a simulação o máximo possível de um sistema industrial real, aplicou-se ao processo uma perturbação externa para a verificação do desempenho do método de Mudanças no Ganho do Controlador. O ruído escolhido para os testes foi do tipo estacionário, com média nula, variância de 0,0025 e tempo de amostragem de $10 \mathrm{~s}$. Além deste, foi introduzido ao sistema um ruído de medição 
de alta freqüência com média nula, variância de 0,003 e tempo de amostragem de 0,01 s. Os ruídos são os mesmos em todos os ensaios deste item.

Assim como no item 4.1.2, os ensaios realizados tiveram as seguintes características:

- Duração da simulação $\left(T_{\text {sim }}\right)=900$ segundos para as válvulas Ideal e Fabricante e 1800 para a Nominal;

- Passo de integração $=10^{-5}$ segundos;

- Decimação dos pontos $=10^{4}$;

- Instante do degrau inicial = 1 segundo;

- Amplitude do degrau inicial $=10 \%$ do valor de referência.

Com relação ao controlador PI da malha de vazão, a sintonia utilizada durante as simulações e considerada a sintonia que estabiliza a malha é a seguinte:

- Ganho do controlador $\left(K_{c}\right)=1,115$;

- $\quad$ Tempo integral do controlador $\left(T_{i}\right)=1,93$.

Ensaios semelhantes aos da seção 4.1.2 foram feitos com as Mudanças no Ganho do Controlador, desta vez com a presença de uma perturbação externa ao processo. As Figuras 26 e 27 apresentam o efeito dessa perturbação na vazão $Q$ com a malha aberta.

Pela Figura 26 pode-se ter uma idéia de como essa perturbação seria demonstrada em uma tela de um sistema de supervisão e controle industrial SCADA (Supervisory Control and Data Acquisition) ou DCS (Digital Control System). Os parâmetros do ruído estacionário utilizado foram ajustados tendo-se por referência esta semelhança visual qualitativa com o que seria um comportamento convencional de uma variável de processo qualquer, durante a operação normal de uma malha de controle.

A Figura 27 mostra o sinal da perturbação em detalhes, podendo-se distinguir a composição dos ruídos de baixa e alta freqüência. 


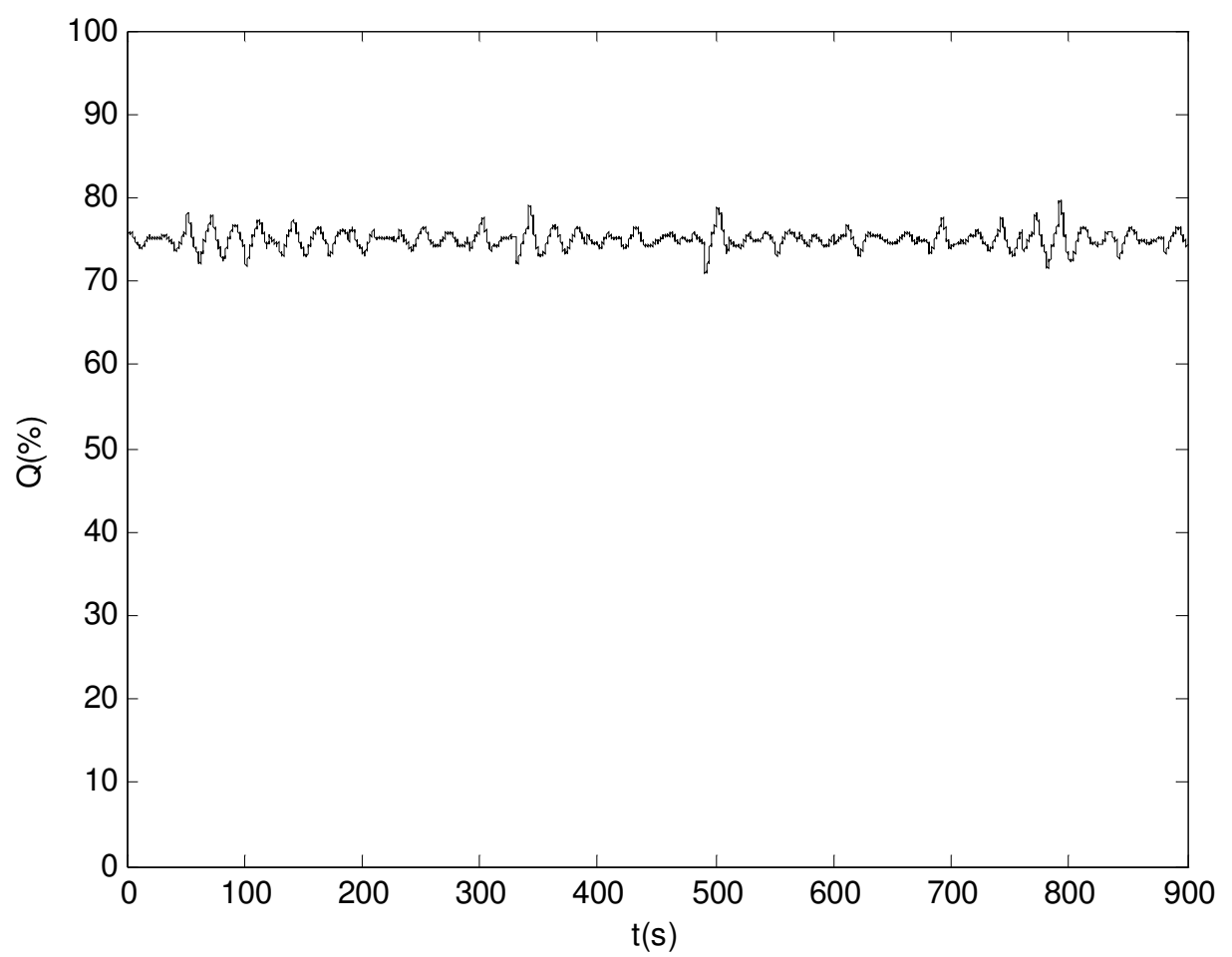

Figura 26: Vazão $Q(\%)$ com perturbação.

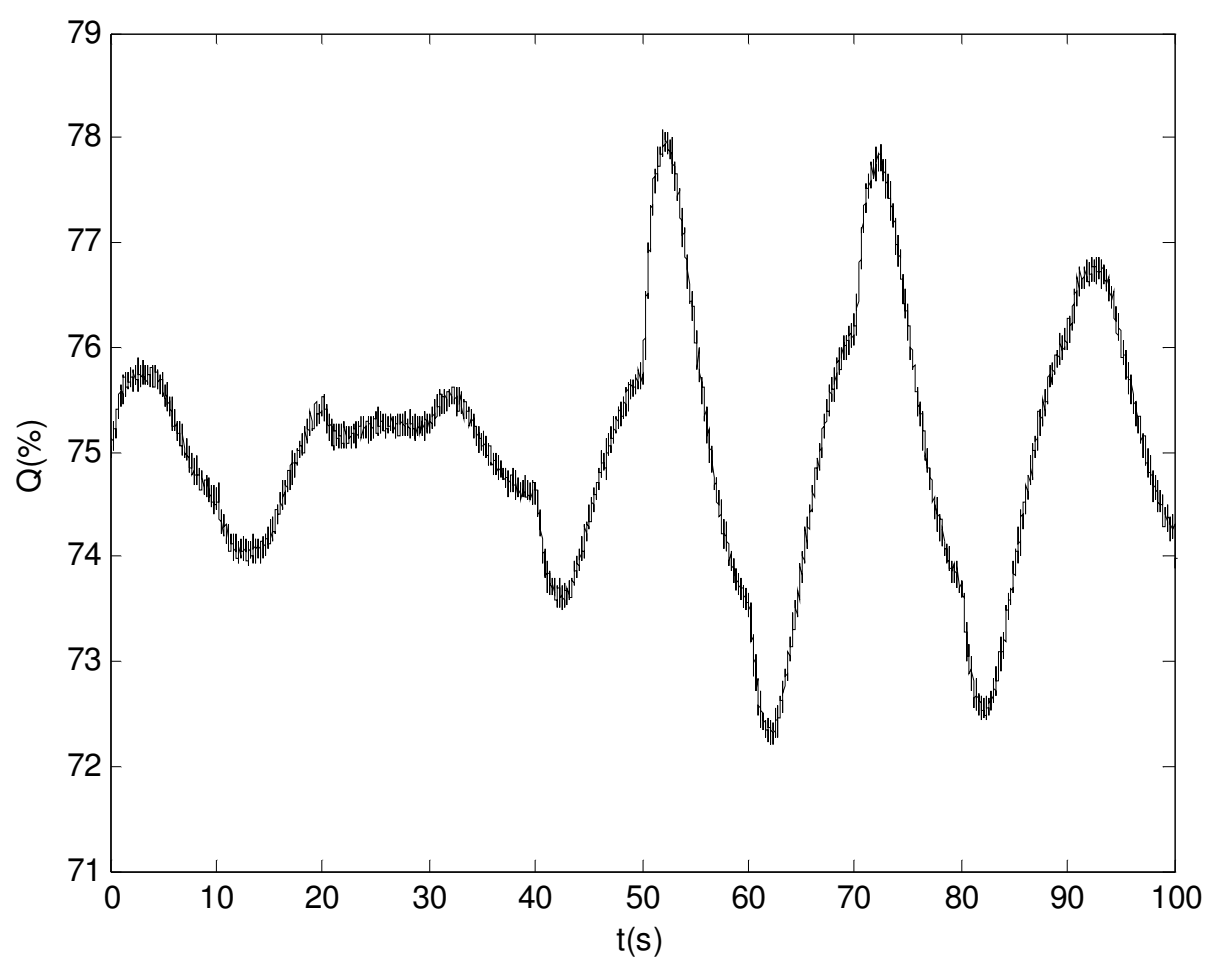

Figura 27: Detalhe do sinal de vazão $Q(\%)$ com perturbação. 
Nas Figuras 28 e 29 são apresentados resultados com a válvula Ideal.

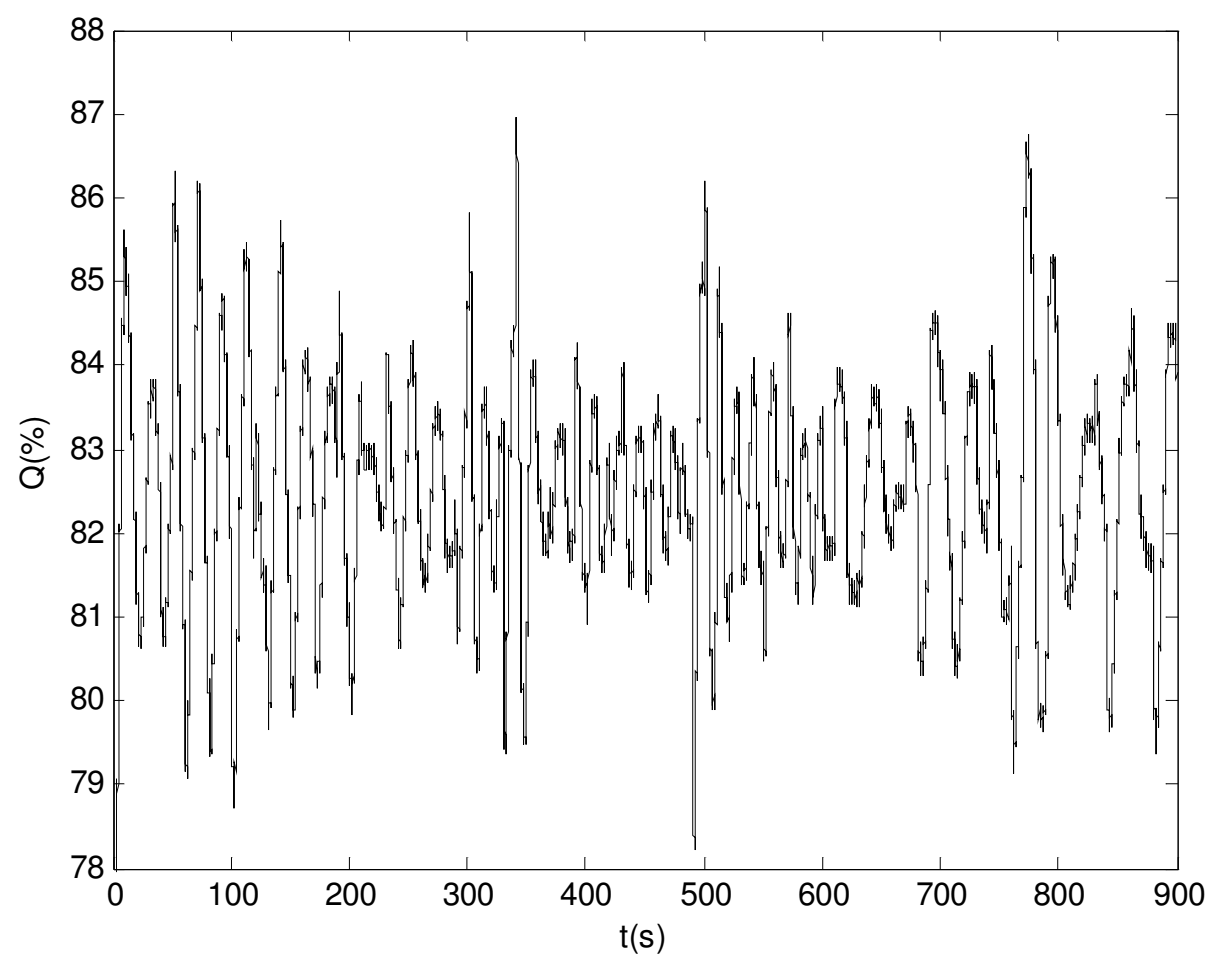

Figura 28: Vazão $Q(\%)$ com perturbação para a válvula Ideal.

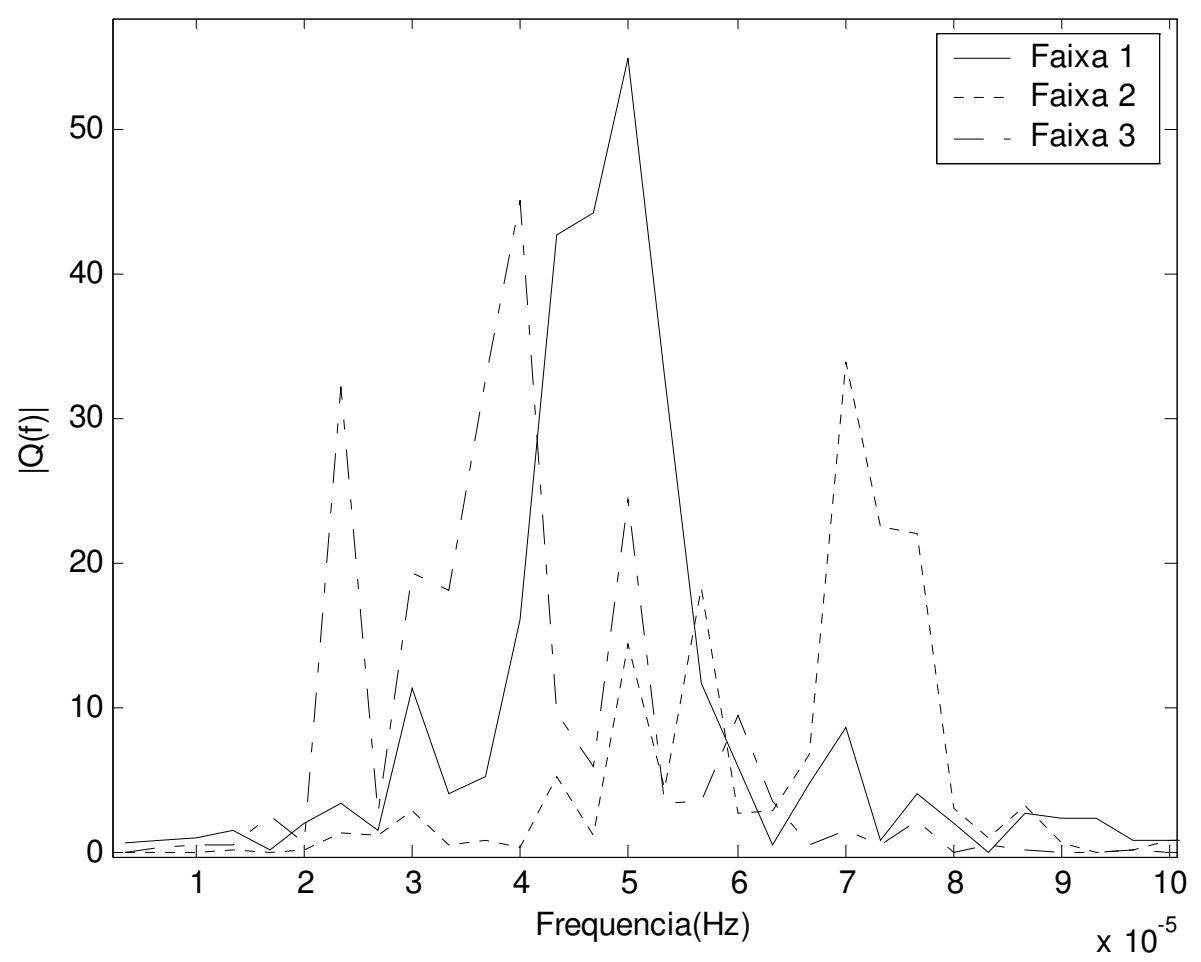

Figura 29: FFT de $Q$ com perturbação para a válvula Ideal. 
No caso da válvula Ideal, como se pode observar pelas Figuras 28 e 29, o método aparentemente apresentou uma falha ao apontar a presença de stiction, quando em verdade, sabe-se que o mesmo não existe nesta válvula (Tabela 2). Aparentemente, o método não soube diferenciar neste caso a oscilação causada pela perturbação externa, de uma oscilação causada por atrito estático.

Nas Figuras 30 e 31 são apresentados resultados com a válvula Fabricante.

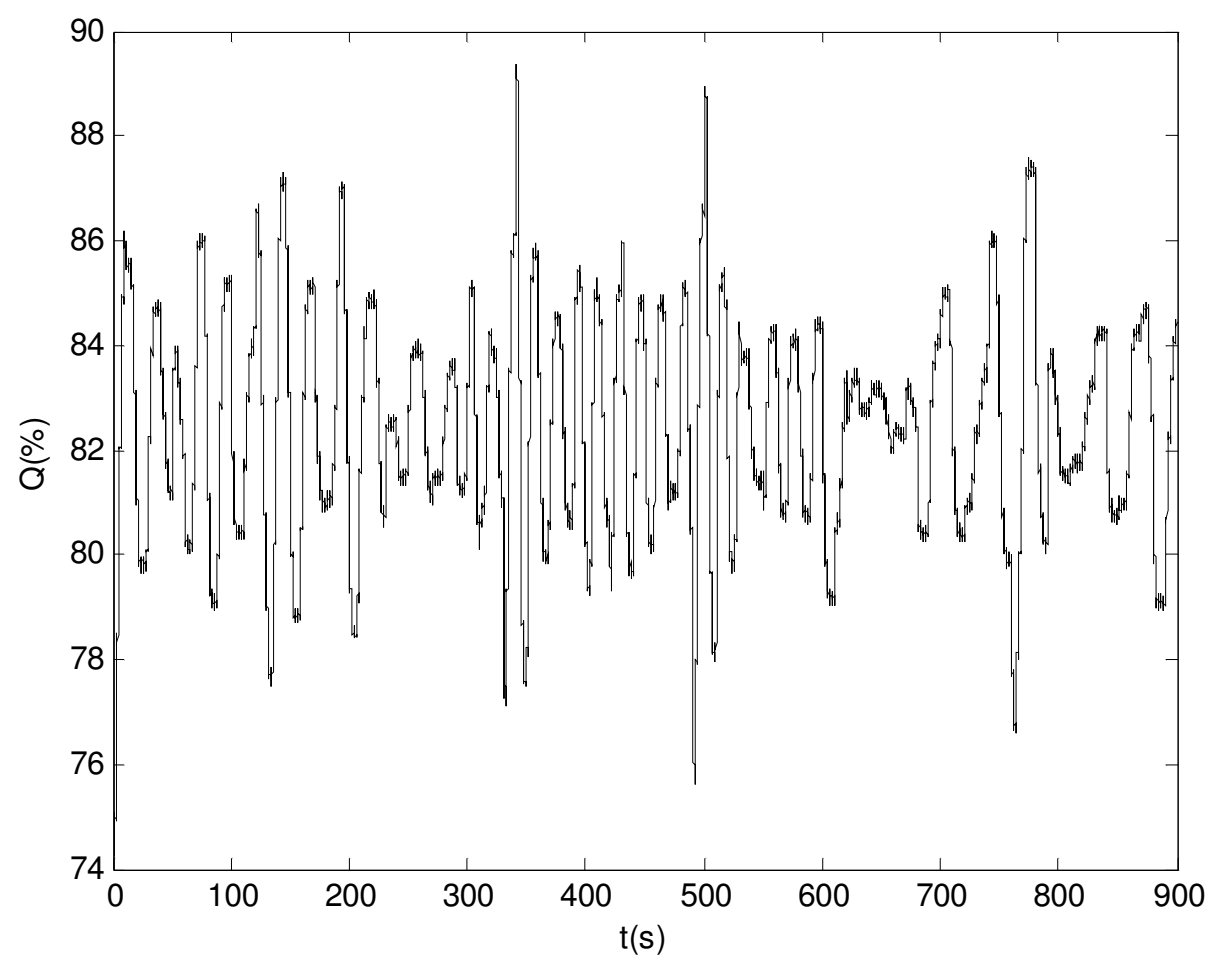

Figura 30: Vazão $Q(\%)$ com perturbação para válvula Fabricante. 


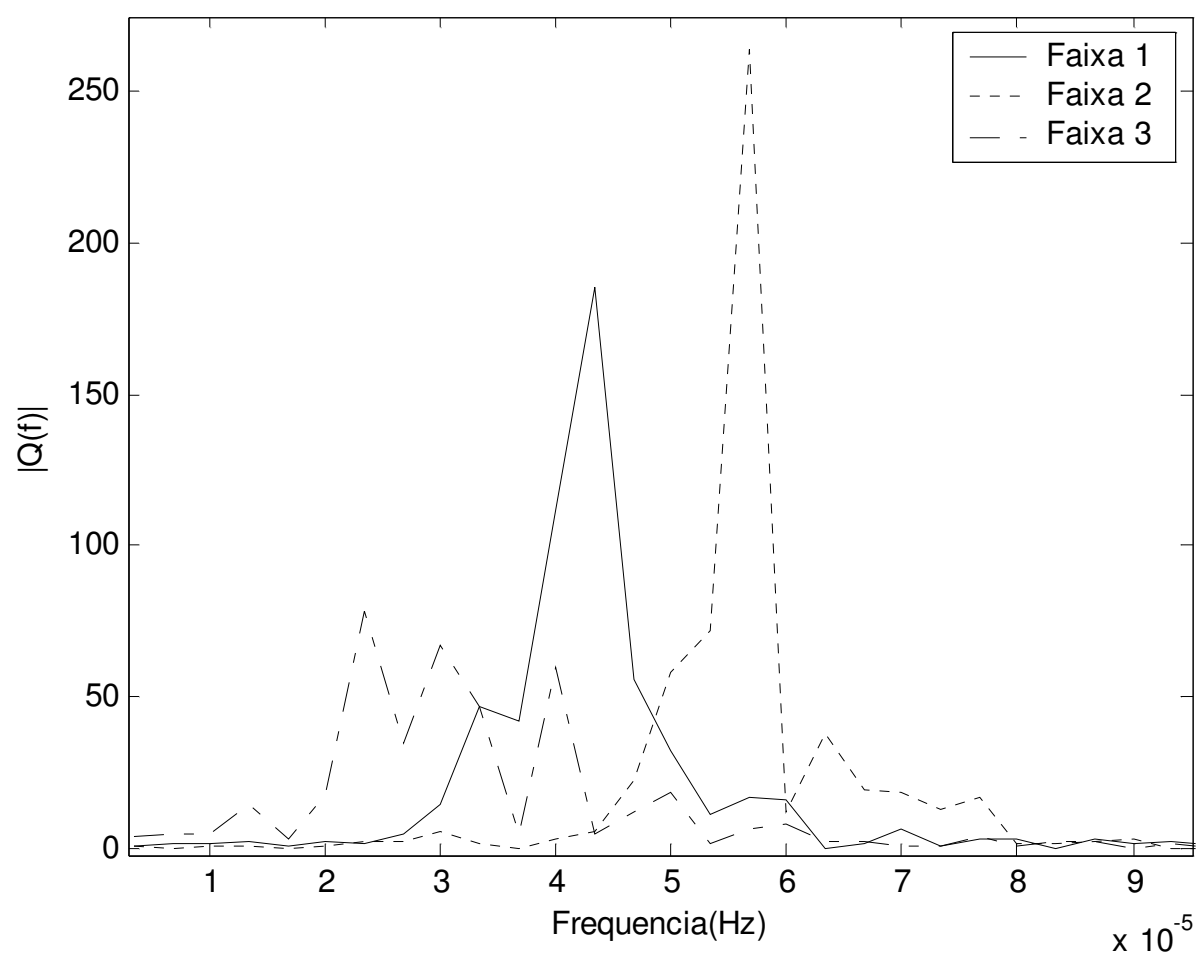

Figura 31: FFT de $Q$ com perturbação para válvula Fabricante.

As figuras 30 e 31 demonstram a variação significativa da freqüência da PV para o caso da válvula Fabricante. Aumentando-se o ganho proporcional $\left(K_{c}\right)$, obteve-se o aumento da freqüência do sinal e, ao diminuir o $K_{c}$, obtive-se a diminuição da mesma. Este resultado confirmou a detecção de stiction na malha, apesar de sabidamente não existir stiction na válvula Fabricante. Aparentemente, para este caso, o método está identificando a existência de outro atrito que não o estático (atrito de Coulomb).

Nas Figuras 32 e 33 são apresentados os resultados com a válvula Nominal. Percebe-se que os resultados gráficos foram muito prejudicados pelo alto agarramento da válvula. 


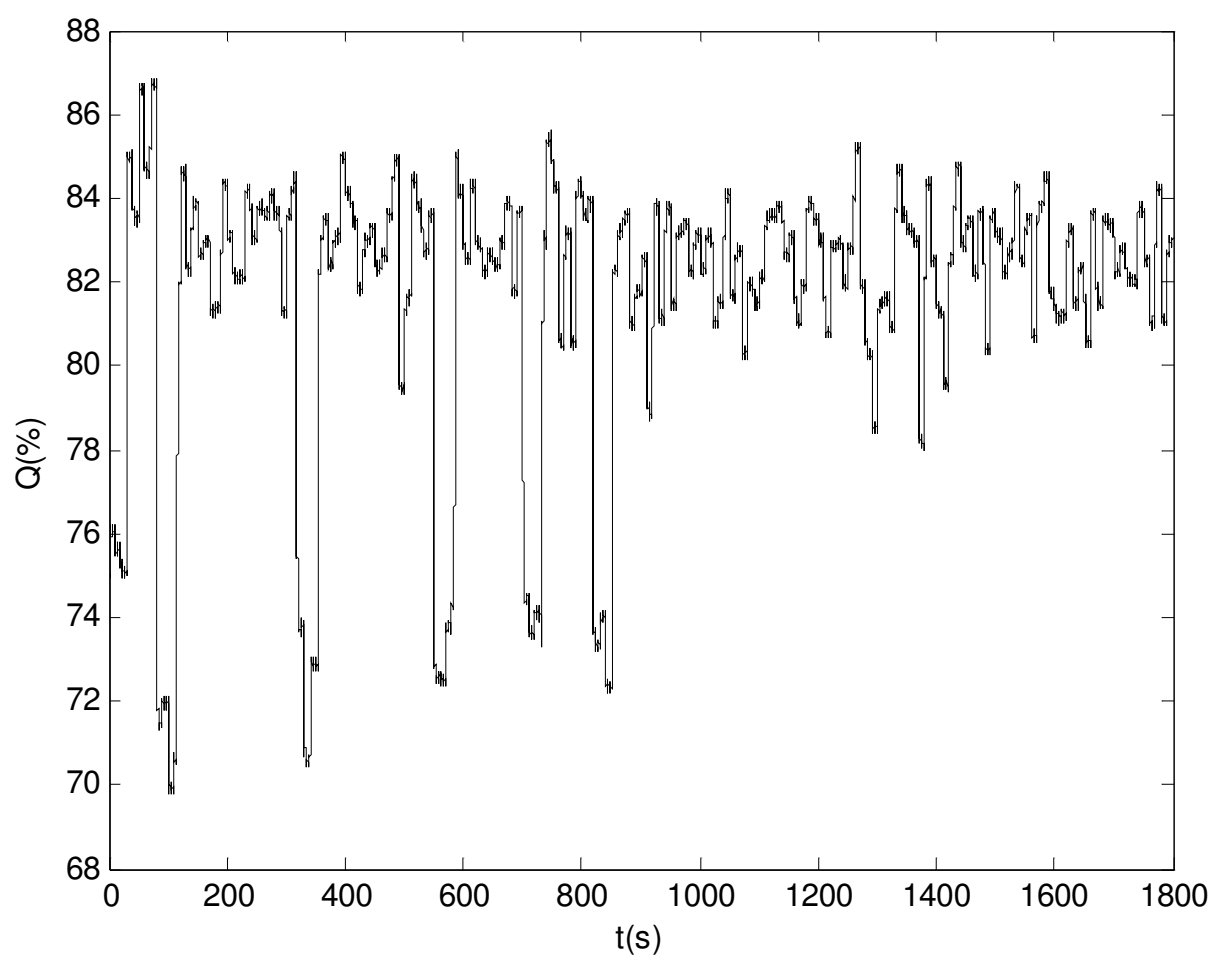

Figura 32: Vazão $Q(\%)$ com perturbação para válvula Nominal.

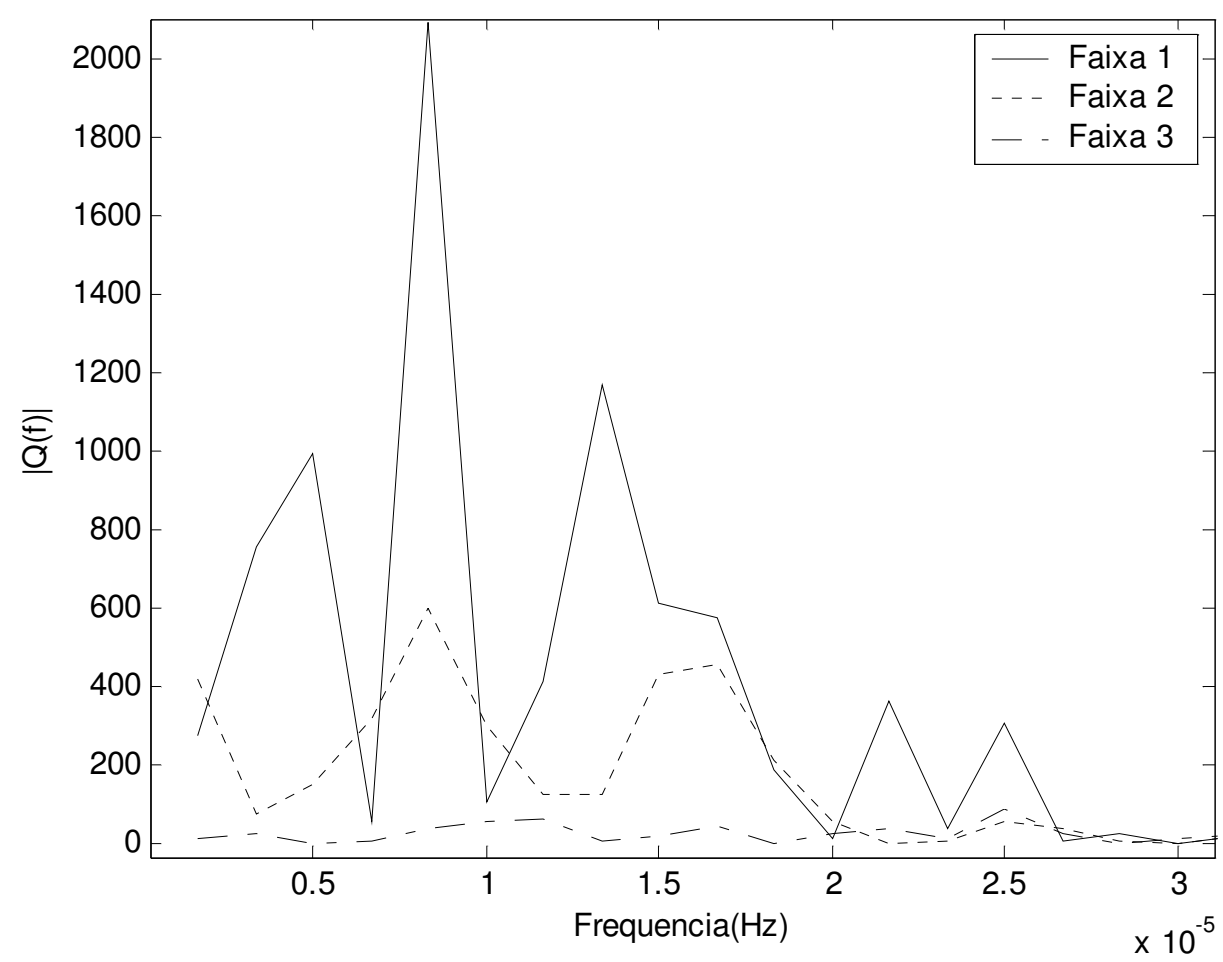

Figura 33: FFT de $Q$ com perturbação para válvula Nominal. 
Os resultados obtidos para a válvula Nominal (Figuras 32 e 33), foram muito afetados pelo alto atrito presente na nesta válvula. De qualquer forma, baseando-se nestes resultados e nas conclusões obtidas sobre o método de Mudanças no Ganho do Controlador (CHOUDHURY et al., 2005), pode-se concluir que não há atrito estático na válvula estudada, uma vez que não há mudança significativa da freqüência do sinal da vazão para uma variação de $K_{c}$. Estes resultados está errado, uma vez que, sabidamente, há stiction na válvula Nominal (Tabela 2).

Pode-se notar para estes resultados que, aparentemente, a presença de um ruído estacionário de alta freqüência pode influenciar o resultado da aplicação do Método de Mudanças no Ganho do Controlador.

\subsubsection{Ensaios com as Mudanças no Ganho do Controlador para um controlador mal sintonizado}

Sabe-se que a presença de atrito pode gerar oscilações no processo. Realmente, estes resultados foram observados através dos ensaios realizados. Porém, em alguns casos, as oscilações no processo também podem ser causadas pela má-sintonia do controlador da planta. O objetivo dos ensaios desta seção é avaliar o desempenho dos métodos quando, além do atrito, o controlador da planta estiver mal-sintonizado.

Os ensaios nesta seção tiveram as seguintes características:

- Duração da simulação $\left(T_{\text {sim }}\right)=900$ segundos para as válvulas Ideal e Fabricante e 1800 para a Nominal;

- Passo de integração = $10^{-5}$ segundos;

- Decimação dos pontos $=10^{4}$;

- Instante do degrau inicial = 1 segundo;

- Amplitude do degrau inicial $=10 \%$ do valor de referência.

Com relação ao controlador PI da malha de vazão, a sintonia utilizada durante as simulações e considerada a sintonia que estabiliza a malha é a seguinte:

- Ganho do controlador $\left(K_{c}\right)=4,46$;

- Tempo integral do controlador $\left(T_{i}\right)=1,93$ 
Como pode-se observar, com relação ao controlador PI da malha de vazão, a sintonia utilizada durante as simulações desta seção é diferente da utilizada nos ensaios anteriores, tendo um ganho proporcional quatro vezes maior, caracterizando a má sintonia do controlador.

Ensaios semelhantes aos das Seções 4.1.2 e 4.1.3 foram realizados, com o método aplicado a um controlador mal sintonizado. Pode-se verificar esta má sintonia através da Figura 34, que apresenta os valores de $Q$ para um ensaio em malha fechada, aplicando-se um pequeno degrau no set point.

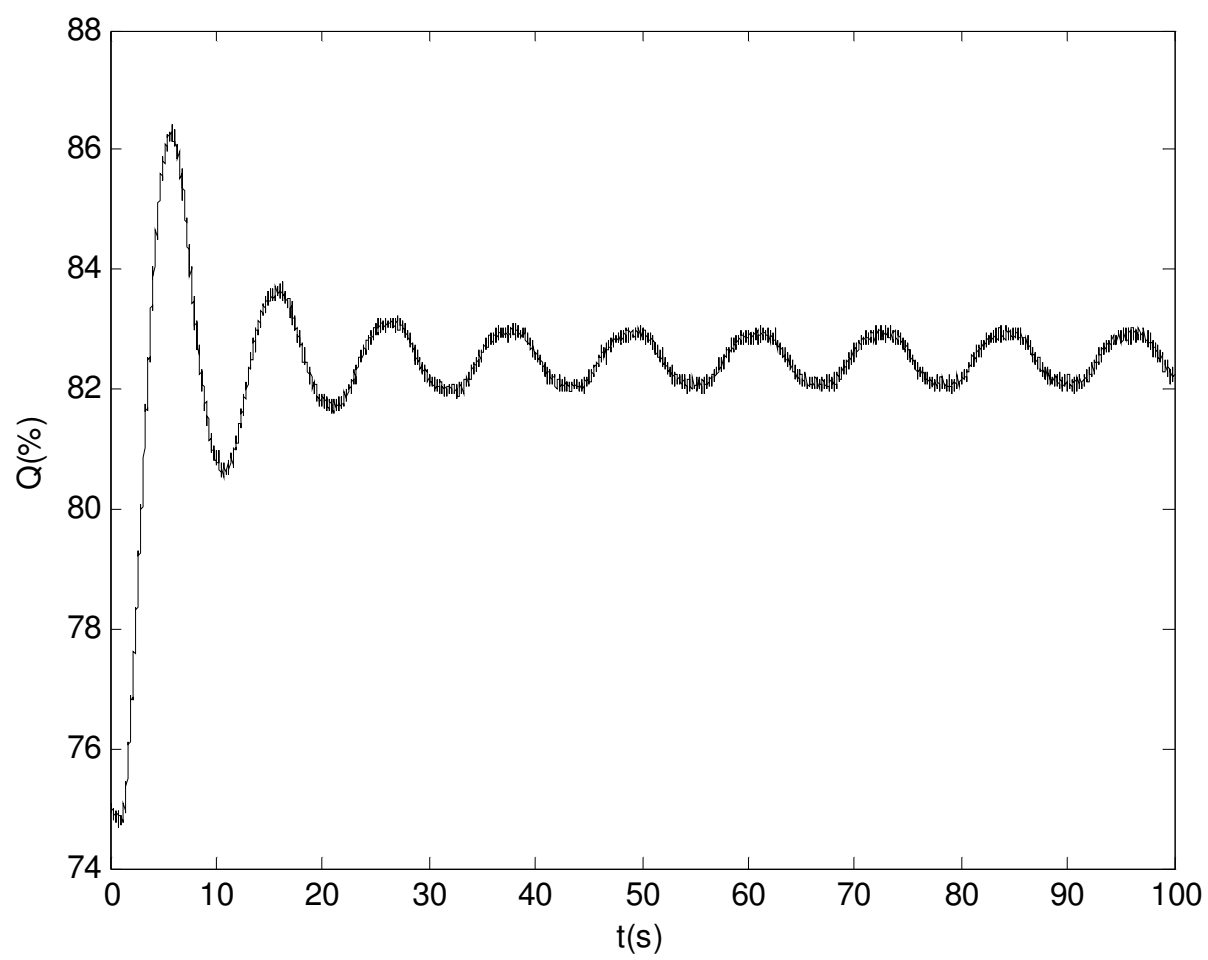

Figura 34: Vazão $Q(\%)$ com controlador mal sintonizado.

Nas Figuras 35 e 36 são apresentados resultados com a válvula Ideal e nas Figuras 37 e 38 com a válvula Fabricante. 


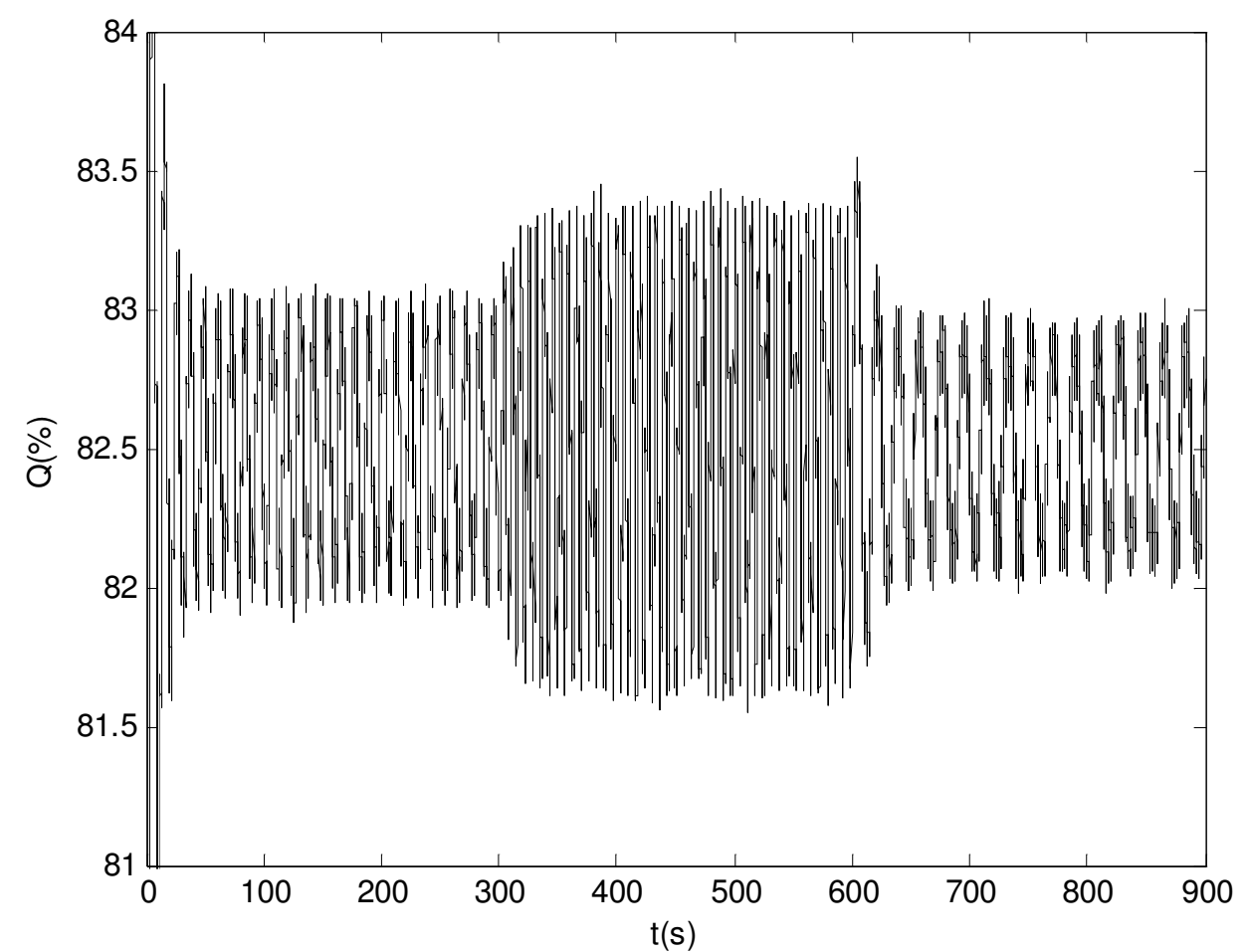

Figura 35: Vazão $Q(\%)$ com má sintonia para válvula Ideal.

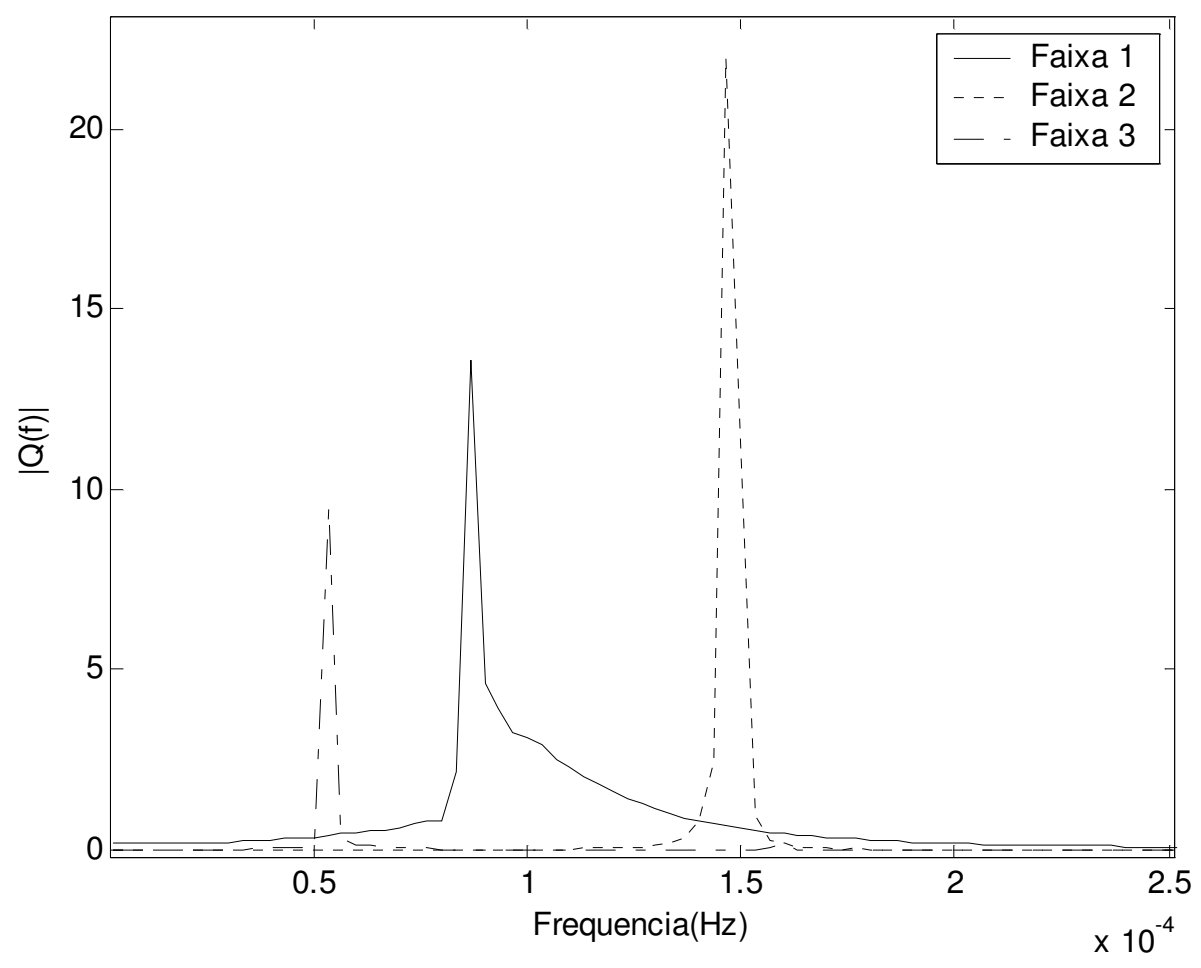

Figura 36: FFT de $Q$ com má sintonia para válvula Ideal. 


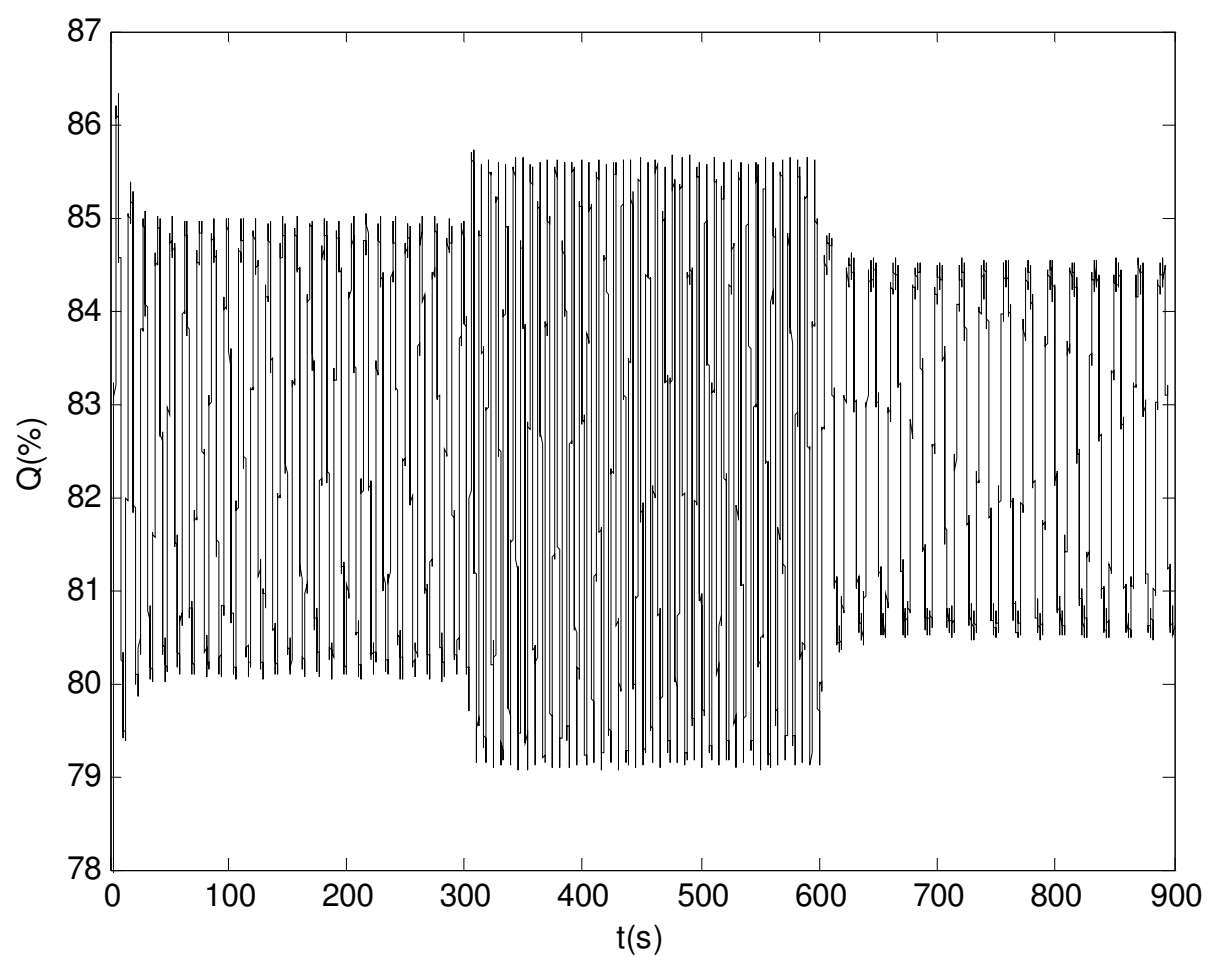

Figura 37: Vazão $Q(\%)$ com má sintonia para válvula Fabricante.

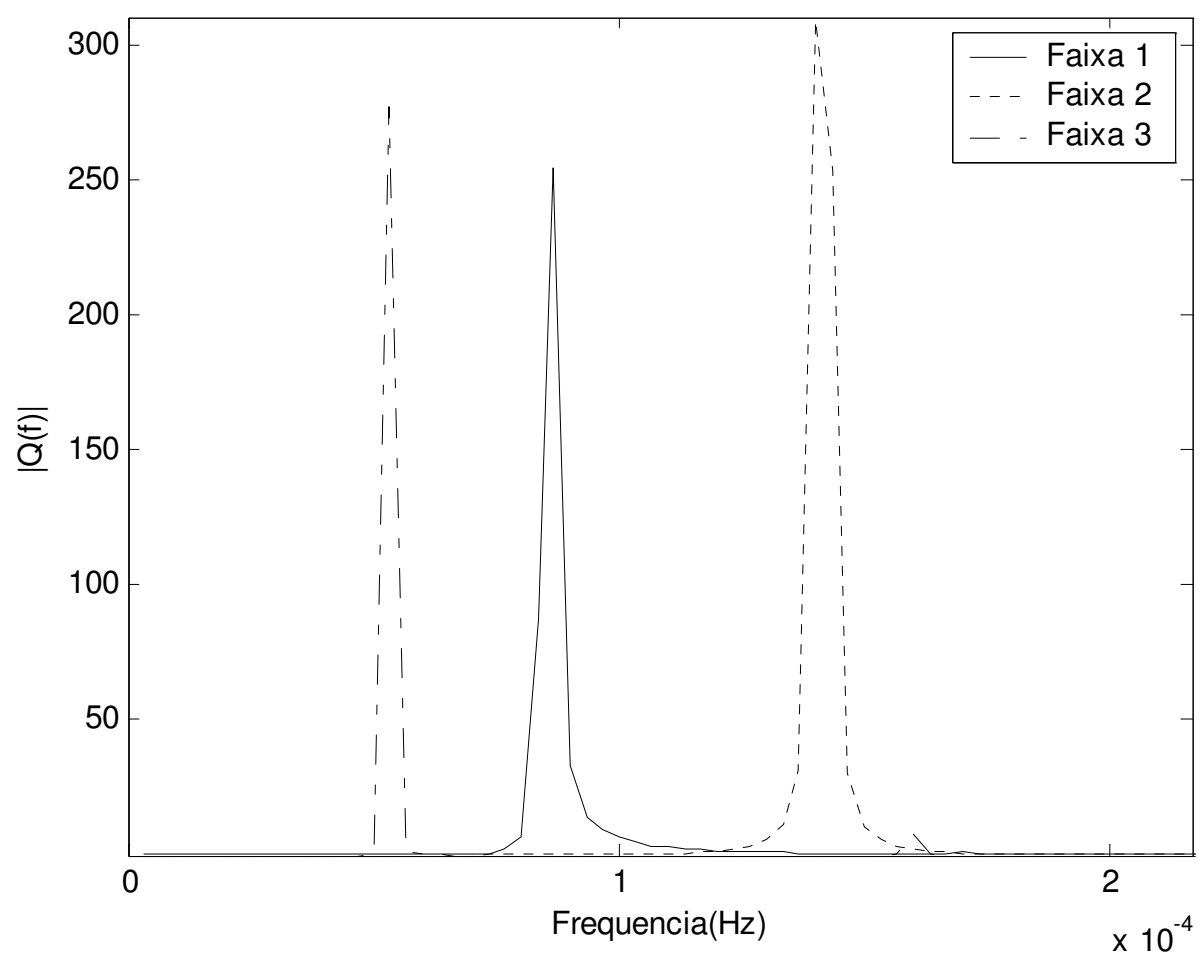

Figura 38: FFT de $Q$ com má sintonia para válvula Fabricante. 
Tanto as Figuras 35 e 36 (para a válvula Ideal) quanto 37 e 38 (para a válvula Fabricante) mostram a variação da freqüência do sinal de $Q$ para cada mudança do ganho proporcional, indicando portanto, a presença do stiction quando, em verdade, sabe-se que ele não está presente (Tabela 2) em nenhum dos dois casos.

Desta forma, pode-se concluir que o método pode confundir a má sintonia do controlador com a presença de stiction na malha.

Nas Figuras 39 e 40 são apresentados os resultados com a válvula Nominal. Percebe-se que os resultados gráficos foram muito prejudicados pelo alto agarramento da válvula.

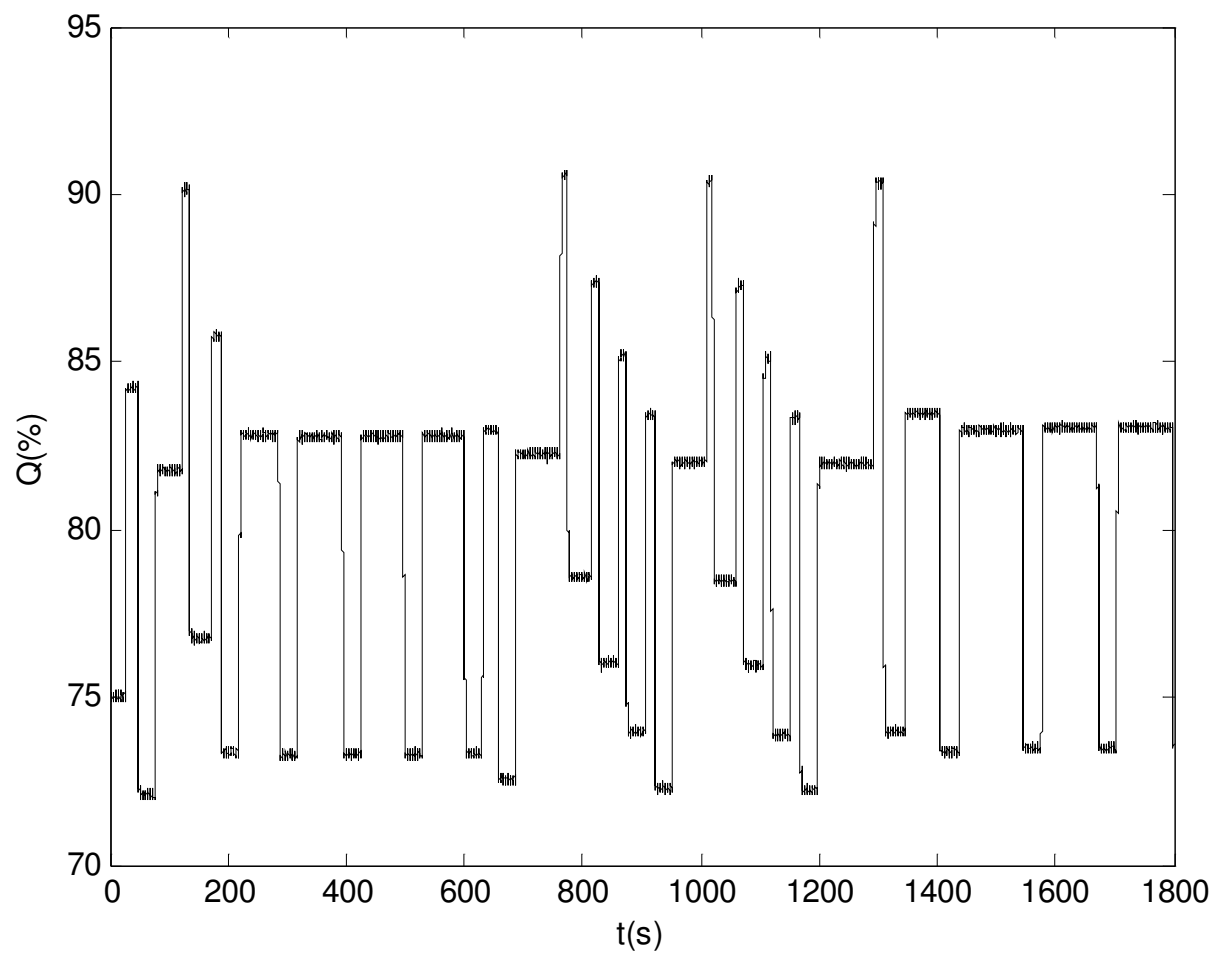

Figura 39: Vazão $Q(\%)$ com má sintonia para válvula Nominal. 


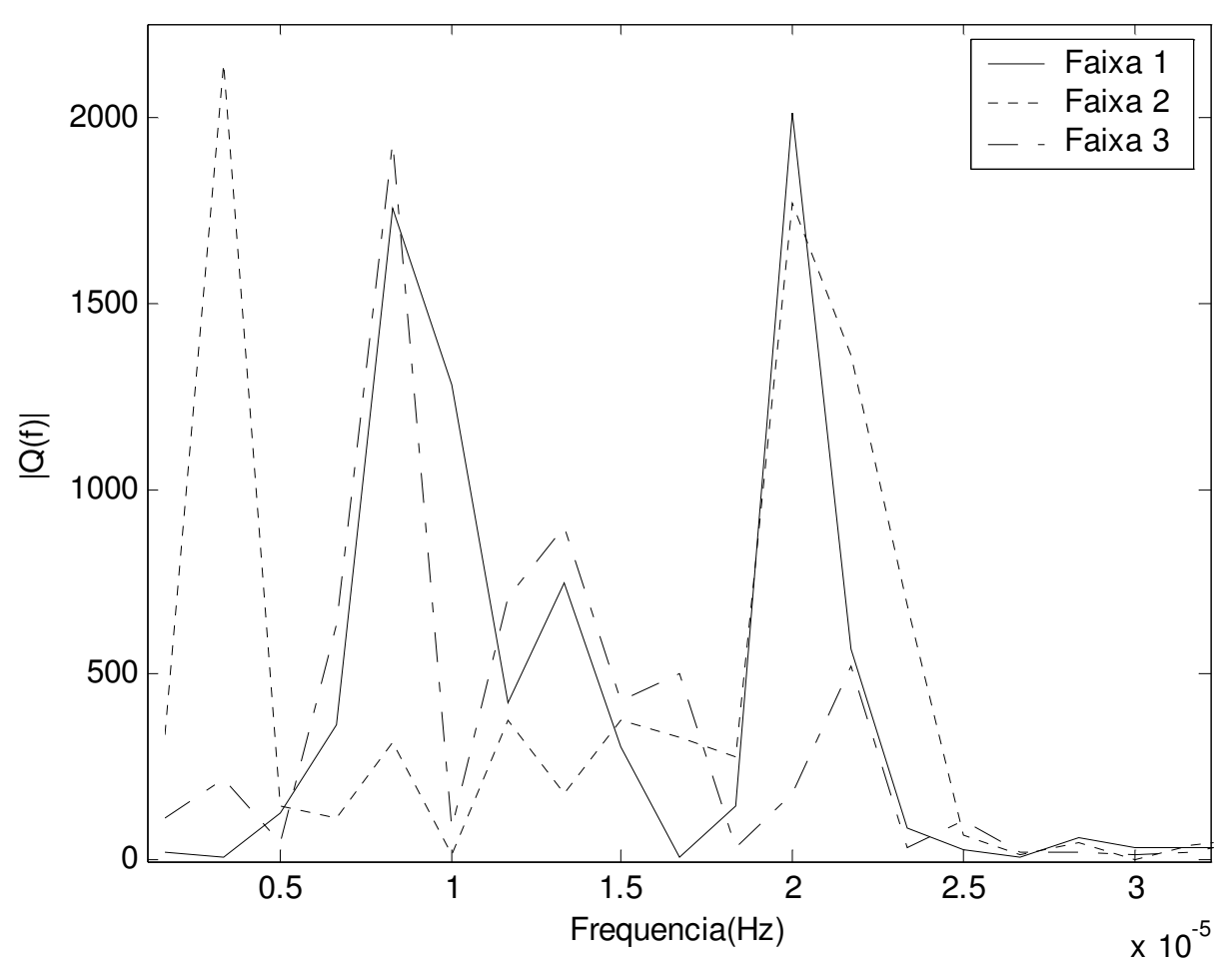

Figura 40: FFT de $Q$ com má sintonia para válvula Nominal.

Os resultados obtidos para a válvula Nominal (Figuras 39 e 40), apesar de afetados pelo alto atrito presente na válvula, comprovam a existência do atrito estático na válvula estudada, uma vez que há variação da freqüência do sinal da vazão, correspondente à variação de $K_{c}$.

\subsection{Ensaios com HIL}

São apresentados nesta seção os resultados dos testes efetuados com cada método intrusivo em uma válvula com dois coeficientes de atrito, os quais são gerados apertando-se ou afrouxando-se as gaxetas da mesma. Estes níveis foram chamados de atrito high e atrito low. Os parâmetros de atrito estão listados na Tabela 3 (UEHARA et al., 2008). Além dos parâmetros da válvula listados, a área do diafragma do atuador é de $0,0445 \mathrm{~m}^{2}$, a massa das partes móveis é de 1,6 kg e a constante elástica da mola é de $2,15^{\star} 10^{5} \mathrm{~N} / \mathrm{m}$. 
Tabela 3: Parâmetros das válvulas ensaiadas no ambiente HIL.

\begin{tabular}{|l|c|c|}
\hline Parâmetro & Atrito High & Atrito Low \\
\hline \hline$F_{C}:$ coef. atrito Coulomb $(\mathrm{N})$ & 537 & 135,3 \\
\hline$F_{S}:$ coef. de stiction $(\mathrm{N})$ & 609,5 & 135,3 \\
\hline$F_{V: \text { coef. atrito viscoso }(\mathrm{N} \cdot \mathrm{s} / \mathrm{m})}$ & 21000 & 4865 \\
\hline
\end{tabular}

Foram efetuados, ao todo, oito ensaios diferentes, quatro para cada nível de atrito, foram eles: Teste de Elevação, Mudanças no Ganho do Controlador, Mudanças no Ganho do Controlador na presença de perturbação externa e Mudanças no Ganho do Controlador com o controlador mal sintonizado. Estas simulações foram realizadas com durações adequadas para a execução de cada método. No caso do Teste de Elevação, o tempo de simulação depende do movimento da válvula e da constante de tempo do processo. No caso das Mudanças no Ganho do Controlador, o tempo de simulação foi escolhido de forma que as oscilações do sistema sejam facilmente observáveis em um terço do seu tempo.

\subsubsection{Ensaios com o Teste de Elevação}

Os ensaios realizados no ambiente HIL para o Teste de Elevação tiveram as seguintes características:

- Duração da simulação $\left(T_{\text {sim }}\right)=200$ segundos;

- Passo de integração = $10^{-3}$ segundos;

- Decimação dos pontos = 1;

- Instante do degrau inicial = 0,7 segundos;

- Amplitude do degrau inicial = 4\% do valor de referência;

- Amplitude dos degraus adicionais = 0,75\% do valor de referência;

Com relação ao controlador PI da malha de vazão, a sintonia utilizada durante as simulações e considerada a sintonia que estabiliza a malha é a seguinte:

- Ganho do controlador $\left(K_{c}\right)=1,115$;

- Tempo integral do controlador $\left(T_{i}\right)=1,93$. 
Para os ensaios com o Teste de Elevação, foram observadas a variável de processo $(\mathrm{PV})$, correspondente à vazão $Q$ em \% e a variável manipulada (MV), também em \%. Na Figura 41 apresenta-se o resultado deste método para o atrito high, aplicando-se inicialmente na MV um degrau de $4 \%$ e depois degraus de $0,75 \%$ no mesmo sentido e na Figura 42 para o atrito low, aplicando-se os mesmos degraus.

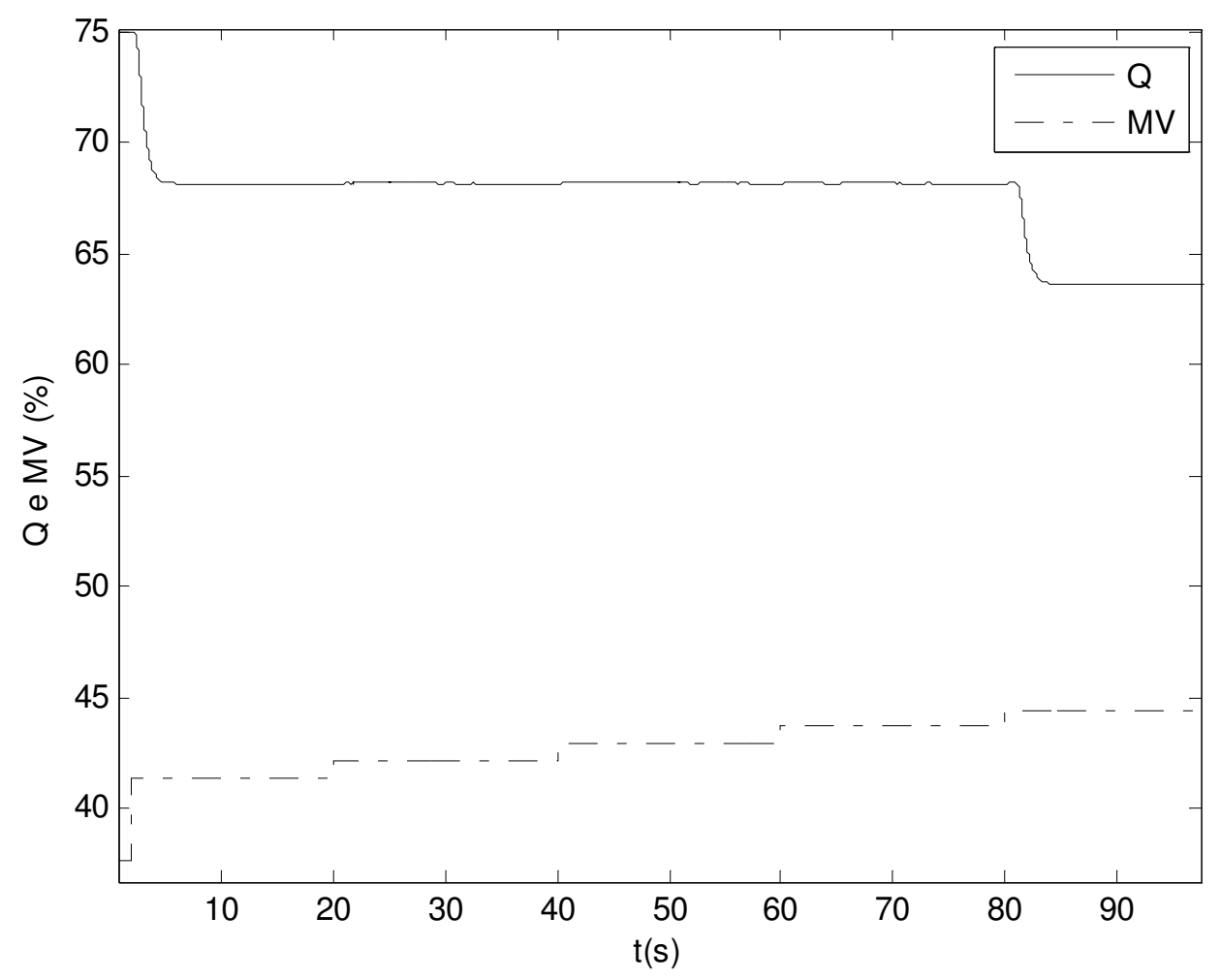

Figura 41: Teste com atrito high.

A Figura 41 demonstra que foram necessários quatro degraus na entrada da válvula para que a variável de processo se movimentasse, portanto houve a detecção do atrito estático. 


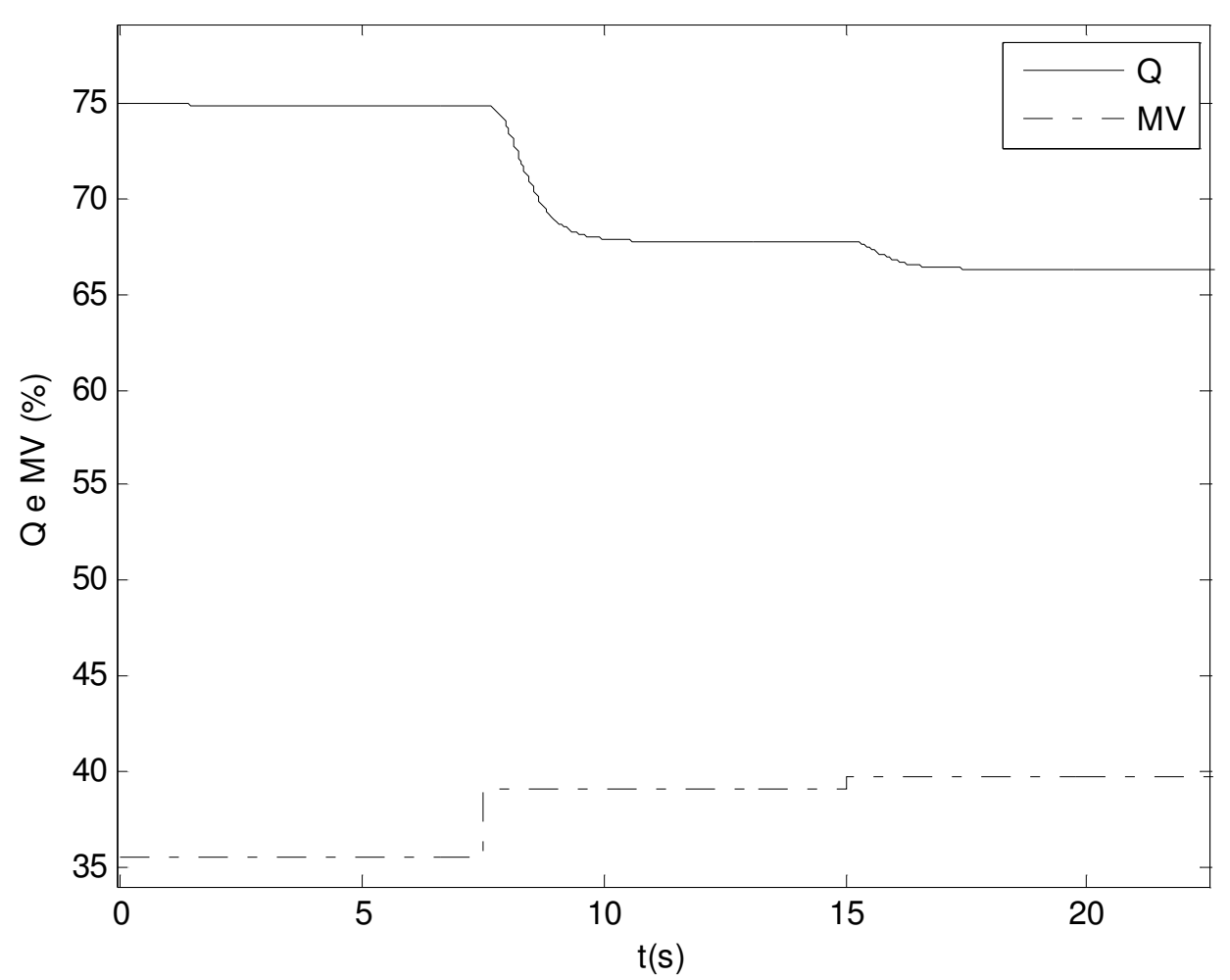

Figura 42: Teste com atrito low.

No caso do atrito low (Figura 42), como era de se esperar, já no primeiro degrau aplicado na entrada, a saída da válvula respondeu e, conseqüentemente, a variável do processo, demonstrando a ausência do atrito estático.

\subsubsection{Ensaios com as Mudanças no Ganho do Controlador}

Os ensaios realizados no ambiente HIL para o método de Mudanças no Ganho do Controlador tiveram as seguintes características:

- Duração da simulação $\left(T_{\text {sim }}\right)=900$ segundos;

- Passo de integração $=10^{-3}$ segundos;

- Decimação dos pontos = 1;

- Instante do degrau inicial = 1 segundo;

- Amplitude do degrau inicial $=10 \%$ do valor de referência; 
Com relação ao controlador PI da malha de vazão, a sintonia utilizada durante as simulações e considerada a sintonia que estabiliza a malha é a seguinte:

- Ganho do controlador $\left(K_{c}\right)=1,115$;

- Tempo integral do controlador $\left(T_{i}\right)=1,93$.

Para os ensaios com as Mudanças no Ganho do Controlador, foi observada somente a variável de processo (PV) e sua FFT (Fast Fourier Transform) para a análise de variação de sua freqüência durante a aplicação do método. Para a análise da FFT, o sinal da PV foi dividido em três faixas de tempos iguais, que acompanham os momentos de variação do ganho do controlador. Nas Figuras 43 e 44 são apresentados os resultados com o atrito high.

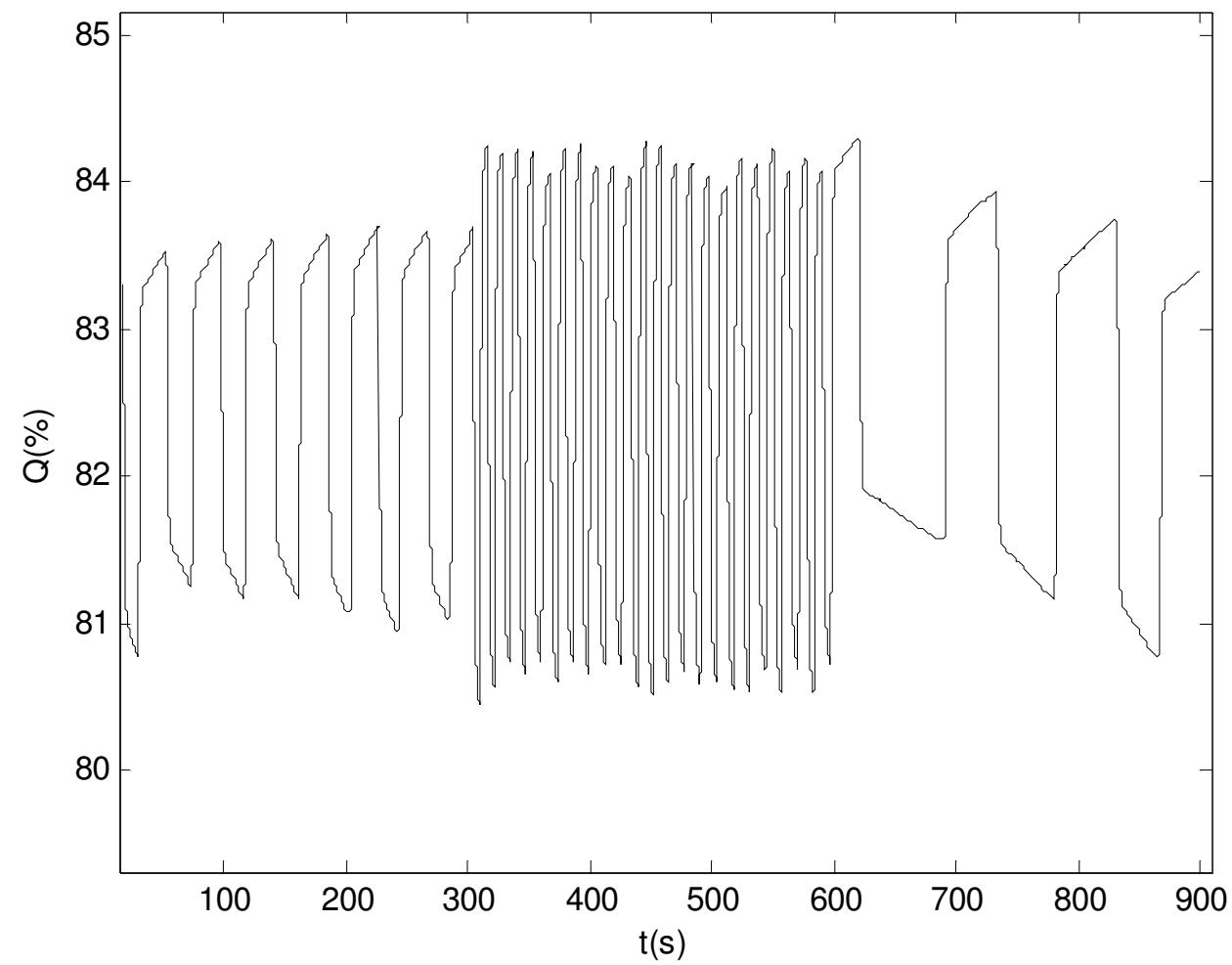

Figura 43: Vazão $Q(\%)$ com atrito high. 


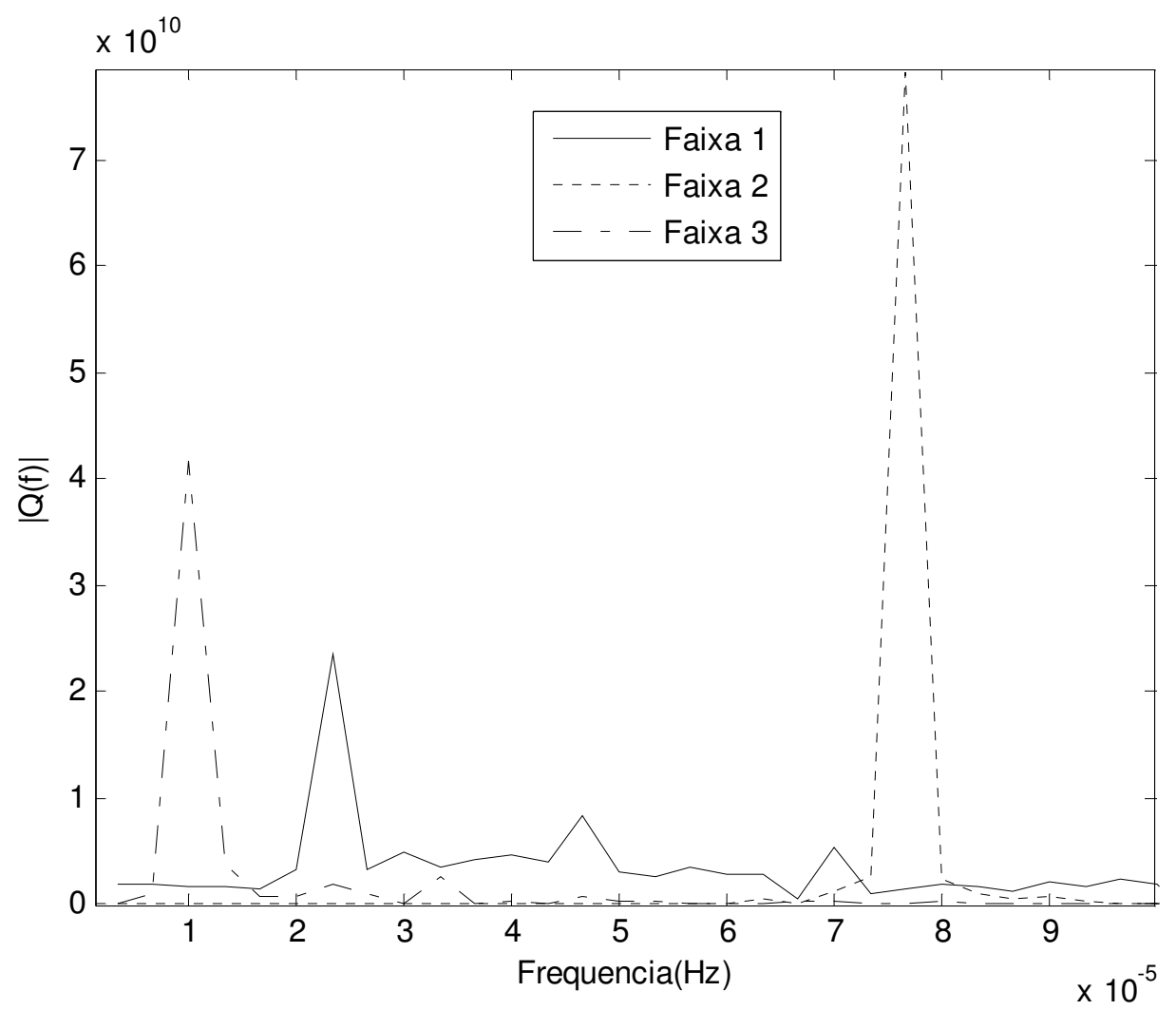

Figura 44: FFT de $Q$ com atrito high.

As figuras 43 e 44 demonstram a variação significativa da freqüência da PV para o caso do atrito high. Aumentando-se o ganho proporcional, obteve-se 0 aumento da freqüência do sinal e, ao diminuir o $K_{c}$, obteve-se a diminuição da freqüência. Este resultado confirmou a detecção de stiction na malha.

Nas Figuras 45 e 46 são apresentados os resultados com o atrito low. 


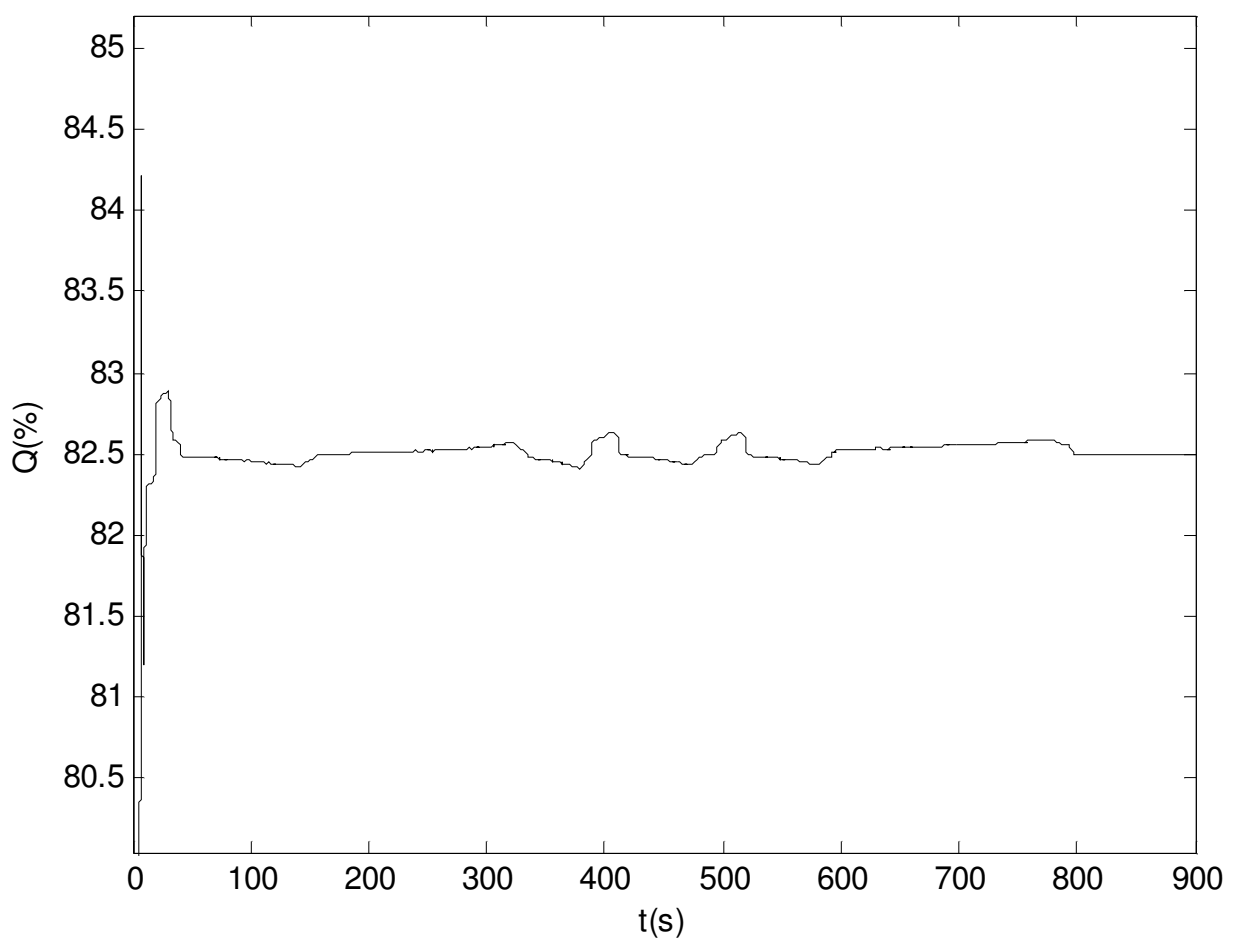

Figura 45: Vazão $Q(\%)$ com atrito low.

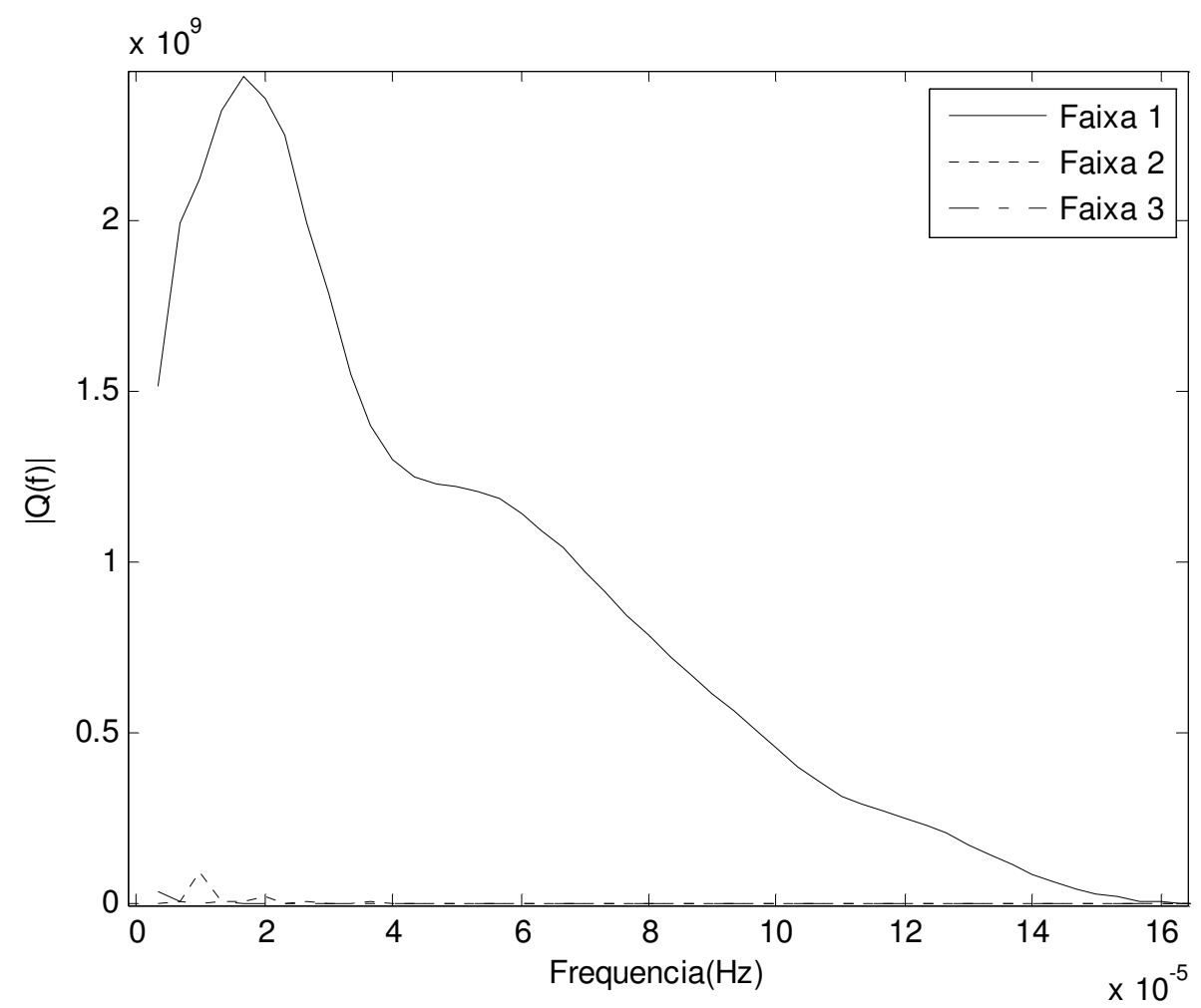

Figura 46: FFT de $Q$ com atrito low. 
No caso do atrito low, como podemos observar pelas Figuras 45 e 46 o método apontou a ausência do stiction, como era esperado, devido à ausência de stiction nessa válvula (Tabela 3).

\subsubsection{Ensaios com as Mudanças no Ganho do Controlador com a presença de perturbação externa}

Ensaios semelhantes aos da Seção 4.2.2 foram feitos com as Mudanças no Ganho do Controlador, na presença de uma perturbação externa, na forma de um ruído estacionário com média nula, variância de 0,0025 e tempo de amostragem de 10 s. Os ruídos são os mesmos em todos os ensaios deste item.

Assim como na seção anterior, os ensaios realizados tiveram as seguintes características:

- Duração da simulação $\left(T_{\text {sim }}\right)=900$ segundos;

- Passo de integração = $10^{-3}$ segundos;

- Decimação dos pontos = 1;

- $\quad$ Instante do degrau inicial = 1 segundo;

- Amplitude do degrau inicial $=10 \%$ do valor de referência.

Com relação ao controlador PI da malha de vazão, a sintonia utilizada durante as simulações e considerada a sintonia que estabiliza a malha é a seguinte:

- Ganho do controlador $\left(K_{c}\right)=1,115$;

- Tempo integral do controlador $\left(T_{i}\right)=1,93$.

A Figura 47 apresenta o efeito dessa perturbação na vazão $Q$ com a malha aberta. 


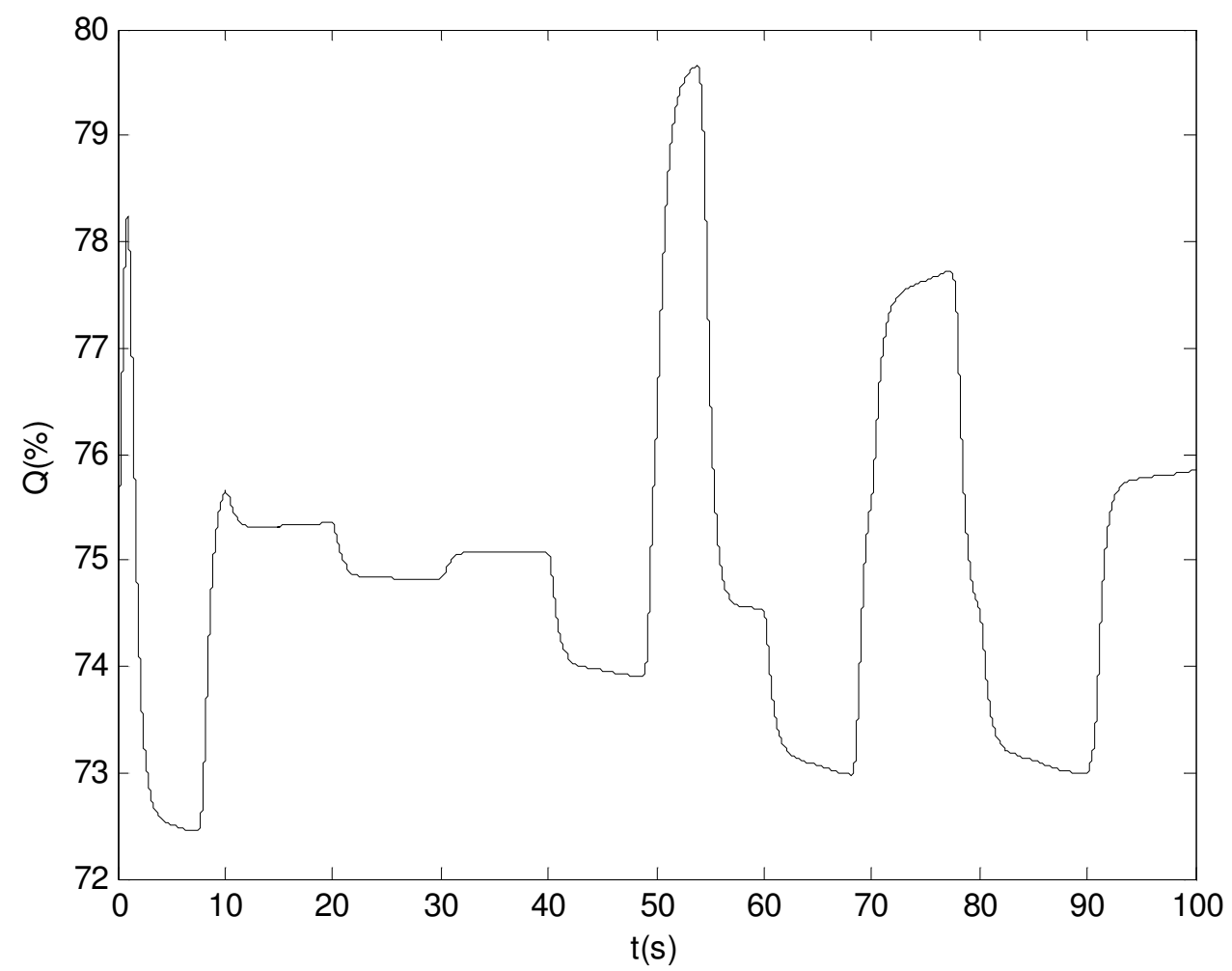

Figura 47: Vazão $Q(\%)$ com perturbação.

Nas Figuras 48 e 49 são apresentados resultados com o atrito high. 


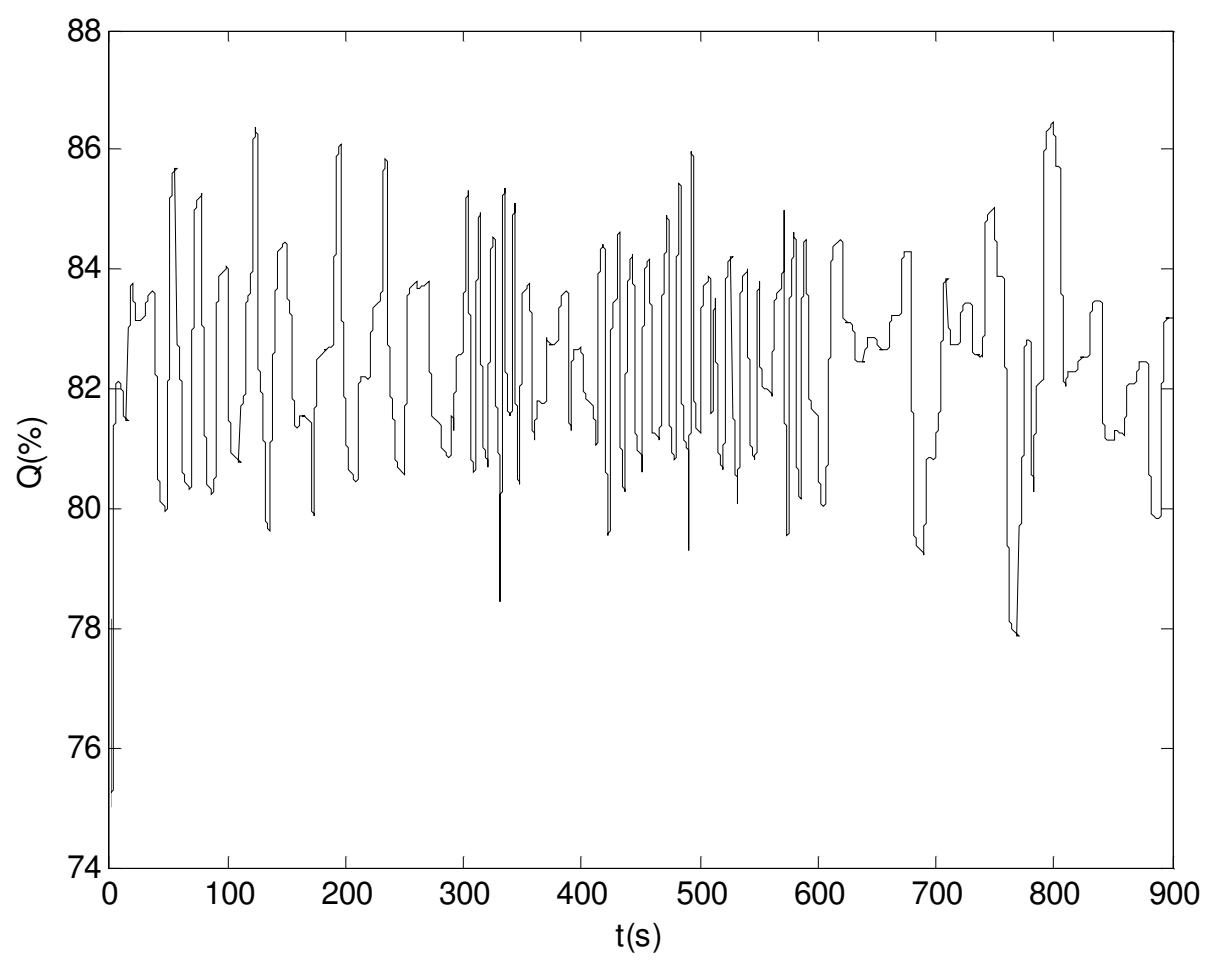

Figura 48: Vazão $Q(\%)$ com perturbação e atrito high.

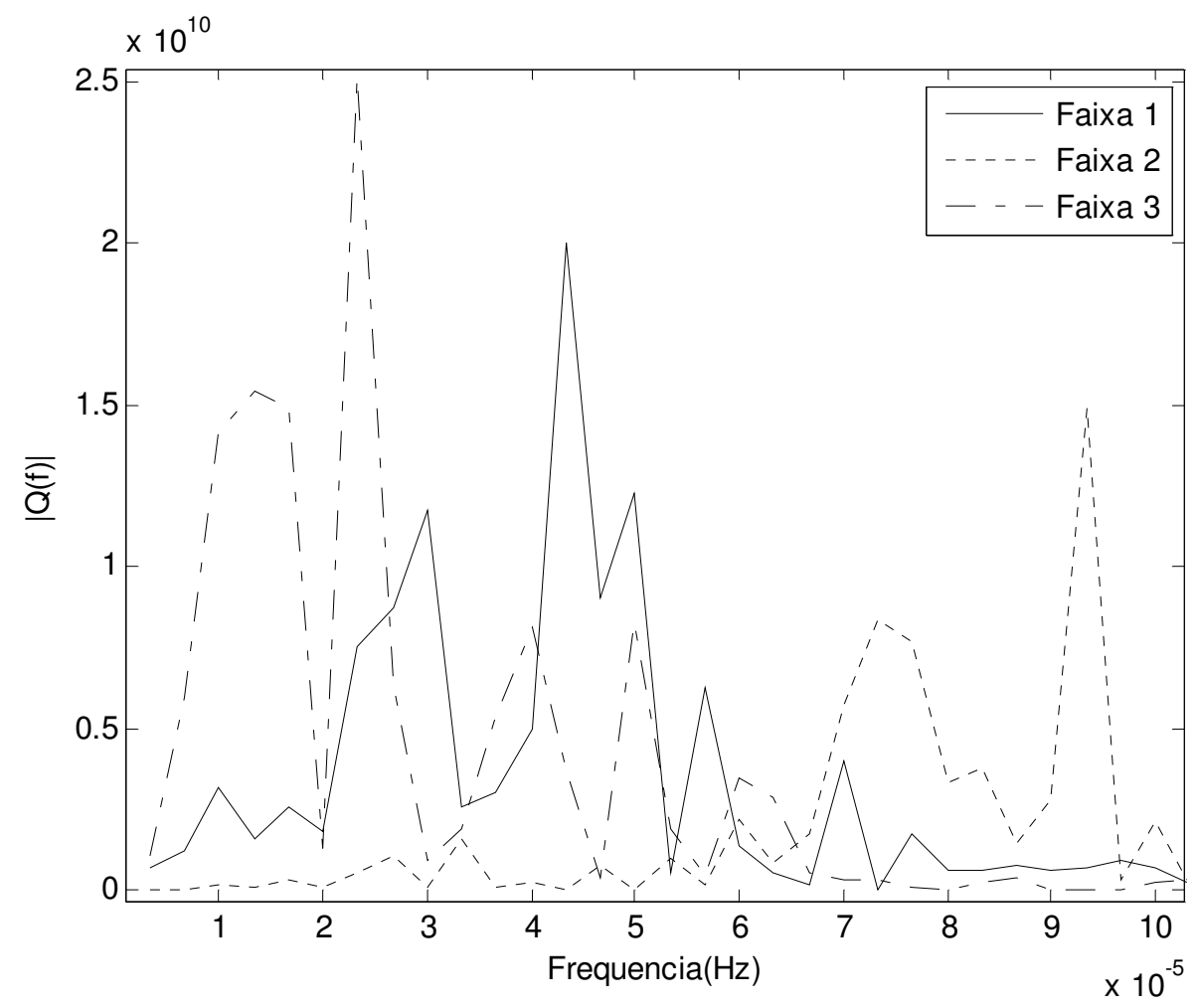

Figura 49: FFT de $Q$ com perturbação e atrito high. 
Nas figuras 48 e 49, pode-se notar que, aumentando o ganho proporcional, tem-se o aumento da freqüência do sinal e, ao diminuir o $K_{c}$, tem-se a diminuição da freqüência. Este resultado apontou a presença de stiction para o caso do atrito high.

Nas Figuras 50 e 51 são apresentados resultados com o atrito low.

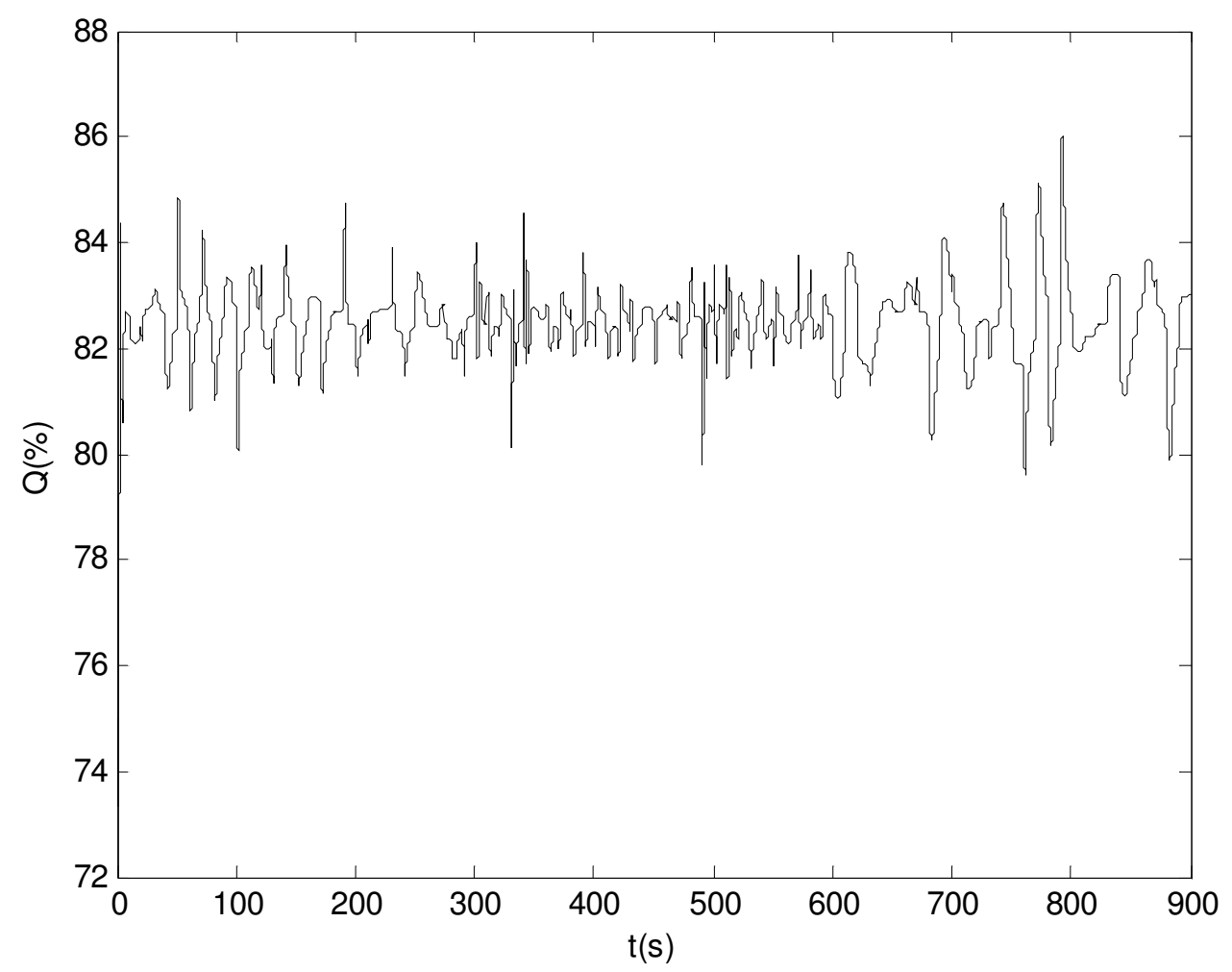

Figura 50: Vazão $Q(\%)$ com perturbação e atrito low. 


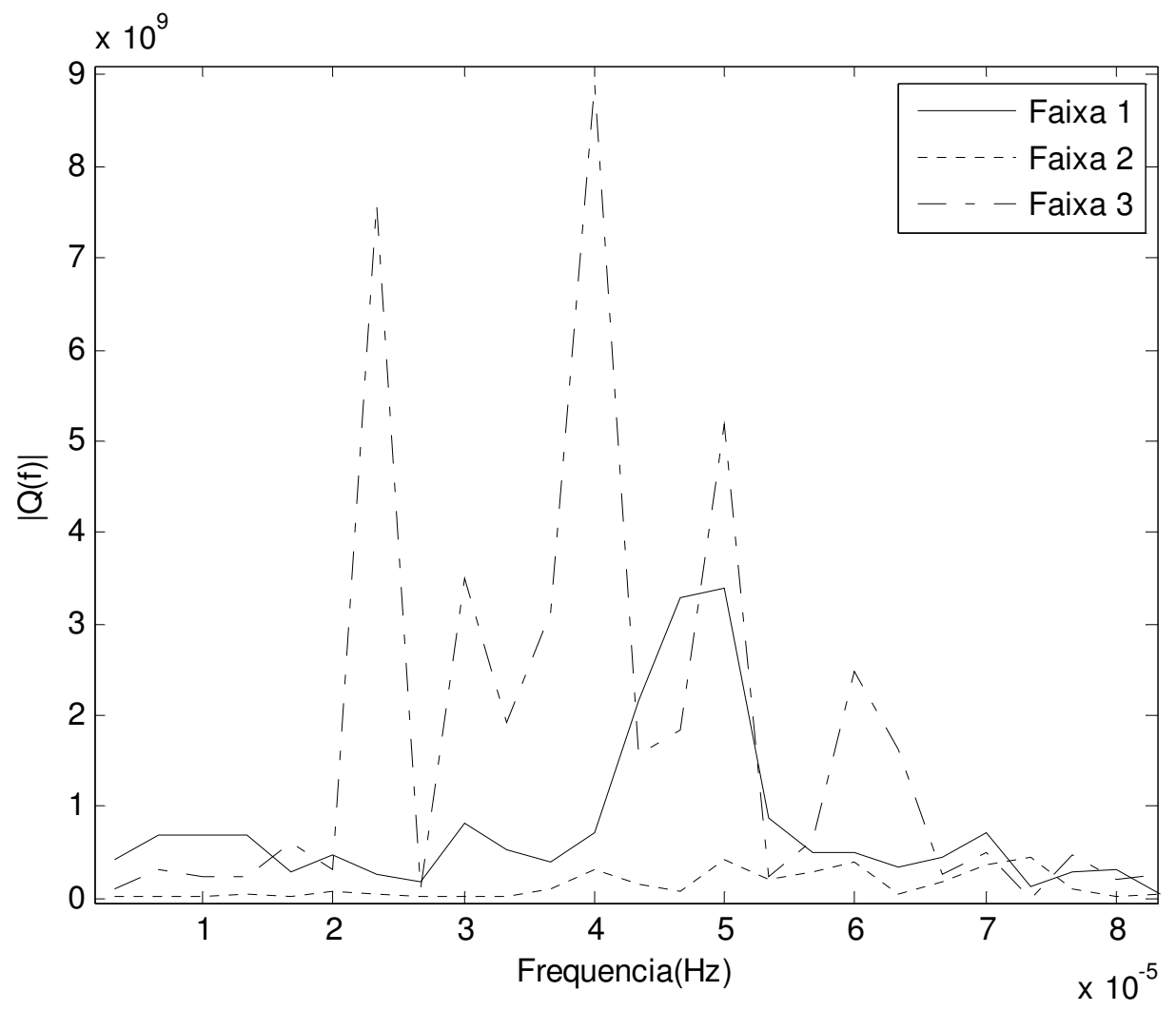

Figura 51: FFT de $Q$ com perturbação e atrito low.

No caso do atrito low, como observado nas figuras 50 e 51, o método apontou a ausência do stiction, pois não se nota variação significativa no sinal da vazão $Q$, para uma correspondente variação de $K_{c}$. Desta forma, nota-se que para o ambiente HIL, a presença da perturbação externa não alterou o resultado esperado da aplicação do método de Mudanças no Ganho do Controlador.

\subsubsection{Ensaios com as Mudanças no Ganho do Controlador para um controlador mal sintonizado}

Ensaios semelhantes aos das Seções 4.2 .2 e 4.2 .3 foram realizados com 0 método aplicado a um controlador mal sintonizado.

Os ensaios nesta seção tiveram as seguintes características:

- Duração da simulação $\left(T_{\text {sim }}\right)=900$ segundos;

- Passo de integração = $10^{-3}$ segundos;

- Decimação dos pontos = 1; 
- $\quad$ Instante do degrau inicial = 1 segundo;

- Amplitude do degrau inicial $=10 \%$ do valor de referência.

Com relação ao controlador PI da malha de vazão, a sintonia utilizada durante as simulações e considerada a sintonia que estabiliza a malha é a seguinte:

- Ganho do controlador $\left(K_{c}\right)=2,23$;

- Tempo integral do controlador $\left(T_{i}\right)=1,93$

Como pode-se observar, com relação ao controlador PI da malha de vazão, a sintonia utilizada durante as simulações desta seção é diferente da utilizada nos ensaios anteriores, tendo um ganho proporcional duas vezes maior, caracterizando a má sintonia do controlador.

Pode-se verificar esta má sintonia através da Figura 52, que apresenta os valores de $Q$ para um ensaio em malha fechada, aplicando-se um pequeno degrau no set point.

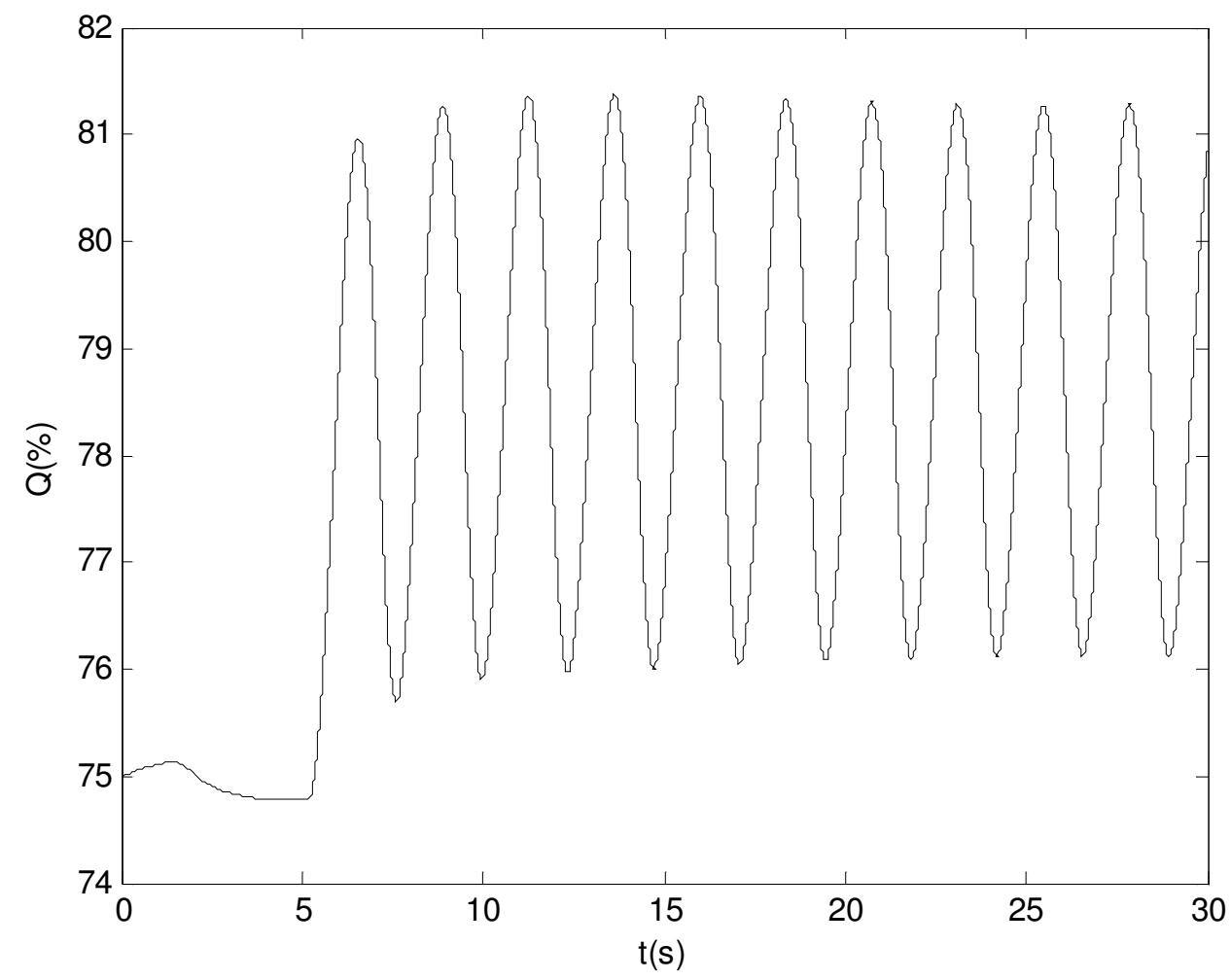

Figura 52: Vazão $Q(\%)$ com controlador mal sintonizado. 
Nas Figuras 53 e 54 são apresentados os resultados com o atrito high.

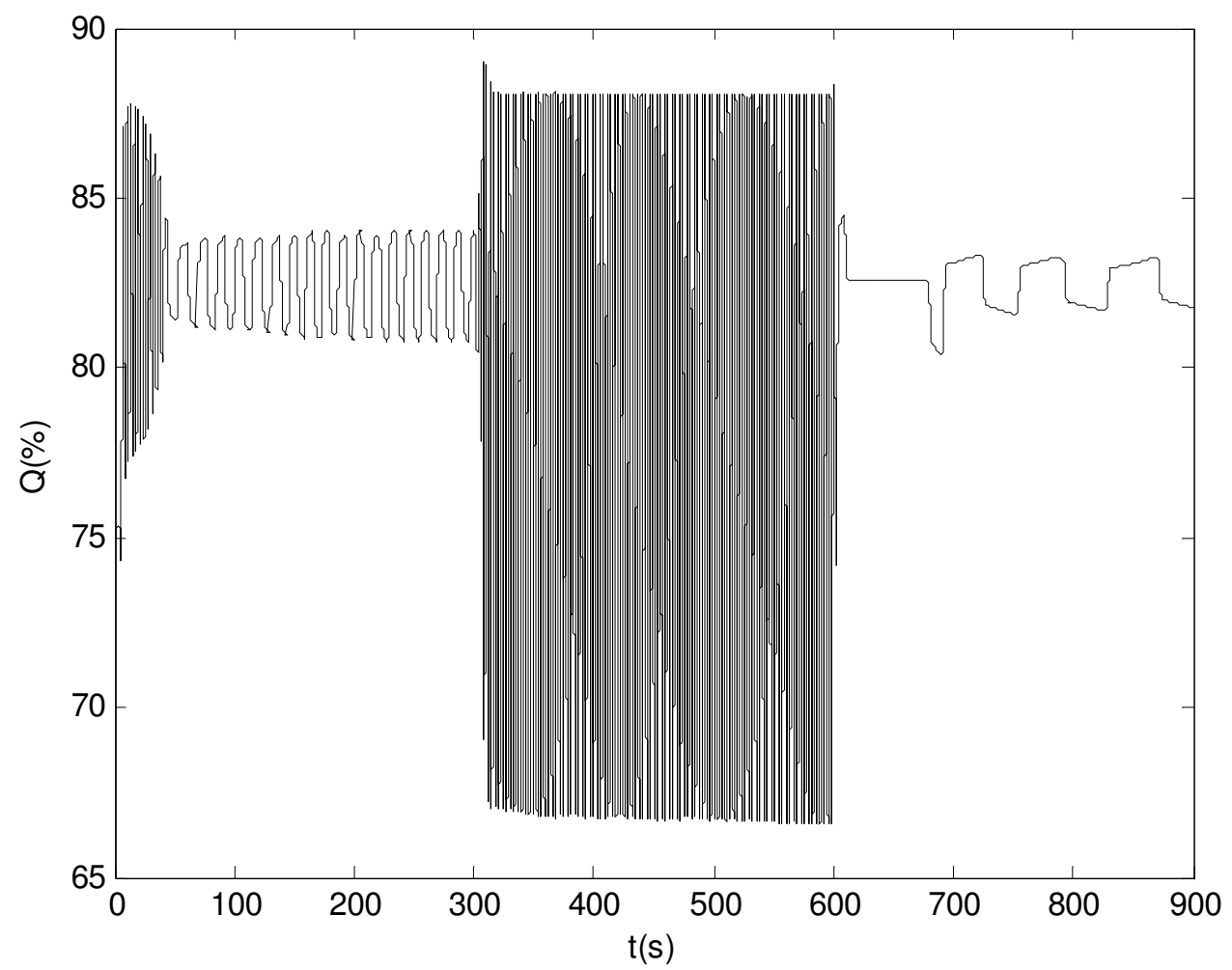

Figura 53: Vazão $Q(\%)$ com má sintonia e atrito high. 


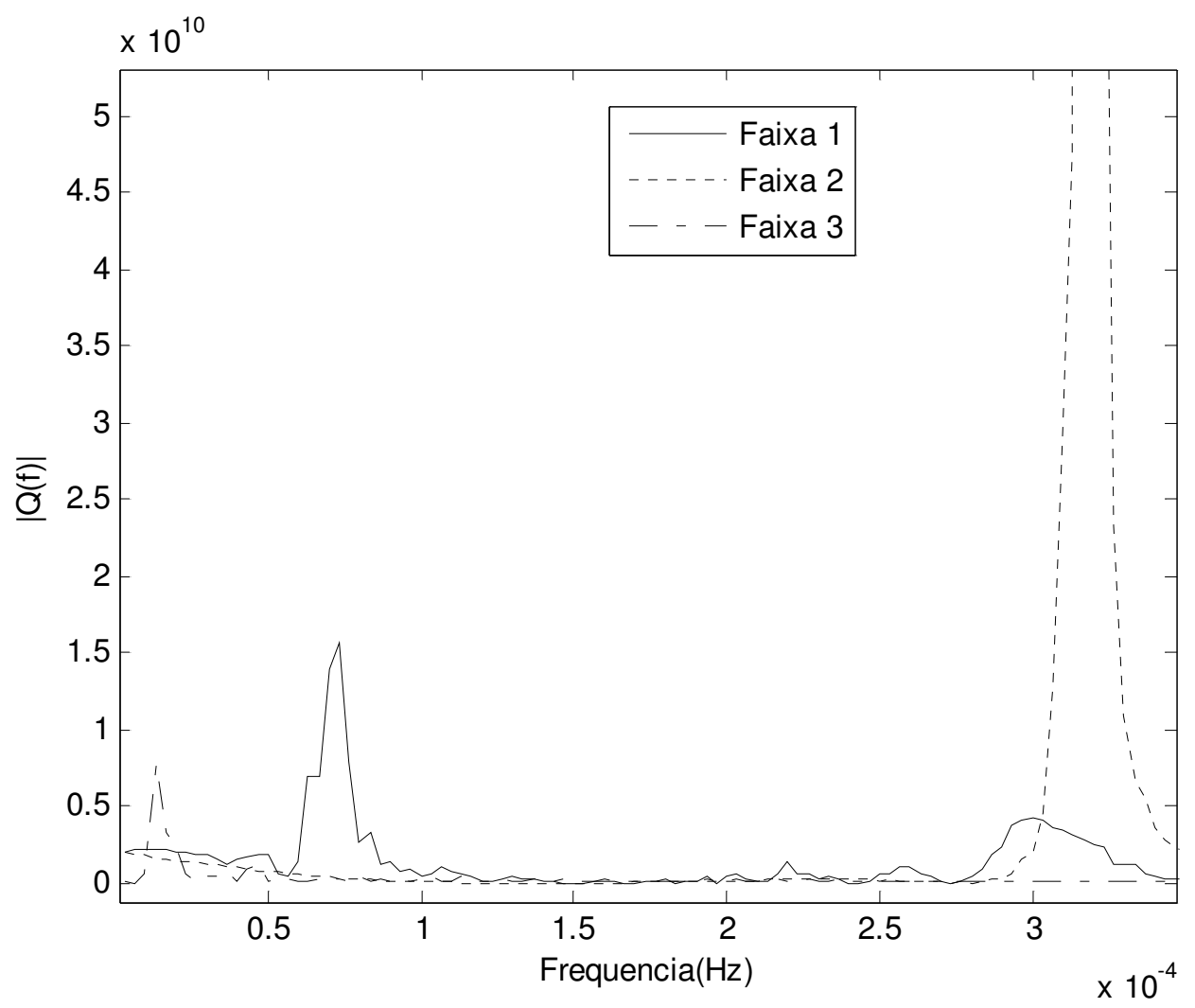

Figura 54: FFT de $Q$ com má sintonia e atrito high.

As figuras 53 e 54 mostram que a aplicação do método em uma malha mal sintonizada pode gerar instabilidade no processo, de modo que nada pode ser concluído acerca do atrito.

Nas Figuras 55 e 56 são apresentados os resultados com o atrito low. 


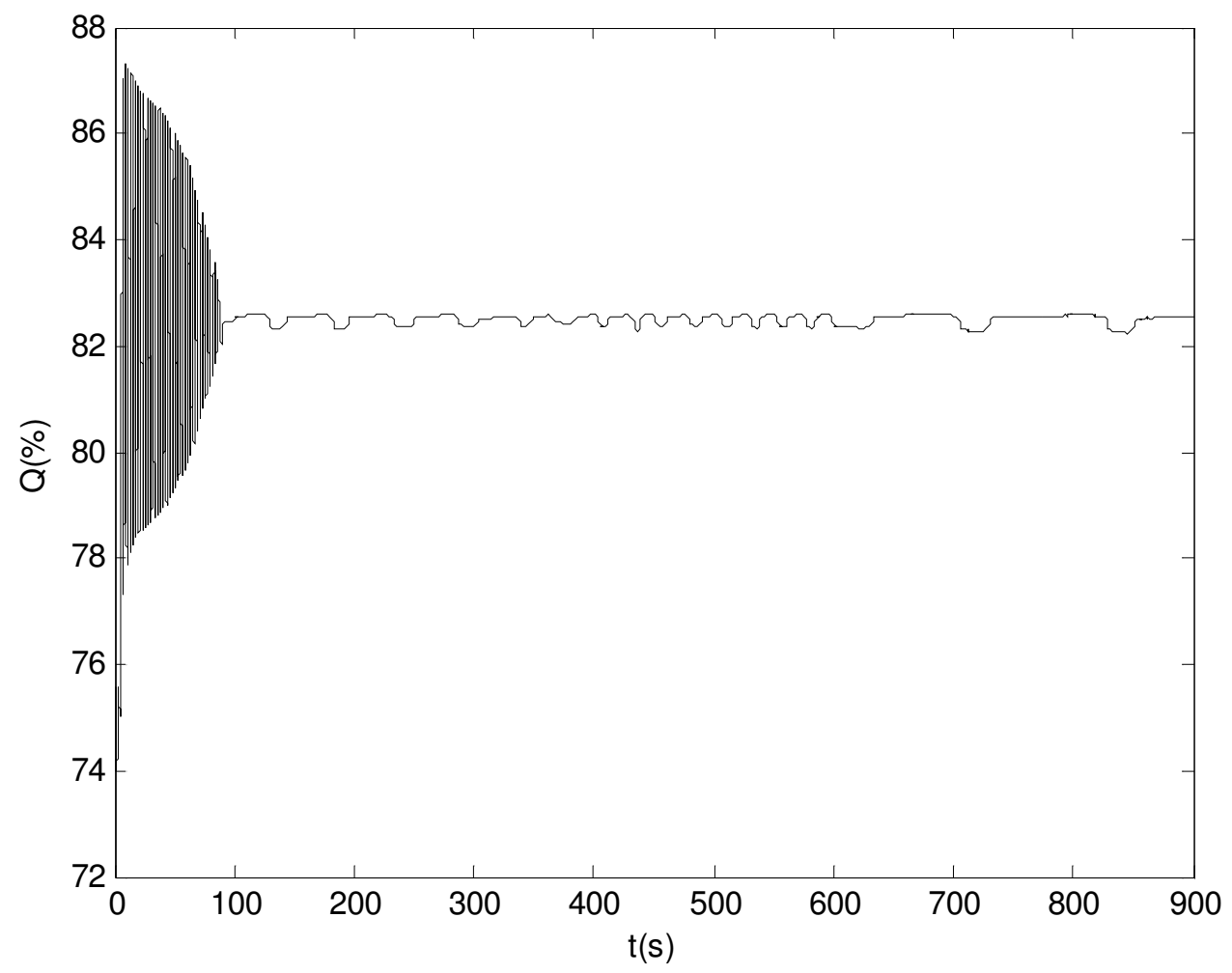

Figura 55: Vazão $Q(\%)$ com má sintonia e atrito low.

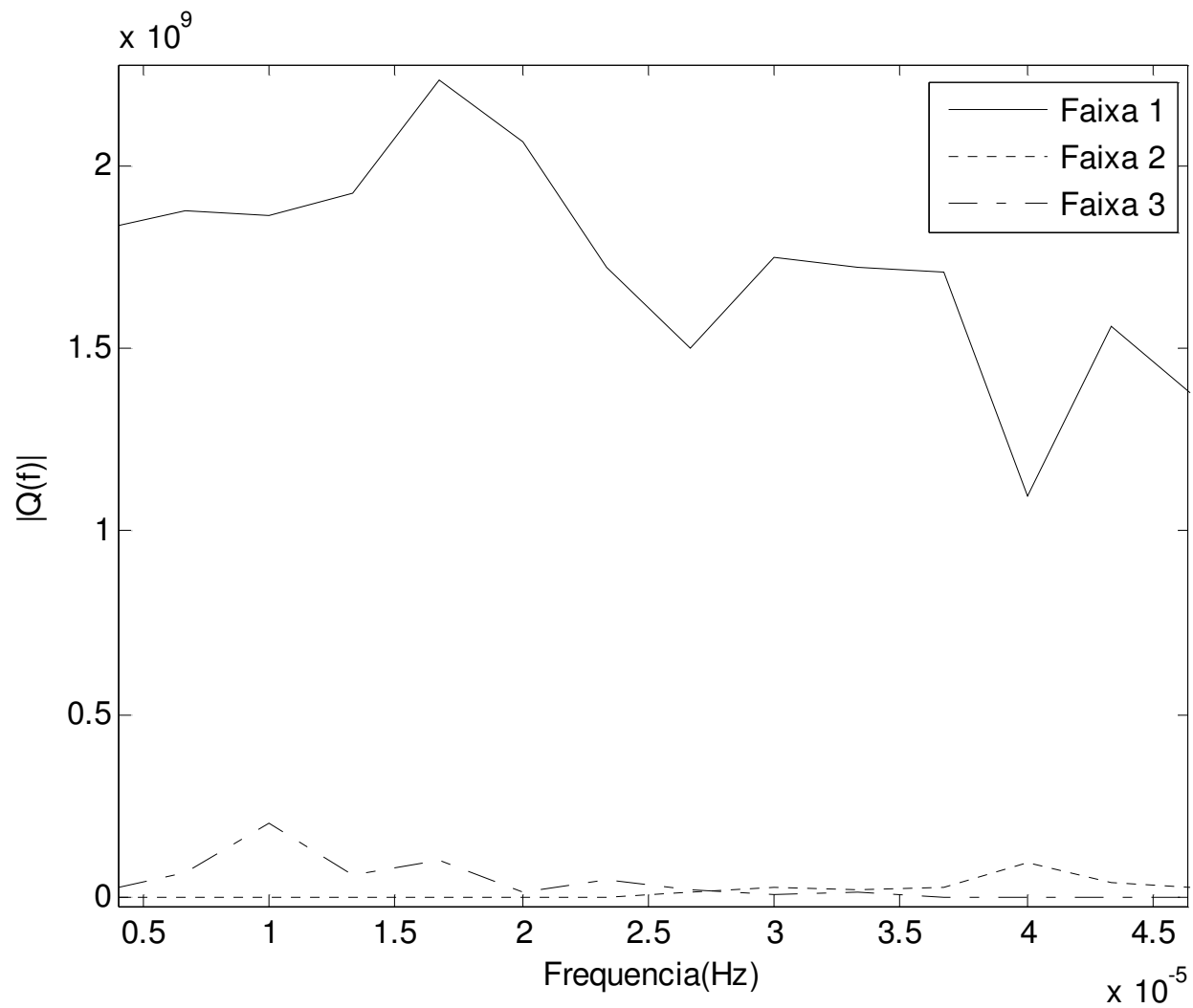

Figura 56: FFT de $Q$ com má sintonia e atrito low. 
As Figuras 55 e 56, principalmente a primeira, apontam para a presença do stiction quando, em verdade, sabe-se que ele não está presente. Este resultado prova que o método pode confundir a má sintonia de uma malha com a presença de stiction.

\subsection{Discussão geral dos resultados}

Os resultados obtidos para o Teste de Elevação comprovam a sua eficiência na detecção do stiction, como proposto por (TAHA; DUMONT; DAVIES, 1996; WALLÉN, 1997; GERRY; RUEL, 2001). Isso pode ser observado tanto pelos ensaios em ambiente HIL quanto no ambiente totalmente simulado. Para as válvulas com stiction, o mesmo foi identificado: válvula Nominal (Figura 19) e válvula Fisher (ambiente HIL) com ajuste de atrito high (Figura 41). Para as válvulas sem stiction, o mesmo não foi diagnosticado: válvula Ideal (Figura 17), válvula Fabricante (Figura 18) e válvula Fisher (ambiente HIL) com ajuste de atrito low (Figura 42). Pode-se notar ainda, que outros tipos de atrito não são detectados por este tipo de teste, como era esperado.

Com relação ao método de Mudanças no Ganho do Controlador, pode-se observar que, com relação à sua proposta original (CHOUDHURY et al., 2005), é um método passível de falhas ao identificar o stiction. $O$ resultado de sua aplicação pode ser comprometido, principalmente quando implementado em uma malha com controlador mal sintonizado. Isso pode ser observado nas Figuras 35 e 36, por exemplo.

Além disso, quando há a presença de uma perturbação externa de alta freqüência, o método também pode apresentar um resultado equivocado com relação à presença de stiction (Figuras 28, 29, 32 e 33).

Finalmente, pode-se notar que o método pode identificar a existência de outro atrito que não o estático. Nas Figuras 22, 23, 30, 31, 37 e 38 pode-se notar que houve a identificação do atrito estático, mas nestes casos a válvula estudada só possuía o atrito de Coulomb. 


\section{CONCLUSÃO}

Os resultados obtidos comprovam que o Teste de Elevação é eficiente na detecção do atrito estático. Apesar de sua eficiência, este método pode comprometer a operação normal do processo, uma vez que a malha de controle deve ser colocada em manual para a sua aplicação. Isto pode ocasionar a instabilidade do sistema e a conseqüente perda da produção.

Com relação ao método de Mudanças no Ganho do Controlador, pode-se confirmar que, se uma oscilação é gerada internamente a uma malha de controle devido à presença de atrito em uma válvula, um acréscimo no ganho do controlador irá incrementar a freqüência da oscilação da variável controlada. Entretanto, este método pode confundir a má sintonia do controlador da malha com o atrito na válvula de controle. Isso pode ser observado principalmente para o ensaio com atrito low, no caso dos ensaios com o ambiente HIL. Esse resultado é compreensível, uma vez que o próprio método modifica e, conseqüentemente, pode vir a desajustar o controlador durante sua aplicação, gerando instabilidade no processo.

Este método tem eficiência duvidosa na presença de uma perturbação externa, pelo menos no caso de um ruído estacionário de baixa freqüência, pois apesar de sua presença não alterar os resultados esperados em ambiente HIL (válvula real), alteraram de fato o resultado esperado nos ensaios em ambiente totalmente simulado (válvulas simuladas).

Foi ainda possível notar que o método pode identificar a existência de outro atrito que não o estático. Em alguns ensaios, houve o diagnóstico de atrito estático no sistema quando, em verdade, a válvula estudada só possuía o atrito de Coulomb.

Com relação aos resultados obtidos com a aplicação deste método, é importante destacar que não foi notada uma relação consistente entre a mudança na amplitude da oscilação e no ganho do controlador.

Outra observação importante é de que Choudhury et al. (2005), ao proporem o teste de Mudanças no Ganho do Controlador, não definem o que seria uma variação significativa da freqüência da variável de processo, que seria suficiente 
para provar a existência do stiction na malha de controle estudada. Em seus resultados, a variação é sempre muito evidente e visual. Estipulou-se, portanto, um critério de análise das informações obtidas com os ensaios deste método: foi considerado que havia a variação da freqüência da PV quando, analisando-se o gráfico da potência versus a freqüência do sinal, notava-se diferença entre a freqüência do maior pico de potência de cada faixa. É importante frisar que todas as análises e discussões realizadas neste trabalho para o teste de Mudanças no Ganho do Controlador foram baseadas neste critério.

Um resumo das conclusões resultantes do estudo comparativo entre os dois métodos pode ser observado na Tabela 4.

Tabela 4: Comparação entre os métodos estudados.

\begin{tabular}{|l|c|c|}
\hline Quesito \Método & $\begin{array}{c}\text { Teste de } \\
\text { Elevação }\end{array}$ & $\begin{array}{c}\text { Mud. no Ganho } \\
\text { do Controlador }\end{array}$ \\
\hline \hline Fácil de Implementar & Sim & Sim \\
\hline Fácil de Analisar seus resultados & Sim & Não \\
\hline Risco de perturbar o processo & Sim & Sim \\
\hline $\begin{array}{l}\text { Resultados suscetíveis à presença de } \\
\text { perturbação externa }\end{array}$ & N/A & Sim \\
\hline $\begin{array}{l}\text { Resultados suscetíveis à má sintonia do } \\
\text { controlador }\end{array}$ & N/A & Sim \\
\hline Detecta outro atrito que não Stiction & Não & Não \\
\hline Preciso em seus resultados & Sim & \\
\hline
\end{tabular}

Um teste interessante a ser feito é a aplicação destes métodos em uma válvula com grande índice de stiction, realizando-se os ensaios com má sintonia do controlador e com a perturbação externa para o Mudanças no Ganho do Controlador.

Além disso, seria interessante avaliar o comportamento desses métodos em plantas com diferentes dinâmicas (controle de temperatura, $\mathrm{pH}$, nível etc). Por exemplo, qual a diferença de desempenho do método aplicado a uma planta de controle de vazão, de dinâmica acelerada, com relação à sua aplicação numa malha de controle de temperatura de dinâmica extremamente lenta. Para tanto, sugiro que sejam simuladas diferentes configurações de plantas e de tipos e níveis de atrito, para cada um dos métodos avaliados. 
De uma forma geral, apesar de terem demonstrado desempenho satisfatório na detecção do atrito nas válvulas de controle, notou-se que ambos os métodos podem causar problemas de instabilidade, acarretando sérios problemas à planta, uma vez que são métodos aplicados on-line.

Sendo assim, outra sugestão seria a melhoria da implementação dos métodos, fazendo com que possam ser aplicados da maneira menos impactante possível para o processo. No caso do teste de Mudanças no Ganho do Controlador, por exemplo, seria interessante encontrar uma forma automática de se descobrir a menor variação do ganho do controlador que seja suficiente para ocasionar a correspondente variação da freqüência da PV da malha de controle. Duplicar o ganho do controlador, como é sugerido por Choudhury et al. (2005), é, em geral, suficiente para tornar a malha de controle instável. 


\section{REFERÊNCIAS}

CHOUDHURY, M. A. A. S.; THORNHILL, N. F.; SHAH, S. L. A Data-Driven Model for Valve Stiction. [S.I.]: 2004.

CHOUDHURY, M. A. A. S.; KARIWALA, V.; SHAH, S. L.; DOUKE, H.; TAKADA, H.; THORNHILL, N. F. A simple test to confirm control valve stiction. Praga: IFAC World Congress, 2005.

CHOUDHURY, M. A. A. S.; THORNHILL, N. F.; SHAH, S. L. Modelling valve stiction. Control Engineering Practice, n. 13, p. 641-658, 2005.

CHOUDHURY, M. A. A. S.; SHAH, S. L.; THORNHILL, N. F.; SHOOK, D. S. Automatic Detection and Quantification of Stiction in Control Valves. Control Engineering Practice, n. 14, p. 1395-1412, 2006.

FISHER CONTROLS INTERNACIONAL. Control Valve Handbook. EUA: 283 p, 4 $4^{\text {a }}$ edição, 2005.

GARCIA, C. Modelagem de atrito em válvulas de controle. Salvador, Brasil: XVI Congresso Brasileiro de Automática, 2006.

GARCIA, C. Comparison of friction models applied to a control valve. Control Engineering Practice: artigo aceito para publicação, 2008.

GERRY, J.; RUEL, M. How to Measure and Combat Valve Stiction On Line. Houston: ISA Congress, 2001.

GURY, C. G. L.; GARCIA, C.; UEHARA, D. Compensação de Atrito em Válvulas de Controle Operando em Malha Fechada. Juiz de Fora, Brasil: artigo submetido ao XVII CBA, 2008. 
$\mathrm{HORCH}, \mathrm{A}$. A simple method for detection of stiction in control valves. Control Engineering Practice, n. 7, p. 1221-1231, 1999.

JIANG, H.; CHOUDHURY, M. A. A. S.; SHAH, S. L. Detection and Diagnosis of Plant-Wide Oscillations from Industrial Data using the Spectral Envelope Method. Journal of Process Control, n. 17, p. 143-155, 2007.

KAYIHAN, A.; DOYLE III, J.D. Friction compensation for a process control valve. Control Engineering Practice, n. 8, p. 799-812, 2000.

Matlab: mathematical programming software. Version 6.5 Release 13. [S.I.]: The MathWorks Inc., 2002. 2 CD-ROM.

OGATA, K. Engenharia de Controle Moderno. Rio de Janeiro : Prentice Hall do Brasil, 3ํㅗㄹ edição, 2000.

ROMANO, R. A.; GARCIA, C. Karnopp friction model identification for a real control valve. Seoul, Korea: Artigo aceito para publicação no 17th IFAC World Congress, 2008.

ROSSI, M.; SCALI, C. A comparison of techniques for automatic detection of stiction: simulation and application to industrial data. Journal of Process Control, n. 15 , p. 505-14, 2005.

SINGHAL, A.; SALSBURY, T. I. A Simple Method for Detecting Valve Stiction in Oscillating Control Loops. Journal of Process Control, n. 15, p. 371-382, 2005.

STENMAN, A.; FORSMAN, K.; GUSTAFSSON, F. A Segmentation-Based Approach for Detection of Stiction in Control Valves. Suécia: [s.n.], 2002.

TAHA, O.; DUMONT, G. A.; DAVIES, M. S. Detection and Diagnosis of Oscillations in Control Loops. Kobe: Proceedings of Conference on Decision and Control, p. 2432-37, 1996. 
THORNHILL, N. F.; COX, J. W.; PAULONIS, M. Diagnosis of plant-wide oscillation through data-driven analysis and process understanding. Control Engineering Practice, n. 11, p. 1481-90, 2003.

THORNHILL, N. F.; HORCH, A. Advances and new directions in plant-wide controller performance assessment. Gramado: Proceedings of International Symposium on Advanced Control of Chemical Process, p. 29-36, 2006.

UEHARA, D.; GARCIA, C.; ROMANO, R. A. Comparação e equivalência dos modelos de atrito de Kano e Karnopp aplicados a válvulas de controle. Juiz de Fora, Brasil: artigo submetido ao XVII CBA, 2008.

WALLÉN, A. Valve Diagnostics and Automatic Tuning. Albuquerque: Proceedings of the American Control Conference, p. 2930-34, 1997.

YAMASHITA, Y. An Automatic Method for Detection of Valve Stiction in Process Control Loops. Control Engineering Practice, n. 14, p. 503-510, 2006. 